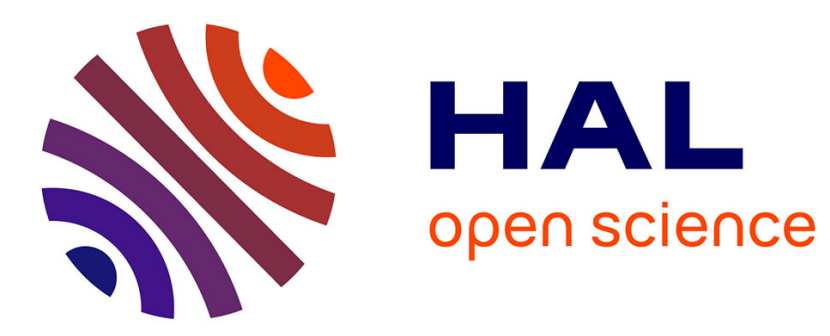

\title{
Managing living marine resources in a dynamic environment: The role of seasonal to decadal climate forecasts
}

Desiree Tommasi, Charles Stock, Alistair Hobday, Rick Methot, Isaac Kaplan, J. Paige Eveson, Kirstin Holsman, Timothy Miller, Sarah Gaichas, Marion

Gehlen, et al.

\section{To cite this version:}

Desiree Tommasi, Charles Stock, Alistair Hobday, Rick Methot, Isaac Kaplan, et al.. Managing living marine resources in a dynamic environment: The role of seasonal to decadal climate forecasts. Progress in Oceanography, 2017, 152, pp.15-49. 10.1016/j.pocean.2016.12.011 . hal-03112989

\section{HAL Id: hal-03112989 \\ https://hal.science/hal-03112989}

Submitted on 24 Jun 2021

HAL is a multi-disciplinary open access archive for the deposit and dissemination of scientific research documents, whether they are published or not. The documents may come from teaching and research institutions in France or abroad, or from public or private research centers.
L'archive ouverte pluridisciplinaire HAL, est destinée au dépôt et à la diffusion de documents scientifiques de niveau recherche, publiés ou non, émanant des établissements d'enseignement et de recherche français ou étrangers, des laboratoires publics ou privés. 


\title{
Managing living marine resources in a dynamic environment: the role of seasonal to
}

\section{decadal climate forecasts}

\author{
Desiree Tommasi ${ }^{\mathrm{a}}$, Charles A. Stock ${ }^{\mathrm{b}}$, Alistair J. Hobdayc, Rick Methot ${ }^{\mathrm{d}}$, Isaac C. Kaplan ${ }^{\mathrm{e}}$, J.
}

Paige Eveson $^{\mathrm{c}}$, Kirstin Holsman ${ }^{\mathrm{f}}$, Timothy J. Miller ${ }^{\mathrm{g}}$, Sarah Gaichas ${ }^{\mathrm{g}}$, Marion Gehlen ${ }^{\mathrm{h}}$, Andrew

Pershing ${ }^{\mathrm{i}}$, Gabriel A. Vecchi ${ }^{\mathrm{b}}$, Rym Msadek ${ }^{\mathrm{j}}$, Tom Delworth ${ }^{\mathrm{b}}$, C. Mark Eakin ${ }^{\mathrm{k}}$, Melissa A.

Haltuch $^{\mathrm{d}}$, Roland Séférian ${ }^{1}$, Claire M. Spillman ${ }^{\mathrm{m}}$, Jason R. Hartog ${ }^{\mathrm{c}}$, Samantha Siedlecki ${ }^{\mathrm{n}}$, Jameal

F. Samhourie , Barbara Muhling ${ }^{\mathrm{a}}$, Rebecca G. Asch ${ }^{\mathrm{a}}$, Malin L. Pinsky ${ }^{\mathrm{o}}$, Vincent S. Saba ${ }^{\mathrm{p}}$, Sarah

B. Kapnick ${ }^{\mathrm{b}}$, Carlos F. Gaitan ${ }^{\mathrm{b}, \mathrm{q}}$, Ryan R. Rykaczewski ${ }^{\mathrm{r}}$, Michael A. Alexander ${ }^{\mathrm{s}}$, Yan Xue ${ }^{\mathrm{t}}$,

Kathleen V. Pegion ${ }^{\mathrm{u}}$, Patrick Lynch ${ }^{\mathrm{v}}$, Mark R. Payne ${ }^{\mathrm{w}}$, Trond Kristiansen ${ }^{\mathrm{x}}$, Patrick Lehodey ${ }^{\mathrm{y}}$,

Francisco E. Werner ${ }^{2}$

${ }^{a}$ Atmospheric and Oceanic Sciences Program, Princeton University, Princeton, NJ 08540, USA; ${ }^{\mathrm{b}}$ Geophysical Fluid Dynamics Laboratory, NOAA, Princeton, NJ 08540, USA; ${ }^{\mathrm{c} C S I R O}$ Oceans and Atmosphere, Hobart Tasmania, Australia; ${ }^{\mathrm{d} N o r t h w e s t ~ F i s h e r i e s ~ S c i e n c e ~ C e n t e r, ~ N a t i o n a l ~}$ Marine Fisheries Service, NOAA, Seattle, WA 98112, USA; ${ }^{\mathrm{e} C o n s e r v a t i o n ~ B i o l o g y ~ D i v i s i o n, ~}$ Northwest Fisheries Science Center, National Marine Fisheries Service, NOAA, Seattle, WA 98117, USA; ${ }^{\mathrm{f}}$ Alaska Fisheries Science Center, National Marine Fisheries Service, NOAA, Seattle, WA 98115, USA; ${ }^{\mathrm{g} N o r t h e a s t ~ F i s h e r i e s ~ S c i e n c e ~ C e n t e r, ~ N a t i o n a l ~ M a r i n e ~ F i s h e r i e s ~}$ Service, NOAA, Woods Hole, MA 02543, USA; ${ }^{\mathrm{h}}$ Laboratoire des Sciences du Climat et de l'Environnement Institut Pierre Simon Laplace, Orme des Merisiers, Gif-sur-Yvette cedex, France; ${ }^{\mathrm{i}}$ Gulf of Maine Research Institute, Portland ME 04101, USA; ${ }^{\mathrm{j} C e n t r e}$ National de la Recherche Scientifique (CNRS)/CERFACS, CECI, UMR 5318, Toulouse, France; ${ }^{2}$ NOAA Coral Reef Watch, Center for Satellite Applications and Research, College Park, MD 20740, USA; 'Centre National de Recherches Météorologiques, UMR 3589, Météo-France/CNRS, Toulouse, France; ${ }^{\mathrm{m}}$ Bureau of Meteorology, Melbourne, Australia; ${ }^{\mathrm{n} J o i n t}$ Institute for the Study of Atmosphere and Oceanography (JISAO), University of Washington, Seattle, WA 98195; ${ }^{\circ}$ Department of Ecology, Evolution, and Natural Resources and Institute of Earth, Ocean, and Atmospheric Sciences, Rutgers University, New Brunswick, NJ 08901, USA; ${ }^{\text {NNortheast }}$ Fisheries Science Center, National Marine Fisheries Service, NOAA, Geophysical Fluid Dynamics Laboratory, Princeton University, Princeton, NJ 08540, USA; "Now at Arable Labs, Princeton, NJ 08542, USA; ${ }^{\mathrm{r} D e p a r t m e n t ~ o f ~ B i o l o g i c a l ~ S c i e n c e s, ~ M a r i n e ~ S c i e n c e ~ P r o g r a m, ~}$

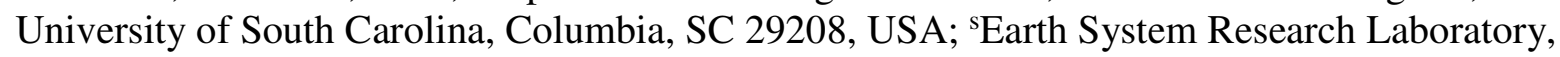
Boulder, CO 80305, USA; ${ }^{\mathrm{t} C l i m a t e}$ Prediction Center, NCEP/NWS/NOAA, College Park, MD 20740, USA; "Department of Atmospheric, Oceanic, and Earth Sciences, George Mason University, Fairfax, VA 22030, USA; ' Office of Science \& Technology, National Marine

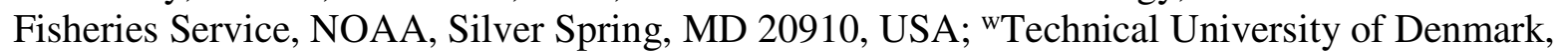
National Institute of Aquatic Resources, Charlottenlund, Denmark; ${ }^{x}$ Institute of Marine Research, Bergen, Norway; ${ }^{\mathrm{y}}$ Collecte Localisation Satellite (CLS), Toulouse, France; ${ }^{\mathrm{z}}$ Southwest Fisheries Science Center, National Marine Fisheries Service, NOAA, La Jolla, CA 92037, USA 


\section{Abstract}

Recent developments in global dynamical climate prediction systems have allowed for skillful predictions of climate variables relevant to living marine resources (LMRs) at a scale useful to understanding and managing LMRs. Such predictions present opportunities for improved LMR management and industry operations, as well as new research avenues in fisheries science. LMRs respond to climate variability via changes in physiology and behavior. For species and systems where climate-fisheries links are well established, forecasted LMR responses can lead to anticipatory and more effective decisions, benefitting both managers and stakeholders. Here, we provide an overview of climate prediction systems and advances in seasonal to decadal prediction of marine-resource relevant environmental variables. We then describe a range of climate-sensitive LMR decisions that can be taken at lead-times of months to decades, before highlighting a range of pioneering case studies using climate predictions to inform LMR decisions. The success of these case studies suggests that many additional applications are possible. Progress, however, is limited by observational and modeling challenges. Priority developments include strengthening of the mechanistic linkages between climate and marine resource responses, development of LMR models able to explicitly represent such responses, integration of climate driven LMR dynamics in the multi-driver context within which marine resources exist, and improved prediction of ecosystem-relevant variables at the fine regional scales at which most marine resource decisions are made. While there are fundamental limits to predictability, continued advances in these areas have considerable potential to make LMR managers and industry decision more resilient to climate variability and help sustain valuable resources. Concerted dialog between scientists, LMR managers and industry is essential to realizing this potential.

\section{Introduction}

Paleoecological and contemporary analyses demonstrate that large fluctuations in fish populations are associated with variations in climate (Baumgartner et al., 1992; Finney et al., 2002; Lehodey et al., 2006; Finney et al., 2010; Brander, 2010; Holsman et al., 2012; Barange et al., 2014). Clearly, climate-driven variability has always been part of the fisher and fisheries manager experience. However, the management response to climate variability has often been reactionary, and enacting efficient coping strategies has, at times, been difficult (McGoodwin, 
2007; Chang et al., 2013; Hodgkinson et al., 2014). For instance, unrecognized periods of environmentally- or climate-driven reduction in productivity contributed to the demise of Pacific sardine (Sardinops sagax) fishery in California in the 1950s (Murphy 1966; Lindegren et al., 2013; Essington et al., 2015), the collapse of the Peruvian anchoveta (Engraulis ringens) fishery in the 1970s (Clark, 1977; Sharp, 1987), and overfishing of cod (Gadus morhua) in the Gulf of Maine (Pershing et al., 2015, Palmer et al. 2016). Unanticipated temperature-induced changes in the timing of Gulf of Maine Atlantic lobster (Homarus americanus) life-cycle transitions resulted in an extended 2012 fishing season and record landings, but outstripped processing capacity and market demand, leading to a collapse in prices and an economic crisis in the lobster fishery (Mills et al., 2013). Similarly, an unforeseen extreme low water temperature event resulted in a \$10-million-dollar loss to the Taiwanese mariculture industry in 2008 (Chang et al., 2013). Failure to prepare for inevitable climate variability on seasonal to decadal scales can also alter the rebuilding times of stocks that have previously been overfished (Holt and Punt, 2009; Punt 2011; Pershing et al., 2015) and break down international cooperative harvesting agreements for border straddling stocks and highly migratory species (Miller and Munro, 2004; Hannesson, 2006; Hannesson, 2012).

Negative impacts of climate variability on coastal economies can be exacerbated when fishers, aquaculturists, and fisheries managers make decisions about future harvests, harvest allocations, and operational planning based on previous experience alone, without consideration of potential novel climate states (Hamilton, 2007). For instance, current fisheries abundance forecasts are largely based on historical recruitment (i.e. addition of new individuals to the fishery) estimates, and aquaculture harvests on the basis of historical growth patterns. While this approach makes harvest decisions robust to a range of historical uncertainty, it may be insufficient when an ecosystem shifts to a new productivity state, when a productivity trend moves beyond historical observations, or when the degree of variation in productivity changes (Wayte, 2013; Audzijonyte et al., 2016). Past patterns may not always be a good indication of future patterns, especially under anthropogenic climate change (Milly et al., 2008). Species will experience new conditions across multiple ecologically significant climate variables (Williams et al., 2007; Rodgers et al., 2015), challenging our ability to manage living marine resources (LMRs) under the assumption of stationarity. Adapting our decision frameworks to climate variability at seasonal to decadal scales can serve as an effective step towards improving our 
long-term planning ability under future climate change (Link et al., 2015).

Incorporating environmental forcing into management frameworks for LMRs is challenging because the emergent effects of climate on marine ecosystems are complex. For example, atmospheric forcing can drive changes in ecologically significant physical or chemical variables that directly affect organismal physiology and behavior (e.g. temperature-driven changes in oxygen demand; Pörtner and Farrell, 2008), species distribution (e.g. Pörtner and Knust, 2007), phenology (e.g. Asch, 2015), and vital rates, such as growth (e.g. Kristiansen et al., 2011; Audzijonyte et al., 2013; Audzijonyte et al., 2014; Audzijonyte et al., 2016). Additionally, climate can indirectly impact LMR productivity by affecting key biotic processes, such as variation in prey fields and energy transfer in response to fluctuations in alongshore and crossshelf transport (e.g. Bi et al., 2011; Keister et al., 2011; Combes et al., 2013; Wilderbuer et al., 2013) or to climate-driven changes in primary productivity and phytoplankton size-structure (Daufresne et al., 2009). Climate-related variations in the abundance of predators, competitors, and parasites can also have an indirect effect on LMRs (e.g. Boudreau et al., 2015), and concurrent responses to fishing, habitat loss, and pollution may further complicate observed responses (Brander, 2007; Halpern et al., 2008; Andrews et al., 2015; Fuller et al., 2015; Halpern et al., 2015).

While such biophysical complexities challenge efforts to implement climate-informed fisheries management frameworks, concerted observational and modelling efforts across decades have led to some improved understanding of climate-ecosystem interactions in many regions (Lehodey et al., 2006; Alheit et al., 2010; Ainsworth et al., 2011; Hunt et al., 2011; Di Lorenzo et al., 2013; Bograd et al., 2014). These gains have been mirrored by improved climate predictions at the temporal and spatial scales relevant to LMRs and their management, e.g. days to decades (Hobday and Lough, 2011; Stock et al., 2011). Operational seasonal predictions have now enabled development of climate services for a range of applications relevant to society (Vaughan and Dessai, 2014). For example, improvements in model spatial resolution have allowed skillful prediction of hurricane activity at a sub-basin scale relevant to climate risk management (Vecchi et al., 2014). Seasonal climate forecasts have also reduced vulnerability of the agricultural sector to climate variability (Meinke and Stone, 2005; Meza et al., 2008; Hansen et al., 2011; Zinyengere et al., 2011; Takle et al., 2014, Zebiak et al., 2015 and references therein) and have informed water resources decision making (Hamlet et al., 2002; Abawi et al., 2007). 
134 Furthermore, seasonal climate forecasts have been incorporated into human health early warning 135 systems for diseases, such as malaria, that are influenced by climatic conditions (Abawi et al., 136 2007) and for outbreaks of noxious jellyfish (Gershwin et al., 2014). Enhanced capability has 137 also made possible skillful seasonal forecasts of LMR-relevant variables at fine spatial and 138 temporal scales useful to industry (defined here to include fisheries and aquaculture industries)

139 and management (Stock et al., 2015; Siedlecki et al., 2016). While multi-annual to decadal 140 predictions are at an initial stage of development and are not yet operational (Meehl et al., 2014),

141 in specific ocean regions, particularly the North Atlantic, multi-annual forecasts appear skillful 142 over several years (Yang et al., 2013; Msadek et al., 2014a; Keenlyside et al., 2015), and may 143 show promise for some LMR applications (Salinger et al., 2016).

144 The objective of this paper is to assess present and potential uses of these advances in 145 climate predictions to facilitate improved management of wild and cultured LMRs. This effort 146 was initiated at the workshop "Applications of Seasonal to Decadal Climate Predictions for 147 Marine Resource Management" held at Princeton University on June 3-5 2015, which brought 148 together 60 scientists spanning climate and marine resource disciplines. This resulting synthesis 149 establishes a common understanding of the prospects and challenges of seasonal to decadal 150 forecasts for LMRs to support further innovative and effective application of climate predictions 151 to management decisions. In Section 2, we describe climate prediction systems and discuss their 152 strengths and limitations. In Section 3, we briefly summarize climate-sensitive decisions made 153 within management of commercially exploited species, protected and endangered species, and 154 for fishing and aquaculture industry applications. Section 4 presents case studies drawn from 155 peer-reviewed literature highlighting the scope of past and present applications. Sections 5 and 6 156 distill successful components across these existing applications and identify priority

157 developments based on the material in Sections 2-4. Section 7 offers concluding remarks on 158 prospects for expanded use of climate predictions for marine resource management.

\section{Predicting environmental change across space and time scales}

Advances in global dynamic climate prediction systems raise the prospect of skillful environmental prediction at the time scales relevant to LMR management and industry decisions. In this section, we first describe these prediction systems (Section 2.1), emphasizing characteristics relevant to informing the management decisions which will be described in 
Section 3, and then discuss evaluation of forecast skill (Section 2.2). Lastly, we provide a brief overview of existing studies of prediction skill for LMR-relevant climate variables (Section 2.3).

\subsection{Overview of climate prediction systems}

There exist two types of climate prediction models: dynamical models based on knowledge of the underlying physics of the climate system, and statistical models based on empirical relationships. The focus here is on dynamical seasonal to decadal prediction systems derived from Global Climate Models (GCMs), but it is important to note that statistical climate prediction models have also been used with success at seasonal time scales (Xue et al., 2000; van den Dool, 2007; Muñoz et al., 2010; Newman et al., 2011; Barnston et al., 2012; Ho et al., 2013; Barnston and Tippett, 2014; Chapman et al., 2015). Statistical climate predictions require considerably less computing resources than dynamical prediction systems and are used by climate offices throughout the world, particularly where high-performance computing facilities are not available. However, when developing a statistical forecast, care must be taken to not impart artificial skill through the method used to select predictors (DelSole and Shukla, 2009) or through the forecast sets used for training and skill assessment not being sufficiently independent of each other. Statistical predictions are also limited by the assumption that historically observed statistical relationships between climate variables will be maintained in the future (Mason and Baddour, 2007). By contrast, dynamical seasonal to decadal climate predictions arise more directly from fundamental physical principles expected to hold under novel climate states (Randall et al., 2007). Dynamical models can also forecast quantities that are difficult to observe and thus develop statistical models for (e.g., bottom temperature). We note, however, that many small-scale processes, such as cloud microphysics or submesoscale fronts and eddies, are not resolved by most GCMs and uncertainty connected to the parameterization of such "sub-grid scale" processes within GCMs can impact prediction skill (Warner, 2011).

Dynamical climate predictions on seasonal to decadal time scales rest on the premise that knowledge of the present climate and the dynamic principles governing its evolution may yield useful predictions of future climate states. Four core components are thus required to make such predictions at global scales and translate them for users: 1) global dynamical climate models, 2) global observing systems, 3) a data assimilation system, and 4) analysis and dissemination 
systems to provide predictions to stakeholders across sectors. We provide a brief overview of each of these components below.

\subsubsection{Dynamical coupled global climate models for seasonal to decadal prediction}

GCMs are comprised of atmospheric, ocean, sea-ice and land physics and hydrology components, each governed by dynamical laws of motion and thermodynamics solved numerically on a global grid. GCMs used for seasonal to decadal prediction are largely analogous to those used for century-scale climate change projection (e.g. Stock et al. 2011), but the simulation design is different (Fig. 1). In the climate change case (Fig. 1, bottom), the goal is to track the evolution of the climate over multi-decadal time scales as it responds to accumulating greenhouse gases (GHGs) and other anthropogenic forcing. The simulations have three components: a pre-industrial control of several hundred to several thousand years where the model comes to quasi-equilibrium with preindustrial GHGs and aerosol concentrations, a historical segment where GHGs increase in accordance with observed trends, and a projection following one of several future GHGs scenarios (Moss et al., 2010; van Vuuren et al., 2011). Because initial conditions at the start of the preindustrial period are largely "forgotten" except possibly in the abyssal ocean, the only aspects linking historical and future simulations to a specific year are the GHGs, land cover changes, solar forcing, land use changes, and other radiatively active atmospheric constituents (e.g. aerosols). Internal climate variations arising from interactions in the components of the climate system itself such as the El Niño Southern Oscillation (ENSO) are represented in climate simulations, but their timing/chronology does not and is not expected to agree with past observations. The objective is to obtain an accurate representation of the evolving climate statistics over multiple decades, including the statistics of internal climate variation, rather than precise predictions of the climate state at a given time. Indeed, ensembles of historical and future simulations begun from different initial conditions, and containing different realizations of internal climate variations, are often employed in obtaining these statistics (Kay et al., 2015).

On the other hand, seasonal (months to a year) prediction skill (Fig. 1, top) largely depends on initializing the model using information specific to the current climate state. Owing to the chaotic nature of the atmosphere, daily weather has a deterministic predictability limit of 5-10 days (e.g. Lorentz, 1963; Goddard et al., 2001). In seasonal forecasts, the predictability 
horizon is extended by forecasting monthly or seasonally-integrated statistics rather than daily weather, and by exploiting the more slowly evolving elements of the climate system, such as the ocean. It is assumed that the initial climate state sufficiently determines the future evolution of internal climate variations so that skillful predictions of climate states within the forthcoming months are possible. The presence of ENSO in June, for example, will impact extra-tropical seasurface temperature (SST) in September via teleconnections that are now substantially captured by many GCMs, albeit some important biases remain (Deser et al., 2010).

In today's coupled dynamical prediction systems, seasonal prediction is thus classified as an initial value problem rather than a boundary value problem. As the response to changes in external forcing like GHGs occurs over much longer time scales, their predictive skill is more dependent on initialization to current climate conditions rather than boundary conditions (i.e. external forcing). Although external forcing changes are typically small over periods spanned by individual seasonal forecasts, they can be significant over the multi-decadal periods spanned by successive real time forecasts and the accompanying retrospective forecasts discussed in Section 2.1.3, and therefore should ideally remain included in seasonal forecast models (Doblas-Reyes et al., 2006; Liniger et al., 2007). Annual to decadal predictability (1 to 30 years), in contrast, arises from both predictable internal climate variations following model initialization and external forcing, presenting a hybrid problem (Fig. 1, middle panel, Meehl et al., 2014).

Another difference between GCMs configured for climate projections and seasonal to decadal predictions systems has been the successful expansion of the climate change GCM configuration to earth system models (ESMs) that include biogeochemistry (e.g. Bopp et al., 2013). ESMs can simulate biological and chemical properties (e.g. oxygen, pH, nutrients, primary and secondary production) strongly linked to LMRs (Stock et al., 2011), and thus they have been broadly applied to assess climate change impacts on LMRs (e.g. Cheung et al., 2009; Barange et al., 2014). While incorporation of earth system dynamics in global seasonal to decadal prediction models remains in an early stage of development (Séférian et al., 2014; Case Study 4.6), it may yield benefits at the seasonal to decadal scale. In Section 2.3, discussion of LMR-relevant seasonal to decadal predictions will be focused on the physical variables produced by the operational seasonal to decadal global forecast systems, but priority developments to expand biogeochemical prediction capabilities will be discussed in Section 6. 


\subsubsection{The global climate observing system supporting climate prediction}

The initialization of seasonal to decadal climate predictions is generated via a range of data assimilation approaches (Section 2.1.3) that draw observational constraints from the global climate observing system. This system collates diverse observations of many climate quantities across the globe including those obtained from satellites, land-based weather stations, radiosondes, weather radars, aircrafts, weather balloons, profiling floats, moored and drifting ocean buoys, and ships (see http://www.wmo.int/pages/prog/gcos/index.php?name=ObservingSystemsandData for a list of the global climate observing system's observational networks and climate variables). Expansion of the global climate observing system across decades has improved prediction skill. For instance, establishment of the Pacific Tropical Atmosphere-Ocean (TAO) moored buoy array in the early 1990s (McPhaden, 1993) was key in enhancing seasonal prediction skill of ENSO and ENSO-related SSTs (Ji and Leetmaa, 1997; Vidard et al., 2007). Similarly, the addition of Argo profiling floats to the global ocean observing network improved seasonal SST forecast skill (Balmaseda et al., 2007).

\subsubsection{Assimilating observations to constrain the initial climate state}

While the advent of satellites and of observing platforms, such as the TAO array and Argo floats, have considerably increased the number of available observations, much of the Earth system, particularly in the deep ocean (> $2000 \mathrm{~m}$ ), remains unobserved. Climate prediction systems combine observational and model constraints using a data assimilation system to fully initialize climate predictions. Diverse approaches are used, from nudging methods to fourdimensional variational analyses and ensemble Kalman filters. For instance, the NOAA Geophysical Fluid Dynamics Laboratory (GFDL) coupled data assimilation system produces an estimate of the present climate state by using an ensemble Kalman filter algorithm to combine a probability density function (PDF) of observations, both oceanic and atmospheric, with a prior PDF derived from the dynamically coupled model (Zhang et al., 2007). For more details on data assimilation techniques we refer readers to Daley et al. (1991), Kalnay et al. (2003), Tribbia and Troccoli (2007), Edwards et al. (2015), Zhang et al. (2015), and Stammer et al. (2016).

Assimilating observations produces an initialized climate state that differs from what the climate models would simulate were they running freely. This is because dynamical climate 
models are an approximation of the real world, and as such can show systematic bias (Warner, 2011). Once a seasonal forecast begins, dynamical models drift back to their freely running state. In some cases, drifts can be as large as the signal being predicted, particularly for longer leadtimes, and can degrade forecast skill (Goddard et al., 2001; Magnusson et al., 2013; Smith et al. 2013). It is therefore important to remove this drift to obtain the signal of interest for input into LMR models. While diverse approaches for this have been proposed, they primarily involve subtracting the mean drift from across a set of retrospective forecasts (hindcasts). For example, to correct for model drift in a January-initialized SST anomaly forecast for May, the mean drift for January-initialized May forecasts from the past 30 years is subtracted from the predicted temperature trend.

While a primary goal of data assimilation is forecast initialization, the estimates of atmospheric or ocean state produced via data assimilation are also useful for model verification and calibration, retrospective studies of past ocean variability, and "nowcasts" of present conditions. Such historical time series of past ocean state estimates are referred to as reanalysis datasets. While often taken as "observations" they are obtained using the model and a data assimilation system in the same way as was described for model initialization. Hence, reanalyses are model-dependent and each climate prediction center produces its own version of what the earth system looked like in the past (Table A1). While such reanalyses are generally in agreement for variables that are widely sampled (e.g. SST after the advent of satellites) over scales resolved by the GCMs, there are differences, reflecting model uncertainty, the scarcity of observational data, and the fact that single observations may not be representative of the largescale climate state. One way to estimate uncertainties among ocean reanalyses is to conduct ocean reanalysis intercomparisons (Balmaseda et al., 2015). Table A1 lists six operational ocean reanalysis products that are available for the period from 1979 to present and that are used in a Real-time Ocean Reanalysis Intercomparison Project (Xue et al., in review). One example of uncertainties of ocean reanalysis products is shown in Fig. 2 for temperature anomalies at a depth of $55 \mathrm{~m}$ during April 2015. Some areas, such as the west coast of North America, clearly stand out as being consistent between reanalysis products. This has also been shown in some recent seasonal forecast efforts in the region (Siedlecki et al., 2016), increasing confidence in their treatment as "observations". By contrast, temperature values along the Northeast shelf of North America are more uncertain. This highlights the importance of confirming consistency of 
reanalyses with observations at the scales of interest when possible (Stock et al., 2015), and the paucity of oceanic variables for which we can robustly evaluate prediction skill.

\subsubsection{Analysis and dissemination in support of diverse stakeholders}

The goal of analysis and dissemination systems is to take the raw output from the predictions and package it in a way that can be easily accessible and understood by stakeholders. Generally, because of the variety of users and applications of seasonal forecasts, most climate prediction centers focus on ensuring that seasonal climate model output is corrected for model drift (see Section 2.1.3 for more details) and verified. Forecast verification, which entails an assessment of forecast skill, is described in Section 2.2. Any further post-processing, such as downscaling to application-relevant spatial scales, is performed on an ad hoc basis in collaboration with users.

Climate forecasts are inherently uncertain because of the chaotic nature of the climate system, whereby small differences in initial conditions can lead to a diverse range of climate states (Lorenz, 1963; Wittenberg et al., 2014), as well as our imperfect understanding of the climate system. In an attempt to capture some of this uncertainty, a collection of forecasts differing in their initial conditions or model parametrizations, referred to as an ensemble, is produced (see Section 2.2 for more details). For a forecast to be useful for decision making, it needs to represent the likelihood of different outcomes. Probabilistic forecasts constructed from information provided by the ensemble forecast fill this need. Such forecasts are commonly communicated as probabilities that the outcome will be in the lower, middle or upper tercile of the climatological PDF (Fig. 3), although many other possibilities exist. Reliability, the property that forecast probabilities are similar to observed frequencies, is crucial for decision making. However, probabilistic forecasts based on raw forecast output tend to be overconfident, and are thus often recalibrated to improve their reliability (Sansom et al., 2016). Deterministic forecasts describing the average outcome of the forecast ensemble are also sometimes disseminated. While relatively simple to interpret, they are generally less useful than probabilistic forecasts because they contain no measures of uncertainty or the likelihood of alternative outcomes.

Once the climate predictions are verified, most prediction centers deliver forecasts to users via the internet. For example, seasonal forecasts from NOAA NCEP, GFDL, and numerous other modeling centers can be downloaded from the North American Multi-Model Ensemble 
349

350

351

352

353

354

355

356

357

358

359

360

361

362

363

364

365

366

367

368

369

370

371

372

373

374

375

376

377

378

379

(NMME) (Kirtman et al., 2014) website at http://www.cpc.ncep.noaa.gov/products/NMME/. Hindcasts (i.e. retrospective forecasts) are archived on the same site, and skill assessment maps are also made available. It should be noted that because of the large variety of users and the limited resources devoted to delivery systems, model output presentation and visualization is rarely customized to specific user needs. Thus, there is utility in repackaging standard forecasts specifically for the fisheries and aquaculture sectors as "targeted forecasts" (Hobday et al., 2016; Siedlecki et al., 2016).

\subsection{Forecast skill}

In addition to providing users with information on forecast uncertainty through wellcalibrated probabilistic forecasts as discussed above, skill information is essential for LMR managers or fishing industry personnel to assess confidence in seasonal to decadal forecasts. Hence, model verification, which assesses prediction quality of the forecast through skill assessment, is essential for seasonal to decadal predictions to be practically useful to decisionmaking. As well as enabling drift correction as described in Section 2.1.3, retrospective forecasts are used by climate prediction centers to establish forecast skill. This involves initializing a suite of predictions across the past several decades and testing whether predictions would have been successful (e.g. given an estimate of climate conditions in January of 1982, how well can the model predict temperature and precipitation anomalies for the rest of 1982). These retrospective forecast suites are also made available to potential users to assess predictability of particular variables of interest.

Numerous prediction skill measures have been developed (Stanski et al., 1989; von Storch and Zwiers, 2001; Jolliffe and Stephenson, 2003; Mason and Stephenson, 2007; van den Dool, 2007; Wilks, 2011). Generally, stakeholders are interested in the correctness of a forecast (Mason and Stephenson, 2007), and thus the anomaly (see Section 3.1.3 for details on how anomalies are calculated) correlation coefficient (ACC) and root mean square error (RMSE) between the model retrospective forecast and observations are among the most commonly used prediction skill measures for deterministic forecasts. For a probabilistic forecast, the Brier Score (BS) is often used to measure of the mean squared probability error of whether an event occurred. The value of the dynamical prediction can also be assessed by comparing the skill of a dynamical forecast output to that of climatology. For instance, the ranked probability skill score 
(RPSS), a commonly used measure of probabilistic prediction, is used to reflect the relative improvement given by the forecast over climatology (Fig. 3). Seasonal to decadal prediction skill is also often compared against that of a persistence forecast. A persistence forecast is a forecast produced by simply projecting forward the current climate anomaly. For example, a January onemonth lead SST forecast would be compared against a persistence forecast derived from maintaining the December temperature anomaly into January. Statistical predictions, particularly for decadal forecasts whose skill also depends on changes in radiative forcing not represented in a persistence forecast, can also act as useful tools against which to assess dynamical prediction skill (Ho et al., 2013). While statistical or persistence forecasts provide an important benchmark against which to assess the added value of dynamical seasonal forecasts, a skillful statistical (e.g. Eden et al., 2015) or persistence forecast can be as relevant to users as a skillful dynamical forecast.

As discussed in Section 2.4.1, for a forecast to be useful to LMR managers and the fisheries and aquaculture industries, not only does it need to be skillful, but its uncertainty has to be representative of the spectrum of potential outcomes. Climate prediction uncertainty arises from different sources (Payne et al., 2016), with internal variability and model uncertainty being the most important for seasonal to decadal predictions, particularly at regional scales (Hawkins and Sutton, 2009). Internal variability uncertainty stems from emergent chaotic properties of the climate system, and causes predictions differing only a little in initial conditions to evolve to quite different climate states (Lorenz, 1963; Wittenberg et al., 2014). In an attempt to capture some of this internal variability uncertainty, climate prediction centers produce different forecasts characterized by the same global dynamic model started with slightly different initial conditions chosen to reflect equally probable initial states given a set of observational constraints. The collection of such forecasts is referred to as a single-model ensemble.

Forecast uncertainty also arises from our incomplete understanding of the climate system, as reflected in the forecast model being a simplification of the real world. Model error can stem from uncertainties in the parameterizations of physical processes that are either not well understood, act at a scale below the model's spatial or temporal resolution, or are too computationally expensive to be modeled explicitly. Errors in numerical approximations also add to model uncertainty. Multi-model ensembles are a way to characterize forecast uncertainty arising from this model uncertainty. In such ensembles, simulations from entirely different 
models, often from various prediction centers, are combined to produce a forecast output. The

412 North American Multi-Model Ensemble (NMME) (Section 2.1.4) is an example of such a

413 forecast. Seasonal forecasts from leading US and Canadian prediction systems are combined to

414 produce a multi-model ensemble mean seasonal forecast. Single model forecasts are also

415 provided, but the multi-model mean has been shown to have higher prediction skill than any

416 single model (Becker et al., 2014). The skill increase comes from error cancellation and the non-

417 linearity of model diagnostics (Becker et al., 2014). In addition to a more accurate measure of

418 central tendency, use of a multi-model ensemble often allows for a more complete representation

419 of forecast uncertainty. Ensemble methods thus allow forecasts to be probabilistic, reflecting the

420 range of all potential outcomes (Goddard, 2001). To base decisions on a comprehensive

421 assessment of risk, incorporation of seasonal to decadal predictions into LMR applications

422 should include these estimates of forecast uncertainty.

Dynamical processes that operate at scales finer than a model's resolution must be

424 parameterized. The spatial resolution of a model grid dictates the breadth of processes that may

425 be simulated, and differences in this resolution can influence model error and thus limit forecast

426 skill. Indeed, an increase in resolution from the 100 to $200-\mathrm{km}$ atmospheric resolution common

427 to many of the current seasonal to decadal prediction systems (Kirtman et al., 2013), to 50-km

428 resulted in better seasonal temperature and precipitation forecast skill, particularly at a regional

429 scale (Jia et al., 2015). Nevertheless, in regions where local and/or unresolved sub-grid scale

430 processes strongly modulate the basin-scale climate signal, even such relatively high resolution

431 (50-km atmosphere and 100-km ocean) predictions have limited skill. For example, global

432 climate models that have an ocean resolution of $100-\mathrm{km}$ to $200-\mathrm{km}$ have a bias in both ocean

433 temperature and salinity in complex coastal environments such as the US Northeast Continental

434 Shelf (Saba et al., 2016). These biases may partially explain the relatively poor predictive skill of

435 seasonal SST anomalies predictions in this region (Stock et al., 2015). When both atmosphere

436 and ocean model resolution are increased (50-km atmosphere, 10-km ocean), such biases are

437 substantially reduced (Fig. 4) because the Gulf Stream coastal separation position as well as

438 regional bathymetry are more accurately resolved. We stress, however, that while enhanced

439 resolution appears critical for some scales and ecosystems, existing models show considerable

440 prediction skill for marine resource relevant variables at other scales and ecosystems (Section

441 2.3). High resolution GCMs (10-km ocean versus $100-\mathrm{km}$ in many prediction systems), are also 
considerably more computationally expensive to run, currently limiting their use in operational climate prediction systems. Furthermore, biases can remain at this resolution, and can be quite large in specific ocean regions (Delworth et al., 2012; Griffies et al., 2015). This is due, in part, to the challenges of optimizing sub-gridscale parametrizations for higher resolution models (Goddard et al., 2001).

An alternative means of addressing resolution challenges is to embed a regional dynamical downscaling model in a global climate prediction system (e.g. Section 4.5, Section 6). Most of the world's fish catch is produced (Pauly et al., 2008) and most aquaculture operations are located in coastal and shelf seas. Regional models have the added advantage of improved resolution of coastal process (e.g. tidal mixing) that impact predictive skill of LMR-relevant variables at decision-relevant scales. However, these advantages must be weighed against the challenges, such as boundary condition inconsistencies, encountered when nesting models of considerably different structure and resolution (Marchesiello et al., 2001; Brennan et al., 2016).

It is important to note that while some of the current uncertainty in seasonal to decadal predictions can be reduced by, for example, improved model parameterizations, expanded observational networks, or increased model resolution, irreducible uncertainties will remain.

Owing to the chaotic nature of the atmosphere, there are inherent seasonal and decadal predictability limits, which need to be clearly communicated to stakeholders (Vaughan and Dessai, 2014; Zebiak et al., 2015). For instance, on the west coast of the US, the seasonal upwelling season ends abruptly with the fall transition. This transition is driven mostly by storms, and consequently may not be predictable on seasonal time scales.

Finally, since reanalysis products are often treated as observations in forecast verification (Section 2.1.3), it is important for users to confirm the fidelity of such data sets to their specific area of interest prior to integration with LMR management frameworks. Where possible, this should be done with additional hydrographic data that may not have been incorporated in the reanalysis. We refer readers to Stock et al. (2015) for an example on how such an analysis can be performed.

\subsection{Prediction of living marine resource-relevant physical variables}

Variables routinely predicted using current seasonal to decadal forecast systems are LMR-relevant (e.g. SST), and the objectives of seasonal to decadal climate prediction are 
473

474

475

476

477

478

479

480

481

482

483

484

485

486

487

488

489

490

491

492

493

494

495

496

497

498

499

500

501

502

503

consistent with the spatiotemporal scale of many of the fisheries management decisions.

However, oceanic prediction skill has often only been assessed with a view to its influence on regional weather prediction, rather than being of primary interest in itself (Stockdale et al., 2011). There are, however, a growing number of prediction studies for quantities and spatiotemporal scales relevant to LMR science and management challenges (Fig. 5). Below we discuss several of these, including predictability of SST anomalies, sea ice, and freshwater forcings that influence LMRs, along with recent advances for anticipating extreme events.

SST anomalies are both important drivers and meaningful indicators of ecosystem state (e.g., Lehodey et al., 2006; Brander et al., 2010). Efforts to assess the predictability of SST anomalies have emphasized ocean basin-scale modes of variability often linked to regional climate patterns (e.g., ENSO; Barnston et al., 2012). However, recent work has also revealed considerable SST prediction skill for many coastal ecosystems (Stock et al., 2015). Over short time scales, skill often arises from simple persistence of SST anomalies due to the ocean's substantial thermal inertia (Goddard and Mason, 2002). In many cases, however, skill exceeds that of persistence forecasts and can extend across leads of 6-12 months (Fig. 6). Such seasonal SST predictability may arise from diverse mechanisms, including the seasonal emergence of predictable basin-scale SST signatures following periods dominated by less predictable local variation, transitions between opposing anomalies due to the seasonal migration of ocean fronts, or the predictable re-emergence of sub-surface anomalies following the breakdown of summer stratification (Stock et al., 2015). Further analysis suggests that multi-model based SST predictions can further improve regional SST anomaly prediction skill and more reliably represent prediction uncertainty and the potential for extremes (Hervieux et al., in review). The considerable prediction skill at this LMR-relevant scale has allowed for some pioneering use of SST predictions for marine resource science and management (e.g., see case studies in Section 4), and suggests ample potential for further expansion.

In a few ocean regions, most notably the North Atlantic, SST predictions are skillful for several years (Yang et al., 2013; Msadek et al., 2014a; Keenlyside et al., 2015). This time scale is of particular interest for many LMR applications (Fig. 5). The predictive skill on these time scales emerges from phenomena, primarily in the ocean, that have inherent decadal scales of variability (Salinger et al., 2016). Perhaps the most prominent among these is the Atlantic Meridional Overturning Circulation (AMOC). Decadal-scale variations in AMOC-related ocean 
heat transport can influence SST over a wide area of the North Atlantic, and are thought to be a critical component of North Atlantic basin-scale SST variation characterized by the Atlantic Multidecadal Oscillation (AMO). For example, the abrupt warming observed in the mid-1990s in the North Atlantic has been retrospectively predicted in several models (Pohlmann et al., 2009; Robson et al., 2012; Yeager et al., 2012; Msadek et al., 2014a), with an increase of the AMOC being responsible for the warming. The Pacific Decadal Oscillation (PDO) also has decadal scales of variability and can be predicted a few years in advance, with significant impacts across a broad area of the North Pacific and adjacent continental regions (Mochizuki et al., 2010; Meehl and Teng, 2012). More idealized predictability studies also suggest the potential for substantial decadal predictive skill in the Southern Ocean (Boer, 2004), associated with deep vertical mixing and substantial decadal scale natural variability (Salinger et al., 2016). Nevertheless, unlike seasonal climate predictions, which are operational, the field of decadal prediction is in a very early stage (Meehl et al., 2014). Performance of decadal predictions needs to be assessed over a wider range of models and systematic model errors have to be reduced further to increase their utility to the marine resource community. Furthermore, the limited number of decadal-scale fluctuations of the 30-40 year period for which retrospective forecasts are possible severely restricts the effective sample size with which to characterize decadal prediction skill. Models may demonstrate an ability to capture several prominent events over this time period, but it is difficult to robustly generalize skill for this limited sample of independent decadal-scale events.

Sea ice is another LMR-relevant variable (Coyle et al., 2011; Hunt et al., 2011, Saba et al., 2013), whose seasonal predictive skill has been assessed at a regional scale. Based on estimates by the National Snow and Ice Data Center, September Arctic sea ice extent has declined at a rate of about $14 \%$ per decade since the beginning of satellite records (Stroeve et al., 2014), a trend largely attributed to warming due to accumulating GHGs (e.g. Stroeve et al., 2012). In addition to these long-term changes, large year-to-year variations have been observed in the position of the summer and winter sea ice edge. Operational and quasi-operational initialized predictions show some skill in predicting summer Pan-Arctic sea ice extent when it reaches its minimum in September, with significant correlation 3 to 6 months in advance at best in a few dynamical models (Sigmond et al., 2013; Wang et al., 2013; Chevallier et al., 2013; Msadek et al., 2014b). Sea ice thickness appears to provide the memory for sea ice extent predictability from one summer to the next. Hence more accurate predictions could be expected 
with improved observations of sea ice thickness and sea ice thickness initialization (Guemas et al., 2016). While predictions of summer sea ice have important implications for shipping and resource extraction, sea ice extent in late winter affects spring phytoplankton bloom timing and ultimately fish production (Hunt et al., 2011). However, while enhanced forecast skill with up to 3 to 4 months of lead-time relative to a persistence forecast has been reported during fall and early winter, forecast skill remains limited in late winter (Sigmond et al., 2013; Msadek et al., 2014b). Processes driving winter sea ice predictability include the representation of atmospheric dynamics like the position of the blocking high (Kwok, 2011), but also oceanic processes like heat convergence that drives SST anomalies in the marginal seas (Bitz et al., 2005). On-going studies based on improved model physics, improved parameterizations, and increased resolution in the atmospheric and oceanic components of the models are expected to improve representation of atmospheric dynamics, oceanic processes, and the mean distribution of sea ice, its seasonal variations, and possibly its predictability. Such improvements may also impact SST prediction skill (Stock et al., 2015).

While oceanic variables are of major importance for production and distribution of wild and aquaculture species, river temperature and flow are additional influences on recruitment and survival of commercially-important anadromous fish species, such as Pacific and Atlantic salmon (Bryant, 2009; Jonsson and Jonsson, 2009) and stocks such as northwest Atlantic river herring that have fallen below historical levels (Tommasi et al., 2015). In addition, these variables affect nearshore ocean dynamics and hence impact aquaculture of estuarine species. Seasonal stream flow predictability is thus of high interest to some industry groups and fisheries management agencies. Land models incorporated in current seasonal to decadal climate prediction systems, however, only provide a coarse representation of topography, river networks, and land cover, and forecasts of hydrological properties are not very skillful if taken directly from global dynamical forecast systems (Mo and Lettenmaier, 2014). Historically, land resolution in models has limited topographic variability, which impacts snowfall, and as a result has downstream influences on surface hydrology (e.g. reduced soil moisture and stream flow) in mountainous regions and surrounding areas dependent on orographic precipitation and spring and summer snowmelt (Kapnick and Delworth, 2013; Kapnick et al., 2014). This bias is pronounced in western North America where mountain hydrology drives water availability (Barnett et al., 2005). As a result, higher resolution hydrological models have been forced by the 
larger scale input from coarser global climate models to produce hydrologic forecasts at scales useful for decision makers (e.g. Mo and Lettenmaier, 2014). As prediction systems increase in atmospheric and land surface resolution, precipitation and temperature prediction skill over mountain regions also increases as topography is better resolved (Jia et al., 2015).

Aside from issues in resolution, hydrologic predictability is largely a function of initial land surface conditions (primarily soil moisture and snow cover) and seasonal forecasts of rainfall and temperature (Shukla et al., 2013; Yuan et al., 2015). In regions where snow and soil moisture provide a long hydrological memory, such as the western United States or high altitude locations, accurate initial conditions can provide skillful forecasts out to 3 to 6 months, particularly during cold seasons (Koster et al., 2000; Mahanama et al., 2012; Shukla et al., 2013). Similarly, in regions where the flow regime is controlled by groundwater rather than rainfall, persistence of initial flow can provide a skillful seasonal forecast (e.g. Svensson, 2016).

However, over most of the globe, persistence skill decreases after a month (Shukla et al., 2013), and improvements in the predictability of streamflow are made by incorporating climate information into hydrological forecasting systems. Climate predictions systems can provide such climate forcing inputs (i.e. precipitation and temperature predictions) (Mo and Lettenmaier, 2014). However, the precipitation prediction skill of current global dynamical forecast systems is often too low to extend hydrological forecast skill beyond 1 month, particularly in dynamically active regions (Mo and Lettenmaier, 2014). Skillful seasonal hydrological predictions out to 3 to 9 months lead-times have been obtained, however, by integrating into hydrological models rainfall predictions derived from a climate index, such as the NAO, from a climate prediction system (e.g. Svensson et al., 2015). Alternatively, skillful seasonal hydrological predictions have been achieved by statistically integrating a climate index directly into a hydrological forecast system (e.g. Piechota and Dracup, 1999; Karamouz and Zahraie, 2004; Wang et al., 2011; Bradley et al., 2015).

Over recent years substantial effort has been placed on seasonal predictions of extreme phenomena, particularly tropical (Camargo et al., 2007; Vecchi and Villarini, 2014) and extratropical (e.g., Yang et al., 2015) cyclones. These extreme events threaten fishers' safety at sea and can dramatically impact the aquaculture and fishing industry through lost production and income with changes in fish survival and growth, reduction in water quality, and destruction of essential fish habitat (e.g. coral reefs, seagrass beds) or infrastructure (Chang et al., 2013; 
Hodgkinson et al., 2014). Although individual tropical cyclones are very much "weather" phenomena, with no path to predictability beyond a few days, some aggregate statistics of tropical cyclones are strongly influenced by predictable large-scale aspects of climate, such as ENSO or other modes of variability (e.g., Gray, 1984). This has led to the development of a number of skillful statistical (Klotzbach and Gray, 2009; Jagger and Elsner, 2010), dynamical

602 (Vitart and Stockdale, 2001; Vitart, 2006; Zhao et al., 2010; Chen and Lin, 2011; Vecchi et al., 603 2014; Murakami et al., 2015), and hybrid statistical-dynamical (Wang et al., 2009; Vecchi et al., 604 2011) prediction methodologies, which have targeted primarily basin-wide (e.g., North Atlantic, 605 West Pacific, etc.), seasonally-integrated statistics of tropical cyclone activity. More recently, methodologies that exploit the ability of high-resolution GCMs to represent both regional hurricane activity and its connection to climate variation and change have led to skillful seasonal predictions of tropical cyclone activity at more regional scales (e.g., Vecchi et al., 2014; Zhang et al., 2016, Murakami et al., in review). The coming years are likely to see an expansion in the growth of tools for the seasonal prediction of tropical cyclones and many other extreme phenomena, such as tornadoes (Elsner and Widen, 2014 ; Allen et al., 2015), and heat waves (Jia et al., 2016) enabled by the widespread development of high-resolution dynamical prediction models, improved understanding of the connection of weather extremes to large-scale conditions, and the pressing societal need for information about the statistics of high-impact weather events at regional scales.

616

\section{Managing living marine resources in a dynamic environment}

Management of LMRs is an exercise in trade-offs, requiring that managers balance multiple, often competing objectives (e.g. Jennings et al., 2016). For instance, global policies and the legal mandates of many countries require weighting conservation of commercial stocks against their exploitation, protecting bycatch species that are overfished or listed as endangered or threatened, safeguarding of coastal economies and fishing communities, and balancing present benefits to stakeholders against future losses (King et al., 2015). Fisheries managers acting on the best available science are mandated to prevent overfishing while, on a continuing basis, achieving high levels of benefits to society from fisheries and other seafood products. Fishers must balance a parallel tradeoff between the value of current harvest and the maximum value of future harvests. Similarly, aquaculture industry participants have to balance the value of expected 
returns from capital investment against its opportunity costs.

LMR industry or management decisions are made all the more challenging because these objectives must be achieved against the backdrop of a highly dynamic ocean environment.

Different decisions are made for different spatial and temporal scales (with regard to both leadtime and the application of the decision), and thus their effectiveness is influenced by climatedriven variability from across the climate system (Fig. 5). In this section, we summarize LMR management and industry decisions made with lead-times from days to decades and the frameworks used to make them, identifying the points where seasonal to decadal climate predictions could inform decisions, and discuss the potential benefits of this information.

\subsection{Industry Operations}

For the aquaculture industry, key decisions include when to release fry, 'plant' and harvest fish/shellfish, and when and what remedial actions to take to counter or avoid poor conditions. Extreme events such as floods, storms, and tropical cyclones can dramatically impact the aquaculture industry through reduction in water quality and destruction of infrastructure (Hodgkinson et al., 2014). Anomalously warm or cold conditions can also result in lost production and income via direct mortality effects, changes in growth or disease outbreaks (Chang et al., 2013, Spillman and Hobday, 2014). Hence, nowcasts and daily environmental forecasts are routinely used to improve the operational planning of the aquaculture industry. For example, monitoring networks of coastal water chemistry have been essential to reduce the impact of extremely low $\mathrm{pH}$ waters on oyster larval survival, increasing the economic resilience of the Pacific Northwest shellfish industry (Barton et al., 2015). Similarly, estuarine conditions are monitored to time release of hatchery reared salmon fry with optimal environmental conditions for growth and survival (Kline et al., 2008). While information on current environmental conditions is useful, seasonal forecasts of particular environmental variables can further improve the operational planning activities and climate readiness of the aquaculture industry by giving aquaculture farm managers time to develop and implement management strategies that minimize losses to climate, as is outlined in Case Study 4.1 (Spillman and Hobday, 2014; Spillman et al., 2015), or by allowing hatcheries time to adjust their release schedule (Chittenden et al., 2010).

For the fishing industry, key decisions include investments in boats, gear and labor, as 
660

661

662

663

664

665

666

667

668

669

670

671

672

673

674

675

676

677

678

679

680

681

682

683

684

685

686

687

688

689

690

well as when, where, and what to fish. Fishers rely on historical knowledge of the influence of environment on fish distribution to optimize such investment and harvest decisions. However, movement of environmental conditions into new ranges and associated changes in fish distribution (Section 1) is now affecting the value of fishers' past knowledge, making it harder to locate fish and make optimal pre-season investments, undermining their business performance (Eveson et al., 2015). As demonstrated in Case Study 4.2, seasonal climate forecasts can be incorporated into fish habitat models to produce fish distribution forecasts and improve the operational planning and efficiency of the fishing industry.

Such habitat models generally use correlative techniques to define regions of high abundance, or high probability of occurrence, for a species of interest in relation to oceanographic conditions. Species distribution data can be sourced from tagging studies, fisheries-dependent records, fisheries-independent surveys, or other sources. The distribution data is then related to one or multiple environmental variables (e.g. temperature, Hobday et al., 2011) through a variety of statistical methods, including generalized linear models (GLM), generalized additive models (GAM), classification and regression trees (CART), and artificial neural networks (ANN). When making century-scale projections of how fish distributions will change due to shifts in climate and marine habitat distribution, other commonly used models include Maxent (Phillips et al., 2006), Dynamic Bio-climate Envelope Model (DBEM; Cheung et al., 2009), AquaMaps (Kaschner et al., 2006), and the Non-Parametric Probabilistic Ecological Niche (NPPEN) model (Beaugrand et al., 2011). These models vary in assumptions and complexity, and can at times give markedly different results when applied to the same dataset (Lawler et al., 2006; Jones et al. 2013; Jones and Cheung 2014, Cheung et al. 2016a). For this reason, it is advisable to use an ensemble of multiple models when it is practicable to do so. Regardless of the statistical model used, all correlative habitat models assume that the relationships observed between species distributions and environmental variables in the training dataset are reliable proxies for actual mechanistic drivers of habitat preference. This assumption can be reasonably robust, for example if statistical associations with temperature closely mirror known physiological constraints, or more questionable, where a correlation is observed but the mechanistic basis is unknown (Peck et al., 2013). This can limit the performance of habitat models when they are extrapolated outside the range of the training dataset: either spatially into other geographic regions, or temporally into past or future time periods (Brun et al. 2016). 

by these same habitat models, driven by multi-annual to decadal rather than seasonal, climate forecasts. Such long-term species distribution forecasts would help the fishing industry determine, and initiate a discussion with managers on optimal licensing strategies in the face of a changing environment, such as more flexible quota-transfer frameworks (McIlgorm et al., 2010). For the aquaculture industry, multi-annual to decadal scale species distribution forecasts would improve capital investment decisions such as where to establish a new site or estimate and sell risk in a market place (Little et al., 2015).

\subsection{Monitoring and closures}

Public health officials and fisheries managers have to make decisions on when to close a

703

704

705

706

707

708

709

710 resource to protect the public, the resource itself, or, as for the case of bycatch species, resources caught incidentally to fisheries operations. Decisions also have to be made on how best allocate limited monitoring resources. Advanced estimates of stock distribution via bioclimatic habitat models (Case Study 4.5) or more complex ecosystem models (Case Study 4.6) informed by seasonal climate forecasts can guide planning for observer coverage and for fishery-independent surveys to ensure that stocks are monitored across their distributions. Below we elaborate via three examples on how short-term forecasts of climatic variability can be linked to triggers for fisheries closures (e.g., harmful algal blooms), allow time to prepare response plans (e.g., in response to coral bleaching), and reduce unwanted and incidental captures.

Harmful algal blooms (HABs), pathogens (e.g. Vibrio spp.), and dangerous marine species such as jellyfish pose a significant threat to public health and fishery resources. Total economic costs of HABs, including public health, commercial fishery, and tourism impacts, are an average of \$49 million per year in the US alone (Anderson et al., 2000). For instance, an unprecedented coastwide HAB in spring 2015 caused widespread closures of commercial and recreational fisheries over the entire U.S. West Coast and led to substantial economic losses to the seafood and tourism industries (McCabe et al., 2016). HAB-related fish-mortality is also recognized as a significant problem in Europe (ICES, 2015), and HAB-related closures of fisheries in eastern Tasmania and the west coast of North America have led to economic hardship and are becoming more frequent (Lewitus et al., 2012; van Putten et al., 2015). To limit 
such adverse effects, coastal resource managers have to estimate optimal allocation of monitoring resources, as well as appropriate times and locations for beach and shellfish bed closures. If fishers can anticipate HAB-related closures, they can make informed decisions about which stocks to target and develop approaches to compensate for expected lost revenues.

Nowcasts and short-term (e.g. lead-time less than a month) forecasts of pathogens and HAB likelihood or distribution have been successful in helping coastal planners target monitoring, guide beach and shellfish closures, water treatment practices, and minimize impacts on the tourism and fisheries and aquaculture industries (http://coastalscience.noaa.gov/research/habs/forecasting; Stumpf and Culver, 2003; Constantin de Magny, 2009). Such nowcasts and short-term forecasts are generally derived from an empirical habitat model (Section 3.1) incorporating temperature and salinity fields from regional hydrodynamic models driven by weather models (e.g. Constantin de Magny, 2009), though mechanistic HAB models have also been developed (McGillicuddy et al., 2011). Integration of seasonal climate forecasts into such frameworks could extend the lead-times of HABs and pathogen forecasts, allowing coastal planners and impacted industries more time to develop response strategies. Likewise, temperature-based surveillance tools dependent on seasonal SST forecasts have been proposed to help monitor, research, and manage emerging marine disease threats (Maynard et al., 2016).

Reduction of incidental capture of protected or over-exploited species during fishing operations is an important management objective in many jurisdictions; and fisheries managers are tasked with deciding what management actions are warranted to achieve this objective (e.g. Howell et al., 2008; Smith et al., 2007). Spatial management strategies that restrict fisher access in specific zones and at specific times have been successfully used to limit interactions between bycatch species and fishing gears (Hobday et al., 2014; Lewison et al., 2015). However, as fish move to remain in suitable physical and feeding conditions, fish distributions and phenology change with varying ocean dynamics (Platt et al., 2003; Perry et al., 2005; Nye et al., 2009; Pinsky et al., 2013; Asch, 2015), and therefore static time-area closures can be ineffective (Hobday and Hartmann, 2006; Howell et al., 2008; Hobday et al., 2011; Howell et al., 2015). Integration of real-time or forecast ocean conditions into a habitat preference model (Section 3.1) is now being pursued to determine spatial distributions of species of concern and to set dynamic time-area closures (Hobday and Hartmann, 2006; Howell et al., 2008; Hobday et al., 2011; 
Howell et al., 2015; Dunn et al., 2016). For instance, nowcasts of the preferred habitat of loggerhead and leatherback turtles are helping to reduce interactions between Hawaii swordfish longline fishing vessels and these endangered species (Howell et al., 2008; Howell et al., 2015). The utility of seasonal forecasts in setting effective dynamic spatial management strategies (Maxwell et al., 2015) to reduce bycatch is exemplified in Case Study 4.7.

\subsection{Provision of Catch Advice}

Setting annual catch quotas, or adjustments to fishing seasons or effort, is one of the most critical and difficult decisions taken by fisheries managers. In the United States, Annual Catch Limits (ACLs) are mandated to not exceed scientifically determined sustainable catch levels (Methot et al., 2014). Such intensive management of fishing levels occurs in other fishery systems and has been considered key to effective control of exploitation rates (Worm et al., 2009). ACLs are dependent on a control rule that basically defines the fraction of the fish stock that can be safely harvested each year. The control rule is designed to achieve a large fraction of the biologically possible "Maximum Sustainable Yield", based on a forecast of stock abundance over the next one to several years and biological reference points. Reference points, such as the fishing rate that achieves the maximum long-term average yield $\left(\mathrm{F}_{\mathrm{msy}}\right)$, reflect the long-term productivity of a fish stock and are the basis for a management system to maintain annual fishing mortalities at a target level that does not lead to overfishing (Quinn and Deriso, 1999).

Reference points and forecasts of stock status are based upon stock assessment models, which commonly are data-assimilating, age-structured models of a single stock's population dynamics (Methot, 2009; Maunder and Punt, 2013). Typically, these lack spatial structure, while focusing on temporal dynamics on an annual time step over several decades. We refer readers to Quinn and Deriso (1999) for a detailed description of a range of stock assessment models, differing in complexity and data requirements. The parameters of the model, e.g., annual recruitment, natural mortality rates, annual fishing mortality rates, etc., are calibrated by assimilating data on fishery catch, fish abundance from surveys, and the age or length composition of fish in the surveys and catch. Nielsen and Berg (2014) illustrate recent advances.

The effects of ecological (e.g. predator abundance) or physical factors on population dynamics are rarely modeled explicitly: a recent meta-analysis showed that just 24 out of the 1200 assessments incorporated such information (Skern-Mauritzen et al., 2015). These 
784

785

786

787

788

789

790

791

792

793

794

795

796

797

798

799

800

801

802

803

804

805

806

807

808

809

810

811

812

813

814 Kalman filter, which allow for time varying productivity parameters in stock assessment models,

unmeasured, non-fishing driving factors are only accounted for by allowing the models to incorporate random variability in key model parameters, particularly recruitment, or by incorporating empirical measured inputs, particularly regarding fish body weight-at-age. However, without including the process causing the fluctuations in the model framework, there is no basis for refining the random forecast into the future.

Reference points are thus generally computed assuming quasi-equilibrium conditions and stationary stock productivity (Quinn and Deriso, 1999). However, in many fish populations, ecosystem and climate can shift the production curve over time (Mohn and Chouinard, 2007; Munch and Kottas, 2009; Payne et al., 2009; Payne et al., 2012; Peterman and Dorner, 2012; Vert-pre et al., 2013; Bell et al., 2014; Perälä and Kuparinen, 2015), calling this assumption into question. Failure to include variability in any component of productivity, such as recruitment, natural mortality, and growth, into the development of reference points and annual catch advice can lead to unexpected population declines when productivity shifts to unanticipated low levels (Brunel et al., 2010; Brooks, 2013; Morgan et al., 2014). Furthermore, the use of static reference points can contribute to inaccurate estimates of stock recovery time and rebuilding thresholds (Collie and Spencer, 1993; Holt and Punt, 2009; Hammer et al., 2010; Punt, 2011; Pershing et al., 2015).

Nevertheless, robust alternatives to the status quo definitions of reference points have yet to be developed. For stocks that have undergone recognized shifts in productivity over their catch history, dynamic reference points can be constructed using data from the most current regime, as is currently done for Gulf of Alaska walleye pollock (Dorn et al., 2014) or southeast Australian morwong (Wayte, 2013). However, performance of such reference points in achieving management objectives as compared to the status quo has been mixed (Punt et al., 2014a, b). A common shortcoming is that using a shorter time series leads to less biased, but more uncertain, reference points (Haltuch et al., 2009; Dorner et al., 2013; Punt et al., 2014b). Furthermore, even dynamic reference points assume that the recent past will be representative of near future conditions. Because of the noisy nature of productivity parameters, such as recruitment, productivity shifts tend to be recognizable only well after the change has taken place, preventing managers from adjusting harvest strategies in a timely manner, and increasing the risk of overfishing (A'mar et al., 2009; Szuwalski and Punt, 2013). Statistical techniques such as the 
have proven useful in a timely detection of productivity shifts and improved reference point estimation for semelparous species (Peterman et al., 2000; Peterman et al., 2003; Collie et al., 2012). Temporal variability in reference points can also be introduced via environmental covariates on productivity parameters. When these environmental factors can be skillfully forecasted and the environment-population dynamics relationship is robust, the fish productivity forecast is improved (Maunder and Watters, 2003; Schirripa et al., 2009; Haltuch and Punt, 2011; Johnson et al., 2015; Miller et al., 2016).

Effectiveness of alternative reference point definitions and climate-robust harvest control rules can be tested through Management Strategy Evaluation (MSE). MSE is a simulation tool for comparing the trade-offs in the performance of alternative management strategies while accounting from uncertainty from different sources, such as climate responses, biological interactions, fishery dynamics, model parametrizations, observations, and management approaches (Cooke, 1999; Butterworth and Punt, 1999; Sainsbury et al., 2000). While the utility of accounting for the environment in achieving management objectives has been demonstrated for some species (Basson, 1999; Agnew et al., 2002; Brunel et al., 2010; Hurtado-Ferro et al., 2010; Pershing et al., 2015; Miller et al., 2016), existing MSEs demonstrate that climate drivers of stock productivity show mixed results with respect to the effectiveness of alternative, potentially climate-robust, management strategies when compared to those currently implemented (A'mar et al., 2009; Punt et al., 2011; Szuwalski and Punt, 2013; Punt et al., 2014). One exception is the Pacific sardine fishery; whose catch targets vary with a reference point dependent on a 3-year moving average of past SST (Hill et al., 2014).

Through the use of seasonal climate forecast information, climate informed reference points as used operationally for the US sardine fishery, would be more reflective of future productivity. This may help managers both adjust annual catch targets in a timely manner and set more realistic rebuilding targets (Tommasi et al., accepted.). Effectiveness of such climateinformed reference points will depend upon achieving climate forecast skill at the seasonal to decadal scale, and on past observations used to identify environmental drivers of productivity being able to adequately characterize future relationships.

Addition of climate forecast information into stock assessment models may also reduce uncertainty bounds on stock status projections by narrowing the window of probable outcomes as compared to the use of the entire historical range (Fig. 7a). Furthermore, if a stock 
productivity parameter is subject to an environmentally-driven shift or directional trend, future values may lie outside of the historical probability space, leading to biased estimates of stock status under the assumption of stationarity (Fig. $7 \mathrm{~b}$ and 7c). As a result, a climate forecast may serve as an advance warning of shifts in environmental conditions and stock productivity parameters, and may reduce bias in stock status estimates (Fig. $7 \mathrm{~b}$ and $7 \mathrm{c}$ ).

It must be stressed that the theoretical value of climate forecast information detailed in Fig. 7 is dependent on both the strength of the environment-fisheries relationship and climate forecast skill. That is, we assume that the environment-fisheries relationship is robust and stationary, that a relatively high proportion of the unexplained variability can be explained by the environmental data (e.g. Basson, 1999), and the environment can be well predicted. For instance, if the environment-fisheries relationship breaks down, climate-driven harvest control rules will perform poorly (Fig. 2d), highlighting the need for a strong mechanistic understanding of the environment-fisheries link (Dorner et al., 2013), or more conservative management approaches when the fluctuations cannot be predicted with adequate precision.

\subsection{Spatial Issues and Protected Areas}

In addition to multi-year forecasts of stock status and revisions of reference points (Section 3.3), multi-year to decadal fisheries management decisions encompass long-term spatial planning decisions regarding changes to closed areas, the setting of future closures, preparation for emerging fisheries, and adjustment of quotas for internationally shared fish stocks. Even decisions about which management body has jurisdiction may need adjustment over time.

As for short-term spatial management rules aimed at bycatch reduction (Section 3.2), stock distributions employed in the setting of current long-term closed areas are generally taken as static. Fish assessment models generally lack spatial structure, and thus have no inherent capability to forecast changes in stock distribution as ocean conditions shift the distribution of the stock, nor to calculate the localized impact of a spatially restricted fishery or reserve (McGilliard et al., 2015). However, the spatial distribution of many marine species has been shown to be particularly sensitive to changes in climate over multi-annual to decadal scales (Nye et al., 2009; Pinsky et al., 2013; Poloczanska et al., 2013; Bell et al., 2015; Thorson et al. 2016).

Such climate-driven distributional shifts can have important implications for spatial management measures. For example, shifts of juvenile plaice (Pleuronectes platessa) towards 
deeper waters have made a closed area (the "Plaice Box") set up in the North Sea to prevent recruitment overfishing less effective (van Keeken et al., 2007). One potential solution for stocks that have undergone recognized shifts distribution over their catch history is use of dynamic seasonal-area closures. Climate predictions, particularly of surface and bottom temperatures, could be used to drive species habitat models that help define fishery closure areas (Section 3.1; Link et al., 2011; Makino et al., 2014; Shackell et al., 2014; Rutterford et al., 2015). Furthermore, seasonal to decadal predictions (as well as nowcasts and hindcasts) of environmental conditions may contribute to management even if they are not directly incorporated within stock assessments. For instance, the Northeast US butterfish (Poronotus triacanthus) assessment investigated methods to incorporate historical change in thermal habitat to evaluate changing availability to the survey. While habitat-driven time-varying survey catchability was not included in the final assessment, the focused effort to evaluate survey catchability overall altered assessment estimates of scale, permitted more robust estimation of natural mortality, and ultimately increased the catch quota relative to previous results.

Shifting species distributions can also create important new fishing opportunities, such as the squid fishery in the Gulf of Maine that appeared during a particularly warm year (Mills et al., 2013). Hence, forecasts of species distributions driven by multi-year to decadal climate predictions can help identify which species are likely to spark new fisheries, and then prioritize them for additional research, experimental fishing programs, or short-term closures during the colonization phase. Such forecasts can also warn of distributional shifts outside of the range of current fisheries operations, and may prevent overfishing of the remaining portion of the stock. Advance warning of shifting distributions is particularly important when they impact international agreements, since negotiations can take years. For example, mackerel faced a "double jeopardy" scenario when they partially shifted into Icelandic and Faeroese waters and the additional harvest pressure led to overfishing of the stock (Astthorsson et al., 2012; Hannesson, 2012; Dankel et al., 2015). Pre-agreements between organizations or nations can be drafted to create a clear set of rules for how to adjust quotas and allocations based on indicators of changes in a stock distribution, perhaps including side-payments to compensate for lost fishing opportunities (Miller and Munro, 2004). For instance, forecasts of ocean conditions are used to forecast the proportion of Fraser River salmon migrating around the south end of Vancouver Island, thus dramatically affecting international allocation of the catch opportunity 
(Groot and Quinn, 1987). Forecasts may also be critical for building a common understanding of stock trajectories and for motivating the need for pre-agreements.

\section{Case Studies}

The previous two sections have provided an overview of the range of marine resource decisions that could be improved with climate forecasts and of climate forecast skill for LMRrelevant variables across decision making time scales. In this section, we highlight pioneering applications of the climate predictions discussed in Section 2.

\subsection{Seasonal forecasts to improve prawn aquaculture farm management}

Pond-based prawn aquaculture in Australia is primarily located on the northeast coast of Queensland (Fig. 8). Growing season length, timing of harvest, and farm production in this region are strongly influenced by environmental conditions, such as air temperature, rainfall, and extreme events, including tropical cyclones. Anomalously cool or warm temperatures can impact production and timing of harvest, thus affecting delivery to market. Rainfall extremes, including tropical cyclones, affect freshwater quality and supply to farms, road access in the case of flooding, and can also cause loss of farm infrastructure. In this situation, predictions of environmental conditions weeks to months in advance can improve risk management and allow implementation of proactive management strategies to reduce unfavorable impacts and maximize positive effects of conditions on farm production.

Seasonal forecast products for Queensland prawn farms were first developed in 20112012 (Spillman et al., 2015) and currently continue to be delivered via a password protected website. Regional temperature and precipitation forecasts are derived from the global dynamical seasonal prediction system POAMA (Predictive Ocean Atmosphere Model for Australia; Spillman and Alves, 2009; Spillman et al. 2011), and then downscaled using local weather station information for participating prawn farms. The forecasts were verified by assessing the probabilistic skill of the model predicting the upper terciles for maximum air temperature and rainfall, and the lower tercile for minimum temperature, as these were the events of greatest concern to prawn farm managers. Forecast accuracy is generally higher for temperature than rainfall, and declines with lead-time (Fig. 8). Forecasts out to lead-times of 2 months, which aligns with several farm operational planning timeframes, such as those for feed management or 
harvest time (Hobday et al., 2016), are sufficiently skillful to be integrated within prawn farm management decision framework (Spillman et al., 2015).

Feedback from prawn farm managers following delivery of the first few forecasts led to

943 refinement of forecast format, visualization and delivery, and resulted in an industry award for

944 the project team. This approach has been applied to other marine aquaculture industries (e.g.

945 salmon; Spillman and Hobday, 2014), with industry recognition that a range of management

946 decisions can be supported by environmental forecasts to improve aquaculture production in the

947 face of climate variability and change.

\subsection{Seasonal forecasts to improve economic efficiency of a large-scale tuna fishery} maccoyii) occur in the Great Australian Bight (GAB) during the austral summer (Dec-Apr), where they are caught in a purse-seine fishery worth AUD 60 million annually. In recent

953 fishing seasons, unexpected changes in the distribution of SBT were observed that affected the 954 timing and location of fishing activity and contributed to economic pressure on the fishery. In particular, in the 2011/12 season, SBT moved through the GAB quickly and were distributed further east than in the past two decades. This resulted in less than $15 \%$ of purse-seine catches being taken from fishing grounds reliably used over the previous 20 years. The following season (2012/13) also saw unusual SBT distribution patterns that again impacted the fishery. As a result of these observed changes, the Australian Southern Bluefin Tuna Industry Association recognized the need for scientific support to improve operational planning in the purse-seine

961 fishery. Many decisions central to SBT industry members planning their fishing operations need 962 to be made weeks to months in advance, so seasonal forecasts of environmental conditions were 963 regarded as a useful tool.

Environmental variables influencing the spatial distribution of SBT in the GAB during

965 summer were explored using location data collected on SBT over many years from electronic

966 tags, and comparing the ocean conditions where fish were found with the conditions available to 967 them throughout the region and time period of interest (Eveson et al., 2015). SST was found to 968 have the greatest influence, with fish preferring temperatures in the range of $19-22^{\circ} \mathrm{C}$. Once 969 habitat preferences were established, this information was coupled with POAMA (see Section 970 4.1) to predict locations of preferred SBT habitat in future. Both the habitat preference model 
and POAMA were evaluated against historical observations, and it was concluded that SSTbased habitat forecasts for SBT in the GAB have useful skill for lead-times up to 2 months. A daily-updating website was created to provide industry with forecasts of environmental conditions and SBT distributions for the next fortnight and next 2 calendar months from the date of issue (Fig. 9), along with a suite of other relevant information, including skill of the forecasts (www.cmar.csiro.au/gab-forecasts). Based on feedback from industry stakeholders obtained both formally through a survey and informally through an industry liaison representative, the information provided on the website has proven to be a valuable tool for fishers making decisions such as when and where to position vessels and to conduct fishing operations (Eveson et al., 2015). As the SBT fishery is quota-managed, the forecasting approach will not lead to increased catches (and thus impact sustainability), but will enable fishers to catch their quota more efficiently, thereby increasing profitability.

\subsection{A statistical seasonal forecast to improve the operational planning of a lobster fishery}

The US fishery for American lobster is one of the most valuable in the country. Landings in Maine alone accounted for nearly US\$500M in 2015. The fishery is open year-round, but the catch is highly seasonal. In Maine, where the majority of lobsters are landed, landings typically begin increasing rapidly during the first week of July, when lobster migrate inland and begin to molt. During 2012, the Gulf of Maine was at the center of a prolonged "marine heatwave," which caused temperatures in the spring to lead the normal annual cycle by 3-4 weeks (Mills et al., 2013). The annual lobster migration and molt took place nearly a month early, resulting in very high catches in early June instead of early July. The supply chain was not ready for the influx of newly molted soft-shell lobsters, and the imbalance between supply and demand led to a severe decline in price. Furthermore, record warm air temperatures contributed to increased mortality of lobsters during storage and transport. Thus, even though lobster landings set a record in 2012, it was an economically challenging year for many lobstermen.

Motivated by the events in 2012, the possibility of an early warning indicator of lobster fishery timing was explored and it was found that the date when landings in Maine begin to increase is negatively correlated with subsurface temperatures in March and April. Based on this relationship, a statistical forecast system was developed that takes temperatures at $50 \mathrm{~m}$ from a network of coastal ocean buoys operated by the Northeast Regional Association of Coastal 
1002

1003

1004

1005

1006

1007

1008

1009

1010

1011

1012

1013

1014

1015

1016

1017

1018

1019

1020

1021

1022

1023

1024

1025

1026

1027

1028

1029

1030

1031

1032

Ocean Observing Systems (NERACOOS) in spring and estimates the probability of the fishery shifting into the high-landings period during a particular week in June or July. For the last two years, the first forecast of the year has been announced to the industry at the Maine Fishermen's Forum and then updated weekly at www.gmri.org/lobster-forecast and via Twitter (Fig. 10).

Forecasters have now begun to work more closely with harvesters, dealers, and marketers in the industry to assess how it can be further improved to meet their needs. Other work has identified value in using sea temperature observations and models to help forecast outbreaks of lobster epizootic shell disease (Maynard et al., 2016).

\subsection{Seasonal forecasts to improve coral reef management}

Increases in ocean temperature over a coral's tolerance limit are the leading cause of coral bleaching events (Hoegh-Guldberg et al., 2007). Since 1997, NOAA's Coral Reef Watch has been using SST satellite data to provide near real-time warnings of coral bleaching (Liu et al., 2014). While coral reef managers and scientists have been able to use these nowcasts to execute operational response plans, managers recognized the need for longer lead-time forecasts to improve management responses to coral bleaching. Following these requests, NOAA Coral Reef Watch developed the first seasonal coral bleaching outlook, based on a statistical model from NOAA's Earth System Research Laboratory (Liu et al., 2009). In 2009 the Australian Bureau of Meteorology developed the first dynamical seasonal forecasts for coral bleaching risk on the Great Barrier Reef, based on seasonal SST predictions from POAMA (see Section 4.1; Spillman and Alves, 2009; Spillman, 2011). NOAA Coral Reef Watch, in turn, developed a dynamical 4 month lead coral bleaching outlook for coral reefs globally using seasonal SST predictions from the NOAA National Centers for Environmental Prediction (NCEP) global dynamical climate prediction system, the CFS model (Eakin et al., 2012).

These seasonal coral bleaching forecasts are made publicly available on the internet (http://www.bom.gov.au/oceanography/oceantemp/GBR_SST.shtml, http://coralreefwatch.noaa.gov/satellite/bleachingoutlook_cfs/outlook_cfs.php) and they allow coral reef managers around the world to develop timely and proactive bleaching response plans, brief stakeholders and allocate monitoring resources in advance of bleaching events. Resource managers and scientists have been using these bleaching outlooks extensively throughout the 2014-16 global coral bleaching event (Eakin et al., 2014; Eakin et al., 2016). 
1034 Malaysian governments closed numerous popular dive sites to reduce additional stress to

1035

1036

1037

1038

1039

1040

1041

1042

1043

1044

1045

1046

1047

1048

1049

1050

1051

1052

1053

1054

1055

1056

1057

1058

1059

1060

1061

1062

1063 severely bleached reefs (Thomas and Heron, 2011). In May 2016, Thailand again closed ten reefs, this time in advance of the bleaching peak (The Guardian 2016, https://www.theguardian.com/environment/2016/may/26/thailand-closes-dive-sites-over-coralbleaching-crisis. Accessed August 15, 2016) and in response to these forecast systems. More recently, once Coral Reef Watch alerts were issued in late June 2015 of the high potential for bleaching in Hawaiian waters (Fig. 11), the Hawaii Department of Land and Natural Resources (DLNR) immediately began preparations of resources to monitor this event. Having only seen significant multi-island bleaching in the main islands twice before, in 1996 and 2014 (Jokiel and Brown, 2004; Bahr et al., 2015), a much more comprehensive effort was needed. Additional volunteers were trained, who, together with teams from the state, University of Hawaii, NOAA, and XL Catlin Seaview Survey, were deployed across most of the islands. This group was able to document and monitor this unprecedented event, while the DLNR was able to alert the public and work with marine resource users to encourage reduction of activities that could further stress the corals during the bleaching event. Additionally, DLNR undertook an effort to collect specimens of the rarest coral species from the main Hawaiian Islands and safeguard them in their coral nurseries on Oahu and Maui. Many of these species suffered severe bleaching and mortality, and DLNR staff have been unable to find one of these species alive off Oahu since the 2015 event. Both Bureau of Meteorology and NOAA seasonal forecast tools were also used extensively by reef management during the most recent bleaching event on the Great Barrier Reef in the summer of 2015/2016, currently believed to be the worst on record (http://www.gbrmpa.gov.au).

\subsection{Seasonal forecasts of Pacific sardine habitat}

Pacific sardines are notable as one of the few stocks managed with respect to climatic variability in the US. Just recently, sardine distribution and migration forecasts have been produced (Kaplan et al., 2016; Fig. 12) for the US Pacific Northwest and Canadian British Columbia, based on 6 to 9 month predictions of ocean conditions (http://www.nanoos.org/products/j-scope/; Siedlecki et al., 2016). These predictions rely upon the NOAA NCEP global dynamical climate prediction system Climate Forecast System (Saha et 
1064

1065

1066

1067

1068

1069

1070

1071

1072

1073

1074

1075

1076

1077

1078

1079

1080

1081

1082

1083

1084

1085

1086

1087

1088

1089

1090

1091

1092

1093

1094

al., 2006) to force a high resolution $(\sim 1.5 \mathrm{~km})$ Regional Ocean Modeling System (Haidvogel et al., 2008). The efforts are fully described in Siedlecki et al. (2016), including skill assessment for SST, bottom temperature, and oxygen. Relationships between sardine distribution and JSCOPE predictions of ocean physics and chlorophyll were estimated for 2009. The final fitted relationships between SST and salinity had moderate skill to predict sardine distributions (presence or absence) in summer 2013 and 2014, with up to 4 to 5 month lead-times. Skill assessment focused on a "hit rate" metric, area-under-the-curve (AUC), which balances the desire to correctly predict sardine presence against the risk of false positives. One caveat to the sardine forecasts is that they predict available sardine habitat (Fig. 12) without accounting for sardine stock size. Recent declines in sardine abundance (Hill et al., 2015) have likely meant a contraction of the stock southward (MacCall, 1990), despite availability of suitable habitat in the US Pacific Northwest and British Columbia.

As with many pelagic species, sardines are seasonally migratory and forecasts of their distribution by J-SCOPE may be relevant for fisheries management and industry. The sardine stock is landed by US, Mexican and Canadian fishers and the extent of the northward summer migration is dependent on both water temperature and population contraction due to low population abundance. The sardine forecasts by Kaplan et al. (2016) predict the extent of this northward migration and could be used to plan fishing operations (e.g. whether Canadian fish processors should expect sardine deliveries) or fisheries surveys. Additionally, quotas apportion a fixed percent of sardine catch to Canadian vessels, and J-SCOPE provides foresight that that this portion may be unharvested in a particular cold year. Furthermore, sardine straddle international boundaries, and short-term seasonal forecasts may help international management and industry to cope with and prepare for the long-term distribution shifts expected under climate change (Pinsky and Mantua, 2014). To date, forecasts have primarily been delivered through collaboration with NANOOS (Northwest Association of Networked Ocean Observing Systems) via the web (http://www.nanoos.org/products/j-scope/). Web products include predictions of ecological indicators relevant to the regional fishery management council, and will soon be incorporated in NOAA's Integrated Ecosystem Assessment (Harvey et al., 2014). Other outreach efforts are ongoing and aim to produce targeted forecasts (as discussed for Australia above in Section 4.1) for fishery managers and stakeholders, and to better integrate with fishery management council needs. 


\subsection{Short-term forecasts of Indonesian tuna fisheries to control illegal fishing}

1097

1098

1099

1100

1101

1102

1103

1104

1105

1106

1107

1108

1109

1110

1111

1112

1113

1114

1115

1116

1117

1118

1119

1120

1121

1122

1123

1124

1125

The last decade has seen the generalization of satellite Vessel Monitoring Systems to monitor licensed fishing vessels, the use of satellite radar images to detect illegal fishing and the development of Electronic Reporting Systems (ERS) to provide catch statistics in real time.

Integration of these developments in fishery monitoring with an operational forecasting model of fish spatial dynamics that has the ability to predict the distribution of fish under the influence of both environmental variability and fishing is assisting Indonesian fishing authorities in controlling illegal fishing and implementing conservation measures. This operational monitoring framework (Gehlen et al., 2015) was developed through the INDESO project and integrates a high resolution regional model system coupling ocean physics to biogeochemistry (NEMO/ PISCES; Gutknecht et al., 2016; Tranchant et al., 2016) to a spatially explicit tuna population dynamics model (SEAPODYM; Lehodey et al., 2010; 2015). SEAPODYM simulates functional groups of organisms at the intermediate trophic levels (Lehodey et al., 2010; 2015) and the dynamics of their predators (e.g. tuna) (Lehodey et al., 2008). The model is complemented by a quantitative parameter estimation and calibration approach (Senina et al., 2008) which enables the application of the model to fish stock assessment and testing of management scenarios (Sibert et al., 2012).

Tuna are highly migratory species, and their habitats cover large expanses of the global ocean. Thus, the simulation of fish stock dynamics at high resolution in the Indonesian region requires accounting for exchanges (fluxes) with populations outside of the regional domain (i.e. Pacific and Indian Ocean) under the influence of both environmental variability (e.g. ENSO) and fishing mortality. Boundary conditions for the regional $1 / 12^{\circ}$ SEAPODYM implementation are obtained from a $1 / 4^{\circ}$ global operational configuration (Fig.13) driven by temperature and currents from the operational ocean prediction system Mercator-Ocean PSY3V3 (Lellouche et al., 2013). Biogeochemical forcings (net primary production (NPP), dissolved oxygen) are either derived solely from the coupled physical-biogeochemical model NEMO/ PISCES (forecast mode) or from NEMO/PISCES and satellite ocean color and SST data (to estimate NPP; Behrenfeld and Falkowski, 1997), along with climatological dissolved oxygen $\left(\mathrm{O}_{2}\right)$ (hindcast and nowcast modes). The regional operational model SEAPODYM also uses a climatological data set (i.e., monthly average of the last 5 years) of fishing effort prepared from the best available 
1126 information to apply an average fishing mortality. The forecasting system runs every week and 1127 delivers one week of hindcast, one week of nowcast, and 10 days of forecast. These outputs are 1128 used by the Indonesian Fishing Authority to improve the collection and verification of fishing 1129 data, to assist illegal fishing surveillance, and to establish conservation measures (e.g., 1130 identification and protection of spawning grounds and nurseries) required for the sustainable 1131 exploitation of this essential resource (Marion Gehlen, personal communication, June 22, 2016).

4.7 Seasonal forecasts for dynamic spatial management of the Australian east coast tuna fishery

1134 Since 2003, a dynamic spatial management approach has been used to limit unwanted 1135 capture of a quota-managed species, SBT, in the Australian eastern tuna and billfish fishery. The 1136 approach combines a habitat model, conditioned with temperature preference data obtained from 1137 pop-up satellite archival tags deployed on SBT and an ocean model to produce near real-time 1138 habitat nowcasts, delivered by email and utilized the same day by fishery managers during the 1139 fishing season (Hobday and Hartmann, 2006; Hobday et al., 2010). Managers use this 1140 information along with other data inputs (such as recent fishing catch rates) to restrict access in 1141 the core (high probability of occurrence) zone to vessels that have both observers and SBT quota.

1142 The habitat model was extended in 2011 to include a seasonal forecasting component using 1143 ocean temperature forecasts from the seasonal prediction system POAMA, with useful forecast 1144 skill out to several months (Hobday et al., 2011). Both nowcast and seasonal forecast habitat 1145 maps produced for managers show probabilistic zones of tuna distribution coded as "OK" 1146 (unlikely to encounter SBT), "Buffer" (likely to encounter SBT) and "Core" (very likely to 1147 encounter SBT) (Fig. 14). Incorporating a seasonal forecasting component has been an 1148 important step in informing and encouraging both managers and fishers to think about decisions 1149 on longer time scales (Hobday et al., 2016). Forecasts are now delivered via a dedicated webpage 1150 (http://www.cmar.csiro.au/sbt-east-coast/). The dynamic habitat forecasting approach has 1151 reduced the need for large areas closures while still meeting the management goal, but does

1152 require fishing operators to develop more flexible fishing strategies, including planning vessel 1153 movements, home port selection and quota purchase.

\section{5. Recommended practices}



components to a successful LMR forecast framework: assessment of needs, forecast development, and forecast delivery. Here, we break down the forecast development and delivery stages further to provide more details of the forecast implementation process (Fig. 15). Identification of a clear management need via effective communication between climate scientists and management or industry stakeholders from the start of the forecast development process is essential for the utility and widespread adoption of climate prediction tools for LMRs (Hobday et al., 2016; Harrison and Williams, 2007; Fig. 15). This needs assessment should include the determination of relevant variables, spatial domain, spatial resolution, and timescales. Once needs have been assessed, it is incumbent upon scientists to provide balanced communication of both capabilities and limitations to evaluate whether forecasts are likely to be useful to their partners.

Forecast development is underpinned by an understanding of the mechanisms relating physical climate variables to the LMR of interest. Once such linkages are found, three forecast development steps follow: an assessment of the skill of the physical climate variable forecast, an assessment of the skill of the LMR model forecast, and the uncertainty associated with each. The prediction skill for the physical climate variables must be assessed at an appropriate timescale relative to the management decision timeframe and at a spatial resolution able to resolve environmental driving mechanisms. Skill assessment will make use of retrospective forecasts and observations. When reanalyses are used in lieu of observations, their accuracy at the scale of interest should be confirmed against data prior to forecast skill assessment whenever possible (Section 3). If the skill evaluation indicates that the variables of interest cannot be skillfully forecasted at an adequate lead-time and/or relevant spatial scale, stakeholder expectations may be re-evaluated and alternate variables or scales of interest investigated (i.e. it may be necessary to return to the needs assessment step). Alternatively, downscaling or bias correction techniques may improve skill at the desired scale in some cases (Section 6). Skill may be assessed using at least measures of correlation, variability, and bias between forecast and observations, although further verification analyses are possible (Mason and Stephenson, 2007).

Once a physical climate variable forecast has been developed and determined to be skillful, the value of using it in an LMR model must be determined. LMR model skill assessment can employ skill metrics based on "hit rate", such as AUC or area-under-the-curve (Fielding and 

forecasts reproduce biological phenomena (e.g., presence of tuna, occurrence of a coral bleaching event). While it is well known that climate affects LMRs (Section 1), most of derived climate-LMR relationships are empirical, with climate variables often acting as proxies of complex trophic effects, interspecies interactions, and dispersal processes. For climate information to be included in LMR management frameworks, the environment-fisheries relationship has to be robust and preferably based on mechanistic, ecologically-sound hypotheses. A sufficiently long observational data series is required for model calibration and verification (Haltuch and Punt, 2011), including out-of-sample validation (Francis, 2006; Mason and Baddour, 2007; Mason and Stephenson, 2007). In addition, if the environment-fisheries relationship relies on stock assessment model output (e.g. recruitment), it is important that this relationship be developed within the stock assessment model itself rather than as a post-hoc analysis to ensure uncertainties associated with the stock assessment model are properly propagated (Maunder and Watters, 2003; Brooks and Deroba, 2015). Furthermore, to increase confidence in the robustness of these empirical relationships, meta-analytical techniques can be employed to ensure that the proposed hypothesis is robust across a species range (Myers, 1998), taking into account, however, that environmental variables may affect species differently across their latitudinal range (e.g. Mantua et al., 1997).

As environment-LMR associations may change over time (e.g. with changing baselines under climate change), these empirical relationships need to be periodically re-evaluated as new environmental and LMR data are collected. LMR forecast development will therefore be an iterative process and management has to be dynamic to allow for changing management decisions as the environment-fisheries relationship evolves with the continuous integration of new information. Environment-LMR correlations have been observed to be more robust when tested with new data at the edges of a species range (Myers, 1998). These populations may serve

1212 as initial case studies with which to develop dynamic management frameworks that integrate

1213 climate prediction information. Table A2 includes a list of LMRs for which a sufficient

1214 understanding of how they respond to climate variability has been achieved, and which may

1215 serve as additional case studies. These include those determined by Myers (1998) as robust to re-

1216 evaluation and those that already make use of environmental information in their management as 1217 described by Skern-Mauritzen et al. (2015). 
To provide a thorough presentation of risk to decision makers, it will be important to

1219

1220

1221

1222

1223

1224

1225

1226

1227

1228

1229

1230

1231

1232

1233

1234

1235

1236

1237

1238

1239

1240

1241

1242

1243

1244

1245

1246

1247

1248 assess the uncertainty of the climate prediction as well as that of the LMR models. For the climate prediction, this will involve quantification of processes, variability and model uncertainty via the use of single and multi-model ensembles (Section 3). Forecasts will be inherently probabilistic, and ensembles can be used to estimate the probability. On the fisheries side, there is also uncertainty associated with LMR models' parameterizations (Cheung et al., 2016a, b). As for climate predictions, ensemble approaches can be employed in LMR models to account for the high level of uncertainty in the parameterization of biological processes (e.g. Kearney et al., 2012; Laufkötter et al., 2015; 2016). Uncertainty in the environment-LMR relationship will also need to be accounted for by, for instance, running multiple simulations of the LMR model differing in their stochastic error of the LMR-environment relationship (e.g. Lindegren et al., 2013).

Finally, an effective forecast delivery mechanism is required. The climate prediction needs to be delivered in a format that can be effectively incorporated into LMR models and decision frameworks, such as population models used in fish stock assessment. As in all the stages of LMR forecast development, consistent user engagement is essential to ensure sustained use of such prediction tools (Harrison and Williams, 2007; Hobday et al., 2016). For instance, the general difficulty people have in understanding uncertainty and probabilities has limited the use of climate predictions in the natural resource sector (Nicholls, 1999; Marshall et al., 2011). Collaboration with social scientists on the most appropriate presentation and delivery options may enhance adoption of forecast information (Harrison and Williams, 2007). Automated webbased delivery systems are a common delivery method, although ongoing contact with end users and acknowledgement of user feedback is important to build engagement and for continued forecast use (Hobday et al., 2016). Funding for delivery system maintenance, user engagement, and continued user training should be included in projects to maintain iterative LMR operational forecast systems.

The value of integrating climate predictions into LMR decision frameworks has to then be demonstrated to managers or industry. This can be undertaken by employing cost-benefit analyses (e.g. Asseng et al., 2012) and MSE (Section 2.4, Tommasi et al., accepted). For example, MSEs can assess the performance of different management strategies (e.g. with and without climate predictions) in relation to a suite of performance metrics while taking 
uncertainty into account. They may also include economic models to better evaluate the specific economic value of integrating climate forecasts into LMR decisions (e.g. Richardson, 2000). While MSEs have been developed in the context of fisheries science, such decision support systems could also be applied to industry or coastal manager's decision frameworks. Results from these assessments would inform both climate and LMR prediction development by highlighting further refinements needed to better inform decisions.

\section{Priority developments}

While the potential benefits of seasonal climate forecasts in reducing the climate vulnerability of the fishery and aquaculture industry and in improving fisheries management are clear (Section 4), barriers to their widespread adoption also exist. Social, cultural, economic, or political constraints, such as existing regulations or dissemination difficulties, can limit forecast use (Nicholls, 1999; Goddard et al., 2001; Harrison and Williams, 2007; Davis et al., 2015). However, the discussion herein will be limited to priority developments aimed at reducing technical impediments to climate forecast application. These technical barriers include incomplete understanding of environment-LMR relationships, limited length and availability of physical, biogeochemical and biological time series for model development and validation, and the irreducible predictability limits at seasonal to decadal scales. There is also need for methodological advancements in LMR models to explicitly consider environmental productivity indicators and spatial distributions, and apply empirical models in non-stationary systems. Finally, there is a need for reduction in climate model bias through improvements in model formulation and initialization, verification of LMR-relevant physical variables at LMR-relevant spatial scales beyond SST, the development of biogeochemical forecasting capabilities in global prediction systems, and improvements in climate predictability at LMR-relevant regional scales through higher resolution global prediction systems or the development of downscaling

1274 frameworks.

On the LMR model side, predictive capacity is constrained by our incomplete understanding of environment-LMR relationships, especially their response to environmental

1277 fluctuations (e.g. Chavez et al., 2003; Di Lorenzo et al., 2009; Le Mézo et al., 2016). As a case in 1278 point, only $2 \%$ of managed fisheries worldwide explicitly integrate past environmental 1279 information into their current tactical decision making and provide an existing framework to 
readily incorporate climate forecast information (Skern-Mauritzen et al., 2015). This lies in stark contrast to ubiquitous climate-marine resource correlations reported in the literature (e.g. Hare et al., 2010; Mueter et al., 2011; Ottersen et al., 2013). For most populations, the length of available, co-occurring fishery, biological and environmental time series may be too short to robustly identify the environment-LMR relationship (Haltuch and Punt, 2011) or to develop a habitat preference model, highlighting the importance of maintaining and expanding existing observational data series for environment-LMR model development and verification. Funding for ocean and LMR observations is limited. Given the importance of having climate observations over a period long enough to span different environmental regimes, LMR observations that cover a wide range of population sizes, and large sample sizes to improve estimation of model parameters, establishment of new monitoring networks must be carefully balanced with the critical need to maintain current sampling programs (Haltuch and Punt, 2011; Dorner et al., 2013). Maintenance and expansion of physical climate observing systems, as discussed in Section 3, are also essential to climate model development to improve climate predictability through better model initialization (e.g. Servonnat et al., 2014). Including concurrent measures of basic biogeochemical and lower-trophic-level measurements should be integrated into existing observing systems, when possible, to facilitate better understanding of physical-biological interactions in the marine environment and better assessment of model predictive capability. That said, while spatially-or temporally-constrained (or incomplete) environmental data may be limited in quantitative utility, such data can help provide qualitative context for decision-making. For example, time series of conditions can be used to delineate regime-specific parameter estimates or emergent patterns in indicators can provide justification for precautionary management actions and intensified monitoring (Zador et al., in press).

Non-stationarity issues are particularly critical for decadal to centennial predictions.

1304 However, for many populations, knowledge of environment-fishery interactions is limited to

1305 basic correlations. These correlative (and often linearly approximated) relationships provide a

1306 useful, existing tool to start integrating climate predictions into LMR models. But if an 1307 ecosystem were to shift into a new, no-analog state and the ecosystem processes that were 1308 empirically described by this correlative relationship were to change, subsequent management 1309 decisions may perform poorly (Dorner et al., 2013). Similar shifts can occur at shorter time1310 scales. For example, many species distribution models developed with one decade of data 
1311 perform poorly when used to project species distribution during another decade (Brun et al.,

1312 2016). For bias correction of physical climate models, non-linear statistical techniques that are

1313 better at simulating distribution extremes appear to perform better under novel climate conditions

1314 (Gaitan et al., 2014). More sophisticated, model-free statistical approaches also appear promising

1315 in establishing environmental influences on LMRs that can be applied in a management

1316 framework, particularly over short timescales (e.g. Ye et al., 2015). To improve LMR predictive

1317 capacity, it will be necessary to expand the use of such techniques into tactical management

1318 frameworks, and to characterize their benefits relative to more traditional statistical techniques as

1319 well as ecosystem models.

1320 Dynamic ecosystem models integrate physical variables, lower-trophic-level dynamics,

1321 LMR dynamics, and human impacts, mechanistically, and are critical to enhance our

1322 understanding of LMR responses to climate variability (Travers et al., 2007; Rose et al., 2010;

1323 Le Mézo et al., 2016). Such process-based understanding is necessary to the development of

1324 models able to skillfully predict LMR under novel conditions (Evans, 2012). Furthermore,

1325 because of the inherent complexity, non-linearity, and multi-stressor characteristics of marine

1326 ecosystems, multispecies and ecosystem models can in some cases assess uncertainties and

1327 trade-offs more effectively (Pikitch et al., 2004; Link et al., 2012). Nevertheless, such models are

1328 currently only employed for strategic advice at the decadal and multi-decadal scale, rather than

1329 for short-term tactical decisions (e.g. Smith et al., 2011; Pacific Fishery Management Council

1330 and National Marine Fisheries Service 2014; Fulton et al., 2014; Marine Stewardship Council,

1331 2014). One issue of concern with the use of ecosystem models for tactical decisions is their

1332 inability to integrate all of the data streams, such as catch-at-age data, that are customary in

1333 current tactical fisheries decision frameworks. Another issue is that their complexity comes at the

1334 cost of longer running time, hindering their use within current tactical management process

1335 timelines. Also, they rely on static assumptions and parameterizations, which may not remain

1336 valid under future conditions. Finally, because more processes are modeled and there is

1337 uncertainty in each, the fully characterized uncertainty can be large. This may make decision-

1338 making more difficult but, if this uncertainty accurately reflects the true uncertainty in the

1339 system, it will ultimately result in better decisions. Expanded application of such models for

1340 tactical management decisions will be dependent on improving their parameterizations,

1341 specification of initial conditions, extending quantitative model assessments, and reducing their 
1342 uncertainties through additional physiological studies, process studies, and modeling

1343 experiments aimed at understanding the mechanisms driving LMR's responses to climate. LMR

1344 surveys that include more hydrographic, biogeochemical, and lower-trophic-level (plankton)

1345 observations will also be critical to make progress towards expanded use of ecosystem models in

1346 LMR forecasting applications.

1347 Highly resolved spatial and population dynamics models of a specific target species

1348 coupled to a coarser, lower-trophic-level model (Lehodey et al., 2008; Senina et al., 2008;

1349 Section 4.2) or "models of intermediate complexity" - MICE - (Lindegren et al., 2009; Collie et

1350 al., 2014; Plagányi et al., 2014) may be more immediately suited for tactical management

1351 decisions, as their uncertainties are more tractable. MICE use statistical parameter estimation

1352 methods common in current tactical fisheries models to fit multispecies models to data for small

1353 groups of interacting species. Such models are becoming sufficiently advanced, including both

1354 species interactions and impacts of temperature on population dynamics (Holsman et al,. in

1355 press.), and can be used in concert with single-species models to provide tactical fisheries advice

1356 from a multi-model suite, similar to operational prediction systems used in weather forecasts

1357 (Ianelli et al., in press.). Combining such models with seasonal and decadal forecasts will help

1358 evaluate risk profiles and trajectories of recovery plans, assess the flexibility of harvest policies

1359 to dynamic conditions, and identify areas of management vulnerability to climate change (e.g.,

1360 are dynamic management policies available in hand to respond to sudden shifts in ecosystem

1361 structure or driving processes?; Holsman et al., in review). While MICE are quite promising for

1362 tactical decision making in the near future, simulation testing to determine whether they can

1363 provide adequate information for tactical management under various information conditions

1364 typical of fisheries management needs to be undertaken. If successful, such applications may

1365 also provide a valuable template for the expansion of holistic whole ecosystem models from

1366 strategic to tactical management decisions.

1367 Expanded use of seasonal to decadal forecasts is also limited by problems of relevance in

1368 terms of critical variables, and spatial and temporal scales (Nicholls, 1999; Hobday et al., 2016).

1369 For some LMR-relevant variables, there are irreducible predictability limits at seasonal to

1370 decadal scales due to the chaotic nature of the atmosphere (Deser et al., 2012). Such variables

1371 will remain unpredictable even with a perfect data assimilation system and model formulation,

1372 and hence management frameworks robust to unpredictable variation will need to be developed. 
1373 It will be important for climate scientist to continue assessing predictability limits of LMR-

1374 relevant variables and to communicate such limitations to users, e.g., by providing reliable

1375 probabilistic forecasts accompanied by appropriate measures of historical skill.

1376 For some regions and time scales, however, predictability of LMR-relevant variables is

1377 limited by the systematic errors of GCMs (Goddard et al., 2001). It is critical to find ways to

1378 either reduce this model bias or reduce its negative impacts on forecast skill through novel

1379 techniques (e.g., Batté et al., 2016). Reduction in model bias will involve improvement in both

1380 model physics and parametrizations, as well as data assimilation systems (Goddard et al., 2001;

1381 Meehl et al., 2014; Siedlecki et al., 2016). For instance, as variability in ocean circulation can

1382 depend on both temperature and salinity variations in the ocean's interior, improved observations

1383 of these quantities, as well as improved assimilation systems to make optimal use of these

1384 observations, are critical. As resolution of GCMs increases, representation of the physical

1385 processes responsible for regional climate predictability improves (e.g. Jia et al., 2015), and, in

1386 some cases, this may lead to improved forecast skill of LMR-relevant variables.

Forecasts at the multi-annual to decadal time scales, while of great interest to LMR management and industry, are not yet operational (Section 3). Continued research to improve our theoretical understanding and representation of the physical processes and feedbacks responsible for decadal scale climate variability are required to reduce model bias and improve decadal forecast skill (Meehl et al., 2014). Furthermore, in order to better assess the performance of decadal forecasts, predictability studies across more models and with larger ensembles need to be carried out (Meehl et al., 2014). Demonstration of reliable skill, however, will remain limited by

1394 the small sample size available for verification due to the high time series autocorrelation and 1395 limited quantity of independent samples at decadal time scales (Kumar, 2009; Meehl et al., 1396 2014). Furthermore, it is important to stress that the decadal predictability of regions, such as the 1397 North Pacific, subject to strong atmospheric forcing, will remain limited (Branstator and Teng, 1398 2010; Meehl et al., 2014).

1399 In addition to improvements in models and initialization, predictability across

1400 spatiotemporal scales of more LMR-relevant physical variables such as bottom temperature, sea 1401 surface height, onset of upwelling, or salinity need to be examined. Biogeochemical prediction 1402 (e.g. chlorophyll biomass, net primary productivity (NPP), export production fluxes, aragonite 1403 saturation in coastal zones, oxygen concentration) is also of major relevance to ecosystem-based 
1404

1405

1406

1407

1408

1409

1410

1411

1412

1413

1414

1415

1416

1417

1418

1419

1420

1421

1422

1423

1424

1425

1426

1427

1428

1429

1430

1431

1432

1433

1434

management of marine resources (Levin et al., 2009; Stock et al., 2011). While biogeochemical prediction is in its early stages and no coupled physical-biogeochemical seasonal to decadal forecasting systems are yet operational (but see Case Study 4.6 for their use in sub-seasonal prediction), recent work shows some potential. Predictive skill up to several months has been shown in the northern CCS for bottom oxygen (Case Study 4.5, Siedlecki et al., 2016), and up to 3 years for NPP in some oceanic domains (Séférian et al., 2014, Chikamoto et al., 2015). In most cases, the increased predictability in NPP arises from that of nutrients, which directly benefit from the initialization of the model physical fields (Séférian et al., 2014). These pioneering results demonstrate that biogeochemical prediction shows promise and highlight the need to both develop integrated physical-biogeochemical forecast systems, and further quantify biogeochemical predictive skill over a variety of space and time scales to inform ecosystembased management approaches to LMRs. Application of ESMs in a climate change framework has demonstrated that uncertainty in LMR projections can be large due to uncertainty in the many modelling components, from GCMs to upper-trophic level models, required to assess climate change impacts on LMRs (Cheung et al., 2016b). Computing and personnel resources will hence be required to develop an ensemble approach for biogeochemical prediction able to account for this uncertainty. An assessment of prediction skill beyond SST to other properties driving biological responses will also necessitate supporting, collecting, and maintaining sampling programs and observing systems.

The spatial resolution of global climate models poses another limitation to their skill at the regional scale relevant to LMR decisions. Downscaling techniques can be used to generate finer-scale information from large-scale climate predictions. By relating well predicted largescale factors to a local process of interest, downscaling, in addition to providing higher spatially and temporally resolved data, may produce LMR-relevant variables not skillfully generated by global prediction systems (e.g. Siedlecki et al., 2016). There are two types of downscaling techniques: statistical and dynamical. The first links the large-scale output from a global prediction system to local scale variables using statistical-empirical relationships. The second uses the large-scale output as boundary conditions to regional-scale, physics-based dynamical models.

Statistical downscaling techniques are computationally inexpensive, so the large ensembles required to appropriately characterize initial condition and model uncertainty of 
seasonal to decadal predictions (Section 2.1.2) can be run relatively fast. The ability to quickly produce output is an advantage particularly relevant for downscaling of seasonal predictions, as they have to be produced in a timely manner to be relevant to the decision-making process (Laugel et al., 2014). However, to construct robust statistical relationships, long observational records are required (Section 4.1 and 4.3), though are not always available. Second, all statistical downscaling techniques assume that the large-scale, local climate relationship will remain the same in the future. While these assumptions may hold for the relatively short timeframe of seasonal predictions, they may deteriorate over longer-range decadal predictions.

By contrast, dynamical downscaling techniques explicitly model the physical processes involved and therefore may perform better than statistical methods under changing or unprecedented conditions (e.g. van Hooidonk et al., 2015). Dynamical downscaling models, however, will still inherit any bias of large-scale GCMs, and may even amplify such systematic errors (Goddard et al., 2001; Hall, 2014). This stresses again the need to reduce bias in global predictions systems to improve predictability of LMR-relevant variables at a regional scale. Further research will also be necessary to assess the relative costs and benefits of statistical versus dynamical techniques for downscaling of LMR-relevant climate predictions. This will require more resources allocated towards the development of downscaling frameworks for LMRrelevant climate predictions in regions of interest for LMRs. For instance, coupling to fine resolution coastal models, like the efforts in the northern CCS and Indonesian region (Case Studies 4.5 and 4.6), is a promising approach that warrants more studies in other regions. Furthermore, modeling studies aimed at understanding the extent to which LMR-relevant local processes are interactive with the large-scale and to what extent they are primarily "driven" by large-scale processes are required. Such studies would help to identify the type of downscaling method most appropriate and indicate regions requiring higher-resolution global climate prediction systems to further enhance predictability and support decision making at fine spatial scales.

\section{Concluding Remarks}

It is widely recognized that the productivity and distribution of LMR populations change over time in response to climate and ecosystem variability and long-term trends. Fishers, aquaculturists, coastal planners, and fisheries managers recognize that many of their operational 
1465

1466

1467

1468

1469

1470

1471

1472

1473

1474

1475

1476

1477

1478

1479

1480

1481

1482

1483

1484

1485

1486

1487

1488

1489

1490

1491

1492

1493

1494

1495

planning and management decisions should account for this dynamism. We have shown how recent improvements in global dynamical climate prediction systems have resulted in skillful predictions of LMR-relevant variables at many of the spatial and temporal scales at which LMRs are managed, and how such predictions are already helping industry and managers make decisions in dynamic environments. By describing climate prediction systems and their capabilities, as well as the range of decisions currently taken by managers and the fisheries and aquaculture sector that may benefit from the inclusion of future climate information, new applications may be developed for wider use. Successful integration of climate information into LMR decision frameworks will depend on close collaboration and open dialogue between potential users and climate scientists.

While some progress has been achieved within existing frameworks and resources, challenges in both climate and fisheries models need to be addressed to further expand utility of such predictions for LMRs (Section 6). To ensure widespread application of climate forecasts into LMR decision making and prevent unintended consequences of climate and fisheries interactions, new methodological approaches that capture complex ecosystem dynamics and the full range of LMR drivers need to be developed. Such frameworks will inherently be probabilistic and consist of ensemble methods to account for uncertainties in both climate and LMR models, improve model accuracy, and help end users understand risk. These frameworks will also evolve over time as our understanding of environment-LMR links, which remains poor for many species and regions, is improved through more field observations and experimental studies. Therefore, management decision systems will need to become more flexible to the inclusion of new information streams at a variety of both spatial and temporal scales, as well as to frequent re-evaluation.

As we acknowledged above, seasonal to decadal predictions of climate and LMR dynamics will sometime fail despite the best efforts, especially given the increasing potential for no-analog system states and ecological surprises (Williams and Jackson, 2007; Doak et al., 2008). To cope with this inevitability, we also encourage the development of approaches for managing unexpected changes once they have happened (Schindler and Hilborn, 2015).

As predictability is the ultimate test of scientific theory, routinely using these climateforecast informed frameworks to make predictions of LMR dynamics will also improve understanding of ecosystem dynamics. In addition, skillful predictions at seasonal to multi- 
annual scales will lend confidence to the use of such models to project LMR dynamics over longer temporal scales, and can be used to build stakeholder confidence in the use of longer term climate projections. With exploited systems being more sensitive to environmental variability (Hsieh et al., 2006; Perry et al., 2010), development of such capabilities will be essential to the development of climate-ready management systems to effectively manage and culture LMRs in a future environment where long term change renders historical experience less valuable.

\section{Acknowledgements}

The authors would like to thank all the participants of the workshop "Applications of Seasonal to Decadal Climate Predictions for Marine Resource Management" held at Princeton University on June 3-5 2015 for the many insightful discussions that inspired this manuscript. A special thanks to A. Valerio for all the help with the workshop organization and logistics, to the Princeton University Cooperative Institute of Climate Science for hosting the workshop, and to the NOAA Fisheries' Office of Science and Technology and NOAA's Office of Oceanic and Atmospheric Research for funding the workshop. Thank you to Dr. Jon Hare for creating the figure that inspired Figure 3. Many thanks to Dr. Fernando Gonzalez-Taboada, Dr. Angel Muñoz, and three anonymous reviewers for the helpful comments and suggestions. CME and Coral Reef Watch work are supported primarily by the NOAA Coral Reef Conservation Program and the NOAA National Environmental Satellite, Data, and Information Service's Center for Satellite Applications and Research. The contents in this manuscript are solely the opinions of the authors and do not constitute a statement of policy, decision, or position on behalf of NOAA or the U.S. Government.

\section{References}

A'Mar, Z. T., Punt, A.E., Dorn, M.W., 2009. The impact of regime shifts on the performance of management strategies for the Gulf of Alaska walleye pollock (Theragra chalcogramma) fishery. Canadian Journal of Fisheries and Aquatic Sciences 66, 2222-2242.

Abawi, Y., Llanso, P., Harrison, M., Mason, S.J., 2007. Water, health and early warnings. In: Seasonal Climate: Forecasting and Managing Risk (eds A. Troccoli, M. Harrison, D. T. Anderson and S. J. Mason). Springer, London, UK, pp: 351-395. 
1526

1527

1528

1529

1530

1531

1532

1533

1534

1535

1536

1537

1538

1539

1540

1541

1542

1543

1544

1545

1546

1547

1548

1549

1550

1551

1552

1553

1554

Agnew, D. J., Beddington, J.R., Hill, S.L. 2002. The potential use of environmental information to manage squid stocks. Canadian Journal of Fisheries and Aquatic Sciences 59, 18511857.

Agostini, V.N., Francis, R.C., Hollowed, A.B., Pierce, S.D., Wilson, C., Hendrix, A.N., 2006. The relationship between Pacific hake (Merluccius productus) distribution and poleward subsurface flow in the California Current System. Canadian Journal of Fisheries and Aquatic Sciences 63, 2648-2659.

Ainsworth, C., Samhouri, J., Busch, D., Cheung, W.W.L., Dunne, J., Okey, T.A., 2011. Potential impacts of climate change on Northeast Pacific marine foodwebs and fisheries. ICES Journal of Marine Science 68, 1217-1229.

Alheit, J., Drinkwater, K.F., Perry, R.I. (Eds.), 2010. Impact of climate variability on marine ecosystems: A comparative approach [Special Issue]. Journal of Marine Systems 79, 227436.

Allen, J.T., Tippett, M.K., Sobel, A.H., 2015. Influence of the El Nino/Southern Oscillation on Tornado and hail frequency in the United States. Nature Geoscience 8, 278-283.

Allouche, O., Tsoar, A., Kadmon, R., 2006. Assessing the accuracy of species distribution models: prevalence, kappa, and the true skill statistic (TSS). Journal of Applied Ecology 43, 1223-1232.

Anderson, D.M., Hoagland, P., Kaoru, Y., White, A.W., 2000. Estimated annual economic impacts from Harmful Algal Blooms (HABs) in the United States. Woods Hole Oceanographic Institution Technical Report 2000-11, pp. 97.

Andrews, K.S., Williams, G.D., Samhouri, J.F., Marshall, K.N., Gertseva, V., Levin, P.S., 2015. The legacy of a crowded ocean: indicators, status, and trends of anthropogenic pressures in the California Current ecosystem. Environmental Conservation 42, 139-151.

Asch, R. G., 2015. Climate change and decadal shifts in the phenology of larval fishes in the California Current ecosystem. Proceedings of the National Academy of Sciences of the United States of America 112, E4065-E4074.

Asseng, S., McIntosh, P.C., Wang, G., Khimashia, N., 2012. Optimal N fertiliser management based on a seasonal forecast. European Journal of Agronomy 38, 66-73. 
1555

1556

1557

1558

1559

1560

1561

1562

1563

1564

1565

1566

1567

1568

1569

1570

1571

1572

1573

1574

1575

1576

1577

1578

1579

1580

1581

1582

1583

Astthorsson, O.S., Valdimarsson, H., Gudmundsdottir, A., Oskarsson, G.J., 2012. Climaterelated variations in the occurrence and distribution of mackerel (Scomber scombrus) in Icelandic waters. ICES Journal of Marine Science 69, 1289-1297.

Audzijonyte, A., Kuparinen, A., Gorton, R., Fulton, E.A., 2013. Ecological consequences of body size decline in harvested fish species: positive feedback loops in trophic interactions amplify human impact. Biology Letters 9, 20121103, doi: 10.1098/rsbl.2012.1103.

Audzijonyte, A., Kuparinen, A., Fulton, E.A., 2014. Ecosystem effects of contemporary lifehistory changes are comparable to those of fishing. Marine Ecology Progress Series 495, 219-231.

Audzijonyte, A., Fulton, E. A., Haddon, M., Helidoniotis, F., Hobday, A.J., Kuparinen, A., Morrongiello, J.R., Smith, A.D.M., Upston, J., Waples, R.S., 2016. Trends and management implications of human-influenced life-history changes in marine ectotherms. Fish and Fisheries 17, 1005-1028.

Barange, M., Merino, G., Blanchard, J.L., Scholtens, J., Harle, J., Allison, E.H., Allen, J.I., Holt, J., Jennings, S., 2014. Impacts of climate change on marine ecosystem production in societies dependent on fisheries. Nature Climate Change 4, 211-216.

Bahr, K.D., Jokiel, P.L., Rodgers, K.S. 2015. The 2014 coral bleaching and freshwater flood events in Kāne'ohe Bay, Hawai'i. PeerJ 3, e1136, doi: 10.7717/peerj.1136.

Balmaseda, M., Anderson, D., Vidard, A., 2007. Impact of Argo on analyses of the global ocean. Geophysical Research Letters 34, L16605.

Balmaseda, M.A., Hernandez, F., Storto, A., Palmer, M.D., Alves, O., Shi, L., Smith, G.C., Toyoda, T., Valdivieso, M., Barnier, B., Behringer, D., Boyer, T., Chang, Y-S, Chepuring, G.A., Ferry, N., Forget, G., Fujii, Y., Good, S., Guinehut, S., Haines, K., Ishikawa, Y., Keeley, S., Köhl, A., Lee, T., Martin, M.J., Masina, S., Masuda, S., Meyssingnac, K., Mogensen, K., Parent, L., Peterson, K.A., Tang, Y.M., Yin, Y., Vernieres, G., Wang, X., Waters, J., Wedd, R., Wang, O., Xue, Y., Chevallier, M., Lemieux, J-F., Dupont, F., Kuragano, T., Kamachi, M., Awaji, T., Caltablano, A., Wilmer-Becker, K., Gaillard, F., 2015.The Ocean Reanalyses Intercomparison Project (ORA-IP). Journal of Operational Oceanography 7, 81-99. 
1584

1585

1586

1587

1588

1589

1590

1591

1592

1593

1594

1595

1596

1597

1598

1599

1600

1601

1602

1603

1604

1605

1606

1607

1608

1609

1610

1611

1612

1613

Barange, M., Merino, G., Blanchard, J.L., Scholtens, J., Harle, J., Allison, E.H., Allen, J.I., Holt, J., and Jennings, S., 2014. Impacts of climate change on marine ecosystem production in societies dependent on fisheries. Nature Climate Change 4, 211-216.

Barnett, T.P., Adam, J.C., Lettenmaier, D.P., 2005. Potential impacts of a warming climate on water availability in snow-dominated regions. Nature 438, 303-309.

Barnston, A.G., Tippett, M.K., 2014. Climate information, outlooks, and understanding-where does the IRI stand? Earth Perspectives 1, 20, doi.org/10.1186/2194-6434-1-20.

Barnston, A.G., Tippett, M.K., L'Heureux, M.L., Li, S., DeWitt, D.G., 2012. Skill of real-time seasonal ENSO model predictions during 2002-11 is our capability increasing? Bulletin of the American Meteorological Society 93, 631-651.

Barton, A., Waldbusser, G.G., Feely, R.A., Weisberg, S.B., Newton, J.A., Hales, B., Cudd, S., Eudeline, B., Langdon, C.J., Jefferds, I., King, T., Suhrbier, A., McLaughlin, K., 2015. Impacts of Coastal Acidification on the Pacific Northwest Shellfish Industry and Adaptation Strategies Implemented in Response. Oceanography 25, 146-159.

Basson, M., 1999. The importance of environmental factors in the design of management procedures. ICES Journal of Marine Science 56, 933-942.

Batté, L., Déqué, M., 2016. Randomly correcting model errors in the ARPEGE-Climate v6.1 component of CNRM-CM: applications for seasonal forecasts, Geoscientific Model Development 9, 2055-2076.

Baumgartner, T. R., Soutar, A., Ferreira-Batrina, V., 1992. Reconstruction of the history of Pacific sardine and northern anchovy populations over the past two millennia from sediments of the Santa Barbara Basin, California. California Cooperative Oceanic Fisheries Investigations Reports 33, 24-40.

Beaugrand, G., Lenoir, S., Ibañez, F., Manté, C., 2011. A new model to assess the probability of occurrence of a species, based on presence-only data. Marine Ecology Progress Series 424, 175-190.

Becker, E., van den Dool, H., Zhang, Q. 2014. Predictability and forecast skill in NMME. Journal of Climate 27, 5891-5906.

Behrenfeld, M.J., Falkowski, P.G., 1997. Photosynthetic rates derived from satellite-based chlorophyll concentration. Limnology and Oceanography 42, 1-20. 
1614

1615

1616

1617

1618

1619

1620

1621

1622

1623

1624

1625

1626

1627

1628

1629

1630

1631

1632

1633

1634

1635

1636

1637

1638

1639

1640

1641

1642

1643

1644

Bell, R.J., Hare, J.A., Manderson, J.P., Richardson, D.E., 2014. Externally driven changes in the abundance of summer and winter flounder. ICES Journal of Marine Science 71, 24162428.

Bell, R.J., Richardson, D.E., Hare, J.A., Lynch, P.D., Fratantoni, P.S., 2015. Disentangling the effects of climate, abundance, and size on the distribution of marine fish: an example based on four stocks from the Northeast US shelf. ICES Journal of Marine Science 72, 1311-1322.

Bi, H.S., Peterson, W.T., Strub, P.T. 2011. Transport and coastal zooplankton communities in the northern California Current system. Geophysical Research Letters 38, doi: 10.1029/2011GL047927.

Bitz, C.M., Holland, M.M., Hunke, E., Moritz, R.E., 2005. Maintenance of the sea-ice edge. Journal of Climate 18, 2903-2921.

Boer,G., 2004: Long time-scale potential predictability in an ensemble of coupled climate models. Climate Dynamics 23, 29-44.

Bograd, S.J., Hazen, E.L., Howell, E.A., Hollowed, A.B. (Eds.), 2014. Special Issue: Fisheries Oceanography. Oceanography 27, 21-167.

Bopp, L., Resplandy, L., Orr, J.C., Doney, S.C., Dunne, J.P., Gehlen, M., Halloran, P., Heinze, C., Ilyina, T., Séférian, R., Tjiputra, J., Vichi, M., 2013. Multiple stressors of ocean ecosystems in the $21^{\text {st }}$ century: projections with CMIP5 models. Biogeoscienes 10, 62256245.

Boudreau, S.A., Anderson, S.C., Worm, B., 2015. Top-down and bottom-up forces interact at thermal range extremes on American lobster. Journal of Animal Ecology 84, 840-850.

Bradley, A.A., Habib, M., Schwartz, S.S., 2015. Climate index weighting of ensemble streamflow forecasts using a simple Bayesian approach. Water Resources Research 51, 7382-7400.

Brander, K.M., 2007. Global fish production and climate change. Proceedings of the National Academy of Sciences of the United States of America 104, 19709-19714.

Brander, K., 2010. Impacts of climate change on fisheries. Journal of Marine Systems 79, 389402.

Branstator, G., Teng, H., 2010. Two Limits of Initial-Value Decadal Predictability in a CGCM. Journal of Climate 23, 6292-6311. 
Brennan, C.E., Bianucci, L., Fennel, K., 2016. Sensitivity of Northwest North Atlantic shelf circulation to surface and boundary forcing: a regional model assessment. AtmosphereOcean 54, 230-247.

Brooks, E.N., 2013. Effects of variable reproductive potential on reference points for fisheries management. Fisheries Research 138, 152-158.

Brooks, E.N., Deroba, J.J., 2015. When "data" are not data: the pitfalls of post-hoc analyses that use stock assessment model output. Canadian Journal of Fisheries and Aquatic Sciences $72,634-641$.

Brun, P., Kiorboe, T., Licandro, P., Payne, M.R., 2016. The predictive skill of species distribution models for plankton in a changing climate. Global Change Biology 22, 31703181.

Brunel, T., Piet, G.J., van Hal, R., Rockmann C., 2010. Performance of harvest control rules in a variable environment. ICES Journal of Marine Science 67, 1051-1062.

Bryant, M.D, 2009. Global climate change and potential effects on Pacific salmonids in freshwater ecosystems of southeast Alaska. Climatic Change 95, 165-193.

Butterworth, D.S., Punt, A.E., 1999. Experiences in the evaluation and implementation of management procedures. ICES Journal of Marine Science 56, 985-998.

Camargo, S.J., Barnston, A.G., Klotzbach, P., Landsea, C.W., 2007. Seasonal tropical cyclone forecasts. WMO Bulletin 56, 297-309.

Chang, Y., Lee, M., Lee, K., Shao, K., 2013. Adaptation of fisheries and mariculture management to extreme oceanic environmental changes and climate variability in Taiwan. Marine Policy 38, 476-482.

Chapman, D., Cane, M.A., Henderson, N., Lee, D-E., Chen, C., 2015. A vector autoregressive ENSO prediction model. Journal of Climate 28, 8511-8520.

Chavez, F. P., 2003. From Anchovies to Sardines and Back: Multidecadal Change in the Pacific Ocean. Science 299, 217-221.

Chen, J.H., Lin, S.J., 2011. The remarkable predictability of inter-annual variability of Atlantic hurricanes during the past decade. Geophysical Research Letters 38, L11804, doi:10.1029/2011GL047629. 
1674

1675

1676

1677

1678

1679

1680

1681

1682

1683

1684

1685

1686

1687

1688

1689

1690

1691

1692

1693

1694

1695

1696

1697

1698

1699

1700

1701

1702

Cheung, W.W.L., Lam, V.W.Y., Sarmiento, J.L., Kearney, K., Watson, R., Pauly, D., 2009. Projecting global marine biodiversity impacts under climate change scenarios. Fish and Fisheries 10, 235-251.

Cheung, W.W.L., Jones, M.C., Reygondeau, G., Stock, C., Lam, V.W.Y., Frolicher, T.L., $2016 a$. Structural uncertainty in projecting global fisheries catches under climate change. Ecological Modelling 325, 57-66.

Cheung, W.W.L., Frolicher, T.L., Asch, R.G., Jones, M.C., Pinsky, M.L., Reygondeau, G., Rodgers, K.B., Rykaczewski, R.R., Sarmiento, J.L., Stock, C., Watson, J.R., $2016 b$. Building confidence in projections of the responses of living marine resources to climate change. ICES Journal of Marine Science 73, 1283-1296.

Chevallier, M., Salas-Melia, D., Voldoire, A., Deque, M., Garric, G., 2013. Seasonal forecasts of the pan-Arctic sea ice extent using a GCM-based seasonal prediction system, Journal of Climate 26, 6092-6104.

Chikamoto, M.O., Timmermann, A., Chikamoto, Y., Tokinaga, H., Harada, N., 2015. Mechanisms and predictability of multiyear ecosystem variability in the North Pacific, Global Biogeochemical Cycles 29, 2001-2019.

Chittenden, C.M., Jensen, J.L.A., Ewart, D., Anderson, S., Saksida, Smith, B., Vincent, S., Welch, D., McKinley, R.D., 2010. Recent salmon declines: A result of lost feeding opportunities due to bad timing? Plos One 5, e12423

Clark, W.G., 1977. The lessons of the Peruvian anchoveta fishery. California Cooperative Oceanic Fisheries Investigations Reports 19, 57-63.

Collie, J.S., P.D. Spencer. 1993. Management strategies for fish populations subject to long-term environmental variability and depensatory predation. Proceedings of the International Symposium on Management Strategies for Exploited Fish Populations, Alaska Sea Grant College Program.

Collie, J.S., Botsford, L.W., Hastings, A., Kaplan, I.C., Largier, J.L., Livingston, P.A., Plagányi, E., Rose, K.A., Wells, B.K., Werner, F.E., 2104. Ecosystem models for fisheries management: finding the sweet spot. Fish and Fisheries 17, 101-125. 
1703

1704

1705

1706

1707

1708

1709

1710

1711

1712

1713

1714

1715

1716

1717

1718

1719

1720

1721

1722

1723

1724

1725

1726

1727

1728

1729

1730

1731

1732

1733

Collie, J.S., Peterman, R.M., Zuehlke, 2012. A fisheries risk-assessment framework to evaluate trade-offs among management options in the presence of time-varying productivity. Canadian Journal of Fisheries and Aquatic Sciences 69, 209-223.

Combes, V., Chenillat, F., Di Lorenzo, E., Rivière, P., Ohmane, M.D., Bograd, S.J, 2013. Crossshore transport variability in the California Current: Ekman upwelling vs. eddy dynamics. Progress in Oceanography 109, 78-89.

Constantin de Magny, G., Long, W., Brown, C.F., Hood, R.R., Hug, A., Murtugudde, Colwell, R.R., 2009. Predicting the distribution of Vibrio spp. in the Chesapeake Bay: a Vibrio cholerae case study. EcoHealth 6, 378-389.

Cooke, J.G., 1999. Improvement of fishery-management advice through simulation testing of harvest algorithms. ICES Journal of Marine Science 56, 797-810.

Coyle, K. O., Eisner, L.B., Mueter, F.J., Pinchuck, A.I., Janout, M.A., Cieciel, K.D., Farley, E.V., Andrews, A.G., 2011. Climate change in the southeastern Bering Sea: impacts on Pollock stocks and implications for the Oscillating Control Hypothesis. Fisheries Oceanography 20, 139-156.

Daley, R. 1991. Atmospheric Data Analysis. Cambridge, UK: Cambridge University Press.

Dankel, D., Haraldsson, G., Heldbo, J., Hoydal, K., Lassen, H., Siegstad, H., Schou, M., Sverdrup-Jensen, S., Waldo, S., Orebech, P., 2015. Allocation of Fishing Rights in the NEA. Copenhagen, Denmark: Nordic Council of Ministers, doi:10.6027/TN2015-546.

Daufresne, M., Lengfellner, K., Sommer, U., 2009. Global warming benefits the small in aquatic ecosystems. Proceedings of the National Academy of Sciences of the United States of America 106, 12788-12793.

Davis, M., Lowe, R., Steffen, S., Doblas-Reyes, F.J., Rodó, X. 2015. Barriers to using climate information: Challenges in communicating probabilistic forecasts to decision-makers. In J.L. Drake, Y.Y. Kontar, J.C. Eichelberger, S.T. Rupp, K.M. Taylor (Eds.), Communicating Climate-Change and Natural Hazard Risk and Cultivating Resilience. Advances in Natural and Technological Hazards Research 45, 95-113.

DelSole, T., Shukla, J. 2009. Artificial skill due to predictor screening. Journal of Climate 22, 331-345.

Delworth, T.L., Rosati, A., Anderson, W., Adcroft, A.J., Balaji, V., Benson, R., Dixon, K., Griffies, S.M., Lee, H.C., Pacanowski, R.C., Vecchi, G.A., Wittenberg, A.T., Zeng, F.R., 
1734

1735

1736

1737

1738

1739

1740

1741

1742

1743

1744

1745

1746

1747

1748

1749

1750

1751

1752

1753

1754

1755

1756

1757

1758

1759

1760

1761

1762

Zhang, R., 2012. Simulated climate and climate change in the GFDL CM2.5 Highresolution coupled climate model. Journal of Climate 25, 2755-2781.

Deser, C., Alexander, M.A., Xie, S., Phillips, A.S., 2010. Sea surface temperature variability: Patterns and mechanisms. Annual Reviews of Marine Science 2, 115-143.

Deser, C., Knutti, R., Solomon, S., Phillips, A.S., 2012. Communication of the role of natural variability in future North American climate. Nature Climate Change 2, 775-779.

Di Lorenzo, E., Fiechter, J., Schneider, N., Miller, A.J., Franks, P.J.S., Bograd, S.J., Moore, A.M., Thomas, A., Crawford, W., Pena, Herman, A., 2009. Nutrient and salinity decadal variations in the central and eastern North Pacific. Geophysical Research Letters 36, L14601.

Di Lorenzo, E., Combes, V., Keister, J.E., Strub, P.T., Thomas, A.C., Franks, P.J.S., Ohman, M.D., Furtado, J.C., Bracco, A., Bograd, S.J., Peterson, W.T., Schwing, F.B., Chiba, S., Taguchi, B., Hormazabal, S., Parada, C., 2013. Synthesis of Pacific Ocean climate and ecosystem dynamics. Oceanography $26,68-81$.

Doak, D.F., Estes, J.A., Halpern, B.S., Jacob, U., Lindberg, D.R., Lovvorn, J., Monson, D.H., Tinker, M.T., Williams, T.M., Wootton, J.T., Carroll, I., Emmerson, M., Micheli, F., Novak, M. 2008. Understanding and predicting ecological dynamics: are major surprises inevitable? Ecology 89, 952-96.

Doblas-Reyes, F. J., Hagedorn, R., Palmer, T.N., Morcrette, J.-J., 2006. Impact of increasing greenhouse gas concentrations in seasonal ensemble forecasts. Geophysical Research Letters 33, L07708, doi:10.1029/2005GL025061.

Dorn, M., Aydin, K., Jones, D., Palsson, W., Spalinger, K., 2014. Assessment of the walleye pollock stock in the Gulf of Alaska. In: Stock assessment and fishery evaluation report for the groundfish resources of the Gulf of Alaska. US Department of Commerce, Alaska Fisheries Science Center.

Dorner, B., Holt, K.R., Peterman, R.M., Jordan, C., Larsen, D.P., Olsen, A.R., Abdul-Aziz, O.I., 2013. Evaluating alternative methods for monitoring and estimating responses of salmon productivity in the North Pacific to future climatic change and other processes: A simulation study. Fisheries Research 147, 10-23. 
1763

1764

1765

1766

1767

1768

1769

1770

1771

1772

1773

1774

1775

1776

1777

1778

1779

1780

1781

1782

1783

1784

1785

1786

1787

1788

1789

1790

1791

1792

1793

Dunn, D.C., Maxwell, S.M., Boustany, A.M., Halpin, PN., 2016. Dynamic ocean management increases the efficiency and efficacy of fisheries management. Proceedings of the National Academy of Sciences of the United States of America 113, 668-673.

Eakin, C.M., Liu, G., Gomez, A.M., De La Cour, J.L., Heron, S.F., Skirving, W.J., Geiger, E.F., Tirak, K.V., Strong, A.E., 2016. Global coral bleaching 2014-2017: Status and an appeal for observations. Reef Encounter 43, 20-26.

Eakin, C.M., Rauenzahn, J.L., Liu, G., Heron, S.F., Skirving, W.J., Geiger, E.F., Strong, A.E., 2014. Will 20142015 be the Next Big El Niño? If so, what might it mean for coral reefs? Reef Encounter 29, 30-35.

Eakin, C.M., Liu, G., Chen, M., Kumar, A., 2012. Ghost of bleaching future: Seasonal outlooks from NOAA's operational climate forecast system. Proceedings of the $12^{\text {th }}$ International Coral Reef Symposium, Cairns, Australia, 9-13 July 2012.

Eden, J.M., van Oldenborgh, G.J., Hawkins, E., Suckling, E.B. 2015. A global empirical system for probabilistic seasonal climate prediction, Geoscientific Model Development 8, 3947 3973, doi:10.5194/gmd-8-3947-2015.

Edwards, C.A., Moore, A.M., Hoteit, I., Cornuelle, B.D., 2015. Regional ocean data assimilation. Annual Reviews of Marine Science 7, 21-42.

Elsner, J.B., Widen, H.M., 2014. Predicting spring tornado activity in the Central Great Plains by 1 March. Monthly Weather Review 142, 259-267.

Essington, T. E., Moriarty, P.E., Froehlich, H.E., Hodgson, E.E., Koehn, L.E., Oken, K.L., Siple, M.C., Stawitz, C.C., 2015. Fishing amplifies forage fish population collapses.

Proceedings of the National Academy of Sciences of the United States of America 112, 6648-6652.

Evans, M.R., 2012. Modelling ecological systems in a changing world. Philosophical Transactions of the Royal Society B 367, 181-190.

Eveson, J.P., Hobday, A.J., Hartog, J.R., Spillman, C.M., Rough, K.M., 2015. Seasonal forecasting of tuna habitat in the Great Australian Bight. Fisheries Research 170, 39-49.

Fielding, A.H., Bell, J.F., 1997. A review of methods for the assessment of prediction errors in conservation presence/absence models. Environmental Conservation 24, 38-49.

Finney, B.P., Gregory-Eaves, I., Douglas, M.S.V., Smol, J.P., 2002. Fisheries productivity in the northeastern Pacific Ocean over the past 2,200 years. Nature 416, 729-733. 
1794

1795

1796

1797

1798

1799

1800

1801

1802

1803

1804

1805

1806

1807

1808

1809

1810

1811

1812

1813

1814

1815

1816

1817

1818

1819

1820

1821

1822

1823

1824

Finney, B.P., Alheit, J., Emeis, K-C., Field, D.B., Gutiérrez, D., Struck, U., 2010.

Paleoecological studies on variability in marine fish populations: A long-term perspective on the impacts of climatic change on marine ecosystems. Journal of Marine Systems 79, 316-326.

Francis, R., 2006. Measuring the strength of environment-recruitment relationships: the importance of including predictor screening with cross-validations. ICES Journal of Marine Science 63, 594-599.

Fuller, E., Brush, E., Pinsky, M.L., 2015. The persistence of populations facing climate shifts and harvest. Ecosphere 6, 153, doi: 10.1890/ES14-00533.1.

Fulton, E.A., Smith, A.D.M., Smith, D.C., Johnson, P., 2014. An Integrated Approach Is Needed for Ecosystem Based Fisheries Management: Insights from Ecosystem-Level Management Strategy Evaluation. PLoS ONE 9, e84242.

Gaitan, C.F., Hsieh, W.W., Cannon, A.J., 2014. Comparison of statistically downscaled precipitation in terms of future climate indices and daily variability for southern Ontario and Quebec, Canada. Climate Dynamics 43, 3201-3217.

Gehlen, M., Barciela, R., Bertino, L., Brasseur, P., Butenschon, M., Chai, F., Crise, A., Drillet, Y., Ford, D., Lavoie, D., Lehodey, P., Perruche, C., Samuelsen, A., Simon, E., 2015. Building the capacity for forecasting marine biogeochemistry and ecosystems: recent advances and future developments. Journal of Operational Oceanography 8, s168-s187.

Gershwin, L-A., Condie, S.A., Mansbridge, J.V., Richardson, A.J., 2014. Dangerous jellyfish blooms are predictable. Journal of the Royal Society Interface 11, 20131168, doi: 10.1098/rsif.2013.1168.

Goddard, L., Mason, S.J., Zebiak, S.E., Ropelewski, C.F., Basher, R., Cane, M.A., 2001. Current approaches to seasonal-to-interannual climate predictions. International Journal of Climatology 21, 1111-1152.

Goddard, L., Mason, S.J. 2002. Sensitivity of seasonal climate forecasts to persisted SST anomalies. Climate Dynamics 19, 619-631.

Gray, W.M., 1984: Atlantic seasonal hurricane frequency. Part I: El Niño and 30 mb quasi-biennial oscillation influences. Monthly Weather Review 112, 1649-1668.

Griffies, S.M., Winton, M., Anderson, W.G., Benson, R., Delworth, T.L., Dufour, C.O., Dunne, J.P., Goddard, P., Morrison, A.K., Rosati, A., Wittenberg, A.T., Yin, J.J., Zhang, R., 
2015. Impacts on ocean heat from transient mesoscale eddies in a hierarchy of climate models. Journal of Climate 28, 952-977.

Groot, C., Quinn, T.P., 1987. Homing migration of sockeye salmon, Oncorhynchus nerka, to the Fraser River. Fishery Bulletin 88, 455-469.

Guemas, V., Chevallier, M., Déqué, M., Bellprat, O., Doblas-Reyes, F., 2016. Impact of sea ice initialization on sea ice and atmosphere prediction skill on seasonal timescales. Geophysical Research Letters 43, 3889-3896.

Gutknecht, E., Reffray, G., Gehlen, M., Triyulianti, I., Berlianty, D., Gaspar, P., 2016. Evaluation of an operational ocean model configuration at 1/12o spatial resolution for the Indonesian seas (NEMO2.3/INDO12) - Part 2: Biogeochemistry. Geoscientific Model Development 9, 1523-1543.

Haidvogel, D., Arango, H., Budgell, W., cornuelle, B.D., Curchitser, E., Di Lorenzo, E., Fennel, K., Geyer, W.R., Hermann, A.J., Lanerolle, L., Levin, J., McWilliams, J.C., Miller, A.J., Moore, A.M., Powell, T.M., Shchepetkin, A.F., Sherwood, C.R., Signell, R.P., Warner, J.C., Wilkin, J., 2008. Ocean forecasting in terrain-following coordinates: Formulation and skill assessment of the Regional Ocean Modeling System. Journal of Computational Physics 227, 3595-3624.

Hall, A., 2014. Projecting regional change. Science 346, 1461-1462.

Halpern, B.S., Walbridge, S., Selkoe, K.A., Kappel, C.V., Micheli, F., D’Agrosa, C., Bruno, J.F., Casey, K.S., Ebert, C., Fox, H.E., Fujita, R., Heinemann, D., Lenihan, H.S., Madin, E.M.P., Perry, M.P., Selig, E.R., Spalding, M., Steneck, R., Watson, R., 2008. A global map of human impact on marine ecosystems. Science 319, 948-952.

Halpern, B.S., Frazier, M., Potapenko, J., Casey, K.S., Koenig, K., Longo, C., Lowndes, J.S., Rockwood, R.C., Selig, E.R., Selkoe, K.A., Walbridge, S., 2015. Spatial and temporal changes in cumulative human impacts on the world's ocean. Nature Communications 6 , 7615, doi: 10.1038/ncomms8615.

Haltuch, M.A., Punt, A.E., 2011. On the promises and pitfalls of including decadal scale climate forcing of recruitment in groundfish stock assessment. Canadian Journal of Fisheries and Aquatic Sciences 68, 912-926.

Haltuch, M.A., Punt, A.E., Dorn, M.W., 2009. Evaluating the estimation of fishery management reference points in a variable environment. Fisheries Research 100, 42-56. 
1856

1857

1858

1859

1860

1861

1862

1863

1864

1865

1866

1867

1868

1869

1870

1871

1872

1873

1874

1875

1876

1877

1878

1879

1880

1881

1882

1883

1884

1885

Hamilton, L.C., 2007. Climate, fishery and society interactions: Observations from the North Atlantic. Deep Sea Research Part II: Topical Studies in Oceanography 54, 23-26.

Hamlet, A.F., Huppert, D., Lettenmaier, D., 2002. Economic value of long-lead streamflow forecasts for Columbia River hydropower. Journal of Water Resources Planning and Management-Asce 128, 91-101.

Hammer, C., von Dorrien, C., Hopkins, C.C.E., Köste, F.W., Nilssen, E.M., St John, M., Wilson, D.C., 2010. Framework of stock-recovery strategies: analyses of factors affecting success and failure. ICES Journal of Marine Science 67, 1849-1855.

Hannesson R., 2006. Sharing the herring: fish migrations, strategic advantage and climate change. In Climate Change and the Economics of the World's Fisheries: Examples of Small Pelagic Stocks (eds R. Hannesson, M. Barange, S. Herrick Jr.). Edward Elgar, Cheltenam, UK, 66-99.

Hannesson, R., 2012. Sharing the Northeast Atlantic mackerel. ICES Journal of Marine Science 70, 259-269.

Hansen, J.W., Mason, S.J., Sun, L., Tall, A., 2011. Review of seasonal climate forecasting for agriculture in sub-saharan Africa. Experimental Agriculture 47, 205-240.

Hare, J.A., Alexander, M., Fogarty, M., Williams, E., Scott, J., 2010. Forecasting the dynamics of a coastal fishery species using a coupled climate-population model. Ecological Applications 20, 452-464.

Harrison, M., Williams, J.B., 2007. Communicating seasonal forecasts. In A. Troccoli, M. Harrison, D. L. T. Anderson, S. J. Mason (Eds.), Seasonal Climate: Forecasting and Managing Risk (167-206). Dordrecht: Springer Academic Publishers.

Harvey, C.J., Hazen, E.L., Garfield, N., 2014. The California Current Integrated Ecosystem Assessment: Phase III Report. Available from http://www.noaa.gov/iea/CCIEAReport/index.

Hawkins, E., Sutton, R., 2009. The potential to narrow uncertainty in regional climate predictions. Bulletin of the American Meteorological Society 90, 1095-1107.

Hervieux, G., Alexander, M., Stock, C., Jacox, M., Pegion, K., Tommasi, D., in review. Seasonal sea surface temperature anomaly prediction skill for coastal ecosystems using the North American multi-model ensemble (NMME). Climate Dynamics. 
Hill, K.T., Crone, P.R., Demer, D.A., Zwolinski, J., Dorval, E., Macewicz, B.J., 2014. Assessment of the Pacific Sardine Resource in 2014 for U.S.A. Management in 2014-15. (US Department of Commerce, La Jolla, CA).

Hill, K.T., Crone, P.R., Dorval, E., Macewicz, B.J., 2015. Assessment of the Pacific Sardine Resource in 2015 for U.S.A. Management in 2015-16. (US Department of Commerce, La Jolla, CA).

Ho, C. K., Hawkins, E., Shaffrey, L., Underwood, F.M., 2013. Statistical decadal predictions for sea surface temperatures: a benchmark for dynamical GCM predictions. Climate Dynamics 41, 917-935.

Hobday, A.J., Hartmann, K. 2006. Near real-time spatial management based on habitat predictions for a longline bycatch species. Fisheries Management and Ecology 13, 365380 .

Hobday, A.J., Hartog, J.R., Timmiss, T., Fielding, J., 2010. Dynamic spatial zoning to manage southern bluefin tuna (Thunnus maccoyii) capture in a multi-species longline fishery. Fisheries Oceanography 19, 243-253.

Hobday, A.J., Hartog, J.R., Spillman, C.M., Alves, O., 2011. Seasonal forecasting of tuna habitat for dynamic spatial management. Canadian Journal of Fisheries and Aquatic Sciences 68, 898-911.

Hobday, A.J., Lough, J., 2011. Projected climate change in Australian marine and freshwater environments. Marine and Freshwater Research 62, 1000-1014.

Hobday, A.J., Maxwell, S.M., Forgie, J., McDonald, J., Darby, M., Seto, K., Bailey, H., Bograd, S.J., Briscoe, D.K., Costa, D.P., Crowder, L.B., Dunn, D.C., Fossette, S., Halpin, P.N., Hartog, J.R., Hazen, E.L., Lascellas, B.G., Lewison, R.L., Poulos, G., Powers, A., 2014. Dynamic ocean management: Integrating scientific and technological capacity with law, policy and management. Stanford Environmental Law Journal 33, 125-165.

Hobday, A.J., Spillman, C.M., Eveson, J.P., Hartog, J.R. 2016. Seasonal forecasting for decision support in marine fisheries and aquaculture. Fisheries Oceanography 25, 45-56.

Hodgkinson, J.A., Hobday, A.J., Pinkard, E.A., 2014. Climate adaptation in Australia's resourceextraction industries: ready or not? Regional Environmental Change 14, 1663-1678.

Hoegh-Guldberg, O., Mumby, P.J., Hooten, A.J., Steneck, R.S., Greenfield, P., Gomez, E., Harvell, C.E., Sale, P.F., Edwards, A.J., Caldeira, K., Knowlton, N., Eakin, C.M., 

Iglesias-Prieto, R., Muthiga, N., Bradbury, R.H., Dubi A., Hatziolos, M.E., 2007. Coral Reefs Under Rapid Climate Change and Ocean Acidification. Science 318, 1737-1742.

Holsman K.K., Essington, T., Miller, T.J., Koen-Alonso, M., Stockhausen, W.J. 2012. Comparative analysis of cod and herring production dynamics across 13 northern marine ecosystems. Marine Ecology Progress Series 459, 231-246.

Holsman, K.K., Hazen, E., Hollowed, A., Aydin, K., In review. Evolution not Revolution in implementing "climate-ready" marine management.

Holsman, K.K., Ianelli, J., Aydin, K., Punt, A.E., Moffitt, E.A., In press. Comparative biological reference points estimated from temperature-specific multispecies and single species stock assessment models. Deep Sea Research II, doi: 10.1016/j.dsr2.2015.08.001

Holt, C.A., Punt, A.E., 2009. Incorporating climate information into rebuilding plans for overfished groundfish species of the U.S. west coast. Fisheries Research 100, 57-67.

Howell, E.A., Kobayashi, D.R., Parker, D.M., Balazs, G.H., Polovina, J.J., 2008. TurtleWatch: a tool to aid in the bycatch reduction of loggerhead turtles Caretta caretta in the Hawaiibased pelagic longline fishery. Endangered Species Research 5, 267-278.

Howell, E.A., Hoover, A., Benson, S.R., Bailey, H., Polovina, J.J., Seminoff, J.A., Dutton, P.H. 2015. Enhancing the TurtleWatch product for leatherback sea turtles, a dynamic habitat model for ecosystem-based management. Fisheries Oceanography 24, 57-68.

Hsieh, C.-h., Reiss, C.S., Hunter, J.R., Beddington, J.R., May, R.M., Sugihara, G., 2006. Fishing elevates variability in the abundance of exploited species. Nature 443, 859-862.

Hunt, G.L., Coyle, K.O., Eisner, L.B., Farley, E.V., Heintz, R.A., Mueter, F., Napp, J.M., Overland, J.E., Ressier, P.H., Salo, S., Stabeno, P.J., 2011. Climate impacts on eastern Bering sea foodwebs: a synthesis of new data and an assessment of the Oscillating Control Hypothesis. ICES Journal of Marine Science 68, 1230-1243.

Hurtado-Ferro, F., Hiramatsu, K., Shirakihara, K., 2010. Allowing for environmental effects in a management strategy evaluation for Japanese sardine. ICES Journal of Marine Science 67, 2012-2017.

Ianelli, J., Holsman, K.K., Punt, A.E., Aydin, K., In press. Multi-model inference for incorporating trophic and climate uncertainty into stock assessment estimates of fishery biological reference points. Deep Sea Research II, doi: 10.1016/j.dsr2.2015.04.002. 
1947

1948

1949

1950

1951

1952

1953

1954

1955

1956

1957

1958

1959

1960

1961

1962

1963

1964

1965

1966

1967

1968

1969

1970

1971

1972

1973

1974

1975

1976

ICES, 2015. Interim Report of the ICES - IOC Working Group on Harmful Algal Bloom Dynamics (WGHABD), 13-18 April 2015, Lisbon, Portugal. ICES CM 2015/SSGEPD:17, 77 pp.

Jagger, T.H., Elsner, J.B., 2010. A consensus model for seasonal hurricane prediction. Journal of Climate 23, 6090-6099.

Jennings, S., Pascoe, S., Hall-Aspland, S., Le Bouhellec, B., Norman-Lopez, A., Sullivan, A., Pecl, G., 2016. Setting objectives for evaluating management adaptation actions to address climate change impacts in south-eastern Australian fisheries. Fisheries Oceanography 25, 29-44.

Ji, M., Leetmaa, A., 1997. Impact of data assimilation on ocean initialization and El Nino prediction. Monthly Weather Review 125, 742-753.

Jia, L., Vecchi, G.A., Yang, X., Gudgel, R., Delworth, T., Stern, W., Paffendorf, K., Underwood, S., Zeng, F., 2016. The roles of radiative forcing, sea surface temperatures, and atmospheric and land initial conditions in U.S. summer warming episodes. Journal of Climate 29, 4121-4135.

Jia, L., Yang, X., Vecchi, G.A., Gudgel, R.G., Delworth, T.L., Rosati, A., Stern, W.F., Wittenberg, A.T., Krishnamurthy, L., Zhang, S., Msadek, R., Kapnick, S., Underwood, S., Zeng, F., Anderson, W.G., Balaji, V., Dixon, K. 2015. Improved seasonal prediction of temperature and precipitation over land in a high-resolution GFDL climate model. Journal of Climate 28, 2044-2062.

Johnson, K.F., Rudd, M.B., Pons, M., Akselrud, C.A., Lee, Q., Hurtado-Ferro, F., Haltuch, M.A., Hamel, O.S., 2015. Status of the U.S. sablefish resource in 2015. Pacific Fishery Management Council. 7700 Ambassador Place NE, Suite 200, Portland, OR 97220.

Jokiel, P.L., Brown, E.K., 2004. Global warming, regional trends and inshore environmental conditions influence coral bleaching in Hawaii. Global Change Biology 10, 1627-1641.

Jolliffe, I.T., Stephenson, D.B., 2003. Forecast Verification: A Practitioner's Guide in Atmospheric Science. Chichester, West Sussex, UK: John Wiley and Sons Ltd.

Jones, M.C., Dye, S.R., Fernandes, J.A., Frolicher, T.L., Pinnegar, J.K., Warren, R., Cheung, W.W.L., 2013. Predicting the impact of climate change on threatened species in UK waters. PLoS ONE 8, e54216, doi: 10.1371/journal.pone.0054216. 
Jones, M.C., Cheung, W.W.L., 2014. Multi-model ensemble projections of climate change effects on global marine biodiversity. ICES Journal of Marine Science 72, 741-752. Jonsson, B., Jonsson, N., 2009. A review of the likely effects of climatic change on anadromous Atlantic salmon Salmo salar and brown trout Salmo trutta, with particular reference to water temperature and flow. Fish Biology 75, 2381-2447.

Kalnay, E. 2003. Atmospheric Modeling, Data Assimilation and Predictability. Cambridge, UK: Cambridge University Press.

Kaplan, I.C., Williams, G.D., Bond, N.A., Hermann, A.J., Siedlecki, S.A., 2016. Cloudy with a chance of sardines: forecasting sardine distributions using regional climate models. Fisheries Oceanography 25, 15-27.

Kapnick, S.B., Delworth, D.L., Ashfaq, M., Malyshev, S., Milly, P.C.D., 2014. Snowfall less sensitive to warming in Karakoram than in Himalayas due to a unique seasonal cycle. Nature Geoscience 7, 834-840.

Kapnick, S.B., Delworth, T.L., 2013. Controls of global snow under a changed climate. Journal of Climate 26, 5537-5562.

Karamouz, M., Zahraie, B., 2004. Seasonal Streamflow Forecasting Using Snow Budget and El Niño-Southern Oscillation Climate Signals: Application to the Salt River Basin in Arizona. Journal of Hydrologic Engineering 9, 523-533.

Kaschner, K., Watson, R., Trites, A.W., Pauly, D., 2006. Mapping world-wide distributions of marine mammal species using a relative environmental suitability (RES) model. Marine Ecology Progress Series 316, 285-310.

Kay, J. E., Deser, C., Phillips, A., Mai, A., Hannay, C., Strand, G., Arblaster, J., Bates, S., Danabasoglu, G., Edwards, J., Holland, M. Kushner, P., Lamarque, J.-F., Lawrence, D., Lindsay, K., Middleton, A., Munoz, E., Neale, R., Oleson, K., Polvani, L., and M. Vertenstein, 2015. The Community Earth System Model (CESM) Large Ensemble Project: A Community Resource for Studying Climate Change in the Presence of Internal Climate Variability, Bulletin of the American Meteorological Society 96, 1333-1349, doi: 10.1175/BAMS-D-13-00255.1.

Kearney, K.A., Stock, C., Aydin, K., 2012. Coupling planktonic ecosystem and fisheries food web models for a pelagic ecosystem: Description and validation for the subarctic Pacific. Ecological modelling 237, 43-62. 
Keenlyside, N. S., Ba, J., Mecking, J., Omrani, N-O., Latif, M., Zhang, R., Msadek, R., 2015. North Atlantic multi-decadal variability - mechanisms and predictability. In: C-P. Chang, M. Ghil, M. Latif, and M. Wallace (Eds.), Climate Change: Multidecadal and Beyond, World Scientific Publishing.

Keister, J.E., Di Lorenzo, E., Morgan, C.A., Combes, V., Peterson, W.T., 2011. Zooplankton species composition is linked to ocean transport in the Northern California Current. Global Change Biology 17, 2498-2511.

King, J.R., McFarlane, G.A., Punt, A.E., 2015. Shifts in fisheries management: adapting to regime shifts. Philosophical Transactions of the Royal Society B: Biological Sciences 370, 20130277-20130277.

Kirtman, B.P., Power, S.B., Adedoyin, A.J., Boer, G.J., Bojariu, R., Camilloni, I., Doblas-Reyes, F., Fiore, A.M., Kimoto, M., Meehl, G., Prather, M., Sarr, A., Schar, C., Sutton, R., van Oldenborgh, G.J., Vecchi, G. and Wang, H.-J. 2013. Near-term Climate Change: Projections and Predictability. In T. F. Stocker, D. Qin, G. K. Plattner, M. Tignor, S. K. Allen, J. Boschung, A. Nauels, Y. Xia, V. Bex and P.M. Midgley (Eds.), Climate Change 2013: The Physical Science Basis. Contribution of Working Group I to the Fifth Assessment Report of the Intergovernmental Panel on Climate Change (953-1028). Cambridge University Press, Cambridge, United Kingdom and New York, NY, USA.

Kirtman, B.P., Dughong, M., Infanti, J.M., Kinter, J.L., Paolino, D.A., Zhang, Q., van den Dool, H., Saha, S., Pena Mendez, M., Becker, E., Peng, P., Tripp, P., Huang, J., DeWitt, D., Tippet, M.K., Barnston, A.G., Li, S., Rosati, A., Schubert, S.D., Rienecker, M., Suarez, M., Li, Z. E., Marshak, J., Lim, Y-K., Tribbia, J., Pegion, K., Merryfield, W.J., Bertrand, D., 2014. The North American Multimodel Ensemble: Phase-1 Seasonal-to-Interannual Prediction; Phase-2 toward Developing Intraseasonal Prediction. Bullettin of the American Meteorological Society 95, 585-601.

Kline, T. C., Boldt, J.L., Farley Jr., E.V., Haldorson, L.J., Helle, J.H., 2008. Pink salmon (Oncorhynchus gorbuscha) marine survival rates reflect early marine carbon source dependency. Progress in Oceanography 77, 194-202.

Klotzbach, P.J., Gray, W.M., 2009. Twenty-five years of Atlantic basin seasonal hurricane forecasts, Geophysical Research Letters, 36, L09711, doi:10.1029/2009GL037580. 
2038

2039

2040

2041

2042

2043

2044

2045

2046

2047

2048

2049

2050

2051

2052

2053

2054

2055

2056

2057

2058

2059

2060

2061

2062

2063

2064

2065

2066

2067

2068

Koster, R.D., Suarez, M.J., Heiser, M. 2000. Variance and predictability of precipitation at seasonal-to-internannual timescales. Journal of Hydrometeorology 1, 26-46.

Kristiansen, T., Drinkwater, K.F., Lough, R.G., Sundby, S., 2011. Recruitment Variability in North Atlantic Cod and Match-Mismatch Dynamics. Plos One 6, doi: 10.1371/journal.pone.0017456.

Kumar, A., 2009. Finite samples and uncertainty estimates for skill measures for seasonal predictions. Monthly Weather Review 137, 2622-2631.

Kwok, R., 2011. Observational assessment of Arctic ocean sea ice motion, export, and thickness in CMIP3 climate simulations, Journal of Geophysical Research 116, C00D05, doi: 10.1029/2011JC007004.

Laufkötter, C., Vogt, M., Gruber, N., Aita-Noguchi, M., Aumont, O., Bopp, L., Buitenhuis, E., Doney, S.C., Dunne, J., Hashioka, T., Hauck, J., Hirata, T., John, J., Le Quéré, C., Lima, I.D., Nakano, H., Seferian, R., Totterdell, I., Vichi, M., Völker, C., 2015. Drivers and uncertainties of future global marine primary production in marine ecosystem models. Biogeosciences 12, 6955-6984.

Laufkötter, C., Vogt, M., Gruber, N., Aumont, O., Bopp, L., Doney, S. C., Dunne, J.P., Hauck, J., John, J.G., Lima, I.D., Seferian, R., Völker, C., 2016. Projected decreases in future marine export production: the role of the carbon flux through the upper ocean ecosystem. Biogeosciences 13, 4023-4047.

Laugel, A., Menendez, M., Benoit, M., Mattarolo, G., Mendez, F., 2014. Wave climate projections along the French coastline: Dynamical versus statistical downscaling methods. Ocean Modelling 84, 35-50.

Lawler, J.J., White, D., Neilson, R.P., Blaustein, A.R., 2006. Predicting climate-induced range shifts: model differences and model reliability. Global Change Biology 12, 1568-1584.

Lehodey, P., Alheit, J., Barange, M., Baumgartner, T., Beaugrand, G., Drinkwater, K., Fromentin, J-M., Hare, S.R., Ottersen, G., Perry, R.I., Roy, C., van der Lingen, C.D., Werner, F., 2006. Climate variability, fish, and fisheries. Journal of Climate 19, 50095030.

Lehodey P., Senina I., Murtugudde R., 2008. A spatial ecosystem and populations dynamics model (SEAPODYM) - modelling of tuna and tuna-like populations. Progress in Oceanography 78, 304-318. 
Lehodey P., Murtugudde R., Senina I., 2010. Bridging the gap from ocean models to population dynamics of large marine preda- tors: a model of mid-trophic functional groups. Progress in Oceanography 84, 69-84.

Lehodey, P., Senina, I., Nicol, S., Hampton, J., 2015. Modelling the impact of climate change on South Pacific albacore tuna. Deep Sea Research Part II: Topical Studies in Oceanography $113,246-259$.

Lellouche, J-M., Le Galloudec, O., Drevillion, M., Regnier, C., Greiner, E., Garric, G., Ferry, N., Desportes, C., Testut, C.E., Bricaud, C., Bourdalle-Badie, R., Tranchant, B., Benkiran, M., Drillet, Y., Daudin, A., De Nicola, C., 2013. Evaluation of global monitoring and forecasting systems at Mercator Ocean. Ocean Science 9, 57-81.

Le Mézo, P., Lefort, S., Séférian, R., Aumont, O., Maury, O., Murtugudde, R., \& Bopp, L., 2016. Natural variability of marine ecosystems inferred from a coupled climate to ecosystem simulation. Journal of Marine Systems 153, 55-66.

Levin, P.S., Fogarty, M.J., Murawski, S.A., Fluharty, D. 2009. Integrated Ecosystem Assessments: Developing the Scientific Basis for Ecosystem-Based Management of the Ocean. PLOS Biology 7: e1000014, doi: 10.1371/journal.pbio.1000014.

Lewison, R. L., Hobday, A.J., Maxwell, S., Hazen, E., Hartog, J.R., Dunn, D.C., Briscoe, D., Fossette, S., O’Keefe, C.E., Barnes, M., Abecassis, M., Bograd, S., Bethoney, N.D., Bailey, H., Wiley, D., Andrews, S., Hazen, L., Crowder, L.B., 2015. Dynamic Ocean Management: Identifying the Critical Ingredients of Dynamic Approaches to Ocean Resource Management. Bioscience 65, 486-498.

Lewitus, A.J., Horner, R.A., Caron, D.A., Garcia-Mendoza, E., Hickey, B.M., Hunter, M., Huppert, D.D., Kudela, R.M., Langlois, GW., Largier, J.L., Lessard, E.J., RaLonde, R., Jack Rensel, J.E., Strutton, P.G., Trainer, V.L., Tweddle, J.F., 2012. Harmful algal blooms along the North American west coast region: History, trends, causes, and impacts. Harmful Algae 19, 133-159.

Lindegren, M., Mollmann, C., Nielsen, A., Stenseth, N.C., 2009. Preventing the collapse of the Baltic cod stock through an ecosystem-based management approach. Proceedings of the National Academy of Science of the United States of America 106, 14722-14727. 
Lindegren, M., Checkley, D.M. Jr., Rouyer, T., MacCall, A.D., Stenseth, N.C., 2013. Climate, fishing, and fluctuations of sardine and anchovy in the California Current. Proceedings of the National Academy of Science of the United States of America 110, 13672-13677.

Liniger, M. A., Mathis, H., Appenzeller, C., Doblas-Reyes, F.J. 2007. Realistic greenhouse gas forcing and seasonal forecasts. Geophysical Research Letters 34, L04705, doi:10.1029/2006GL028335.

Link, J.S., Griffis, R., Busch, S. (Editors), 2015. NOAA Fisheries Climate Science Strategy. U.S. Dept. of Commerce, NOAA Technical Memorandum NMFS-F/SPO-155, 70p.

Link, J.S., Ihde, T.F., Harvey, C.J., Gaichas, S., Field, J.C., Brodziak, J.K.T., Townsend, H.M., Peterman, R.M., 2012. Dealing with uncertainty in ecosystem models: The paradox of use for living marine resource management. Progress in Oceanography 102, 102-114.

Link, J.S., Nye, J.A., Hare, J.A., 2011. Guidelines for incorporating fish distribution shifts into a fisheries management context. Fish and Fisheries 12, 461-469.

Little, L.R., Hobday, A.J., Parslow, J.S., Davies, C.R., Grafton, R.Q., 2015. Funding climate adaptation strategies with climate derivatives. Climate Risk Management 8, 9-15.

Liu, G., L.E. Matrosova, C. Penland, D.K. Gledhill, C.M. Eakin, R.S. Webb, T.R.L. Christensen, S.F. Heron, J.A. Morgan, W.J. Skirving, Strong, A.E., 2009. NOAA Coral Reef Watch Coral Bleaching Outlook System. Proceedings of the 11th International Coral Reef Symposium, Ft. Lauderdale, Florida, 951-955.

Liu, G., Heron, S.F., Eakin, C.M., Muller-Karger, F.E., Vega-Rodriguez, M., Guild, L.S., De La Cour, J.L., Geiger, E.F., Skirving, W.J., Burgess, T.F.R., Strong, A.E., Harris, A., Maturi, E., Ignatov, A., Sapper, J., Li, J., Lynds, S., 2014. Reef-Scale thermal stress monitoring of coral ecosystems: new 5-km global products from NOAA Coral Reef Watch. Remote Sensing 6, 11579-11606.

Lorenz, E. N. 1963. Deterministic nonperiodic flow. Journal of Atmospheric Sciences 20, 130141.

MacCall, A. 1990. Dynamic geography of marine fish populations. Washington Sea Grant Program, Seattle, WA.

Magnusson, L., Alonso-Balmaseda, M., Corti, S., Molteni, F., Stockdale, T., 2013. Evaluation of forecast strategies for seasonal and decadal forecasts in presence of systematic model errors. Climate Dynamics 41, 2393-2409. 
Mahanama, S., Livneh, B., Koster, R., Lettenmaier, D., Reichle, R., 2012. Soil Moisture, Snow, and Seasonal Streamflow Forecasts in the United States. Journal of Hydrometeorology $13,189-203$.

Makino, A., Yamano, H., Beger, M., Klein, C.J., Yara, Y., Possingham, H.P., 2014. Spatiotemporal marine conservation planning to support high-latitude coral range expansion under climate change. Diversity and Distributions 20, 859-871.

Mantua, N.J., Hare, S.R., Zhang, Y., 1997. A Pacific interdecadal climate oscillation with impacts on salmon production. Bulletin of the American Meteorological Society 78, 1069-1079.

Marchesiello, P., McWilliams, J.C., Shchepetkin, A., 2001. Open boundary conditions for longterm integration of regional oceanic models. Ocean Modelling 3, 1-20.

Marine Stewardship Council, 2014. Fisheries Standard. Available at: https://www.msc.org/documents/scheme-documents/fisheries-certification-schemedocuments/fisheries-certification-scheme-documents\#standard [Accessed January 1, 2016].

Marshall, N.A., Gordon, I.J., Ash, A.J., 2011. The reluctance of resource-users to adopt seasonal climate forecasts to enhance resilience to climate variability on the rangelands. Climate Change Economics 107, 511-529.

Mason, S.J., Baddour, O., 2007. Statistical Modelling. In A. Troccoli, M. Harrison, D. L. T. Anderson, S. J. Mason (Eds.), Seasonal Climate: Forecasting and Managing Risk (167206). Dordrecht: Springer Academic Publishers.

Mason, S.J., Stephenson, D.B., 2007. How do we know whether seasonal climate forecasts are any good? In A. Troccoli, M. Harrison, D. L. T. Anderson, S. J. Mason (Eds.), Seasonal Climate: Forecasting and Managing Risk (167-206). Dordrecht: Springer Academic Publishers.

Maunder, M.N., Punt, A.E., 2013. A review of integrated analysis in fisheries stock assessment. Fisheries Research 142, 61-74.

Maunder, M.N., Watters, G.M., 2003. A general framework for integrating environmental time series into stock assessment models: model description, simulation testing, and example. Fishery Bulletin 101, 89-99. 
2159

2160

2161

2162

2163

2164

2165

2166

2167

2168

2169

2170

2171

2172

2173

2174

2175

2176

2177

2178

2179

2180

2181

2182

2183

2184

2185

2186

2187

2188

2189

Maxwell, S.M., Hazen, E.L., Lewison, R.L., Dunn, D.C., Bailey, H., Bograd, S., Briscoe, D.K., Fossette, S., Hobday, A.J., Bennett, M., Benson, S., Caldwell, M.R., Costa, D.P., Dewar, H., Eguchi, T., Hazen, L., Kohin, S., Sippel, T., Crowder, L.B., 2015. Dynamic ocean management: Defining and conceptualizing real-time management of the ocean. Marine Policy 58, 42-50.

Maynard, J., van Hooidonk, R., Harvell, C.D., Eakin, C.M., Liu, G., Willis, B.L., Williams, G.J., Groner, M.L., Dobson, A., Heron, S.F., Glenn, R., Reardon, K., Shields, J.D., 2016. Improving marine disease surveillance through sea temperature monitoring, outlooks and projections. Philosophical Transactions of the Royal Society B 371, 20150208, doi: 0.1098/rstb.2015.0208.

McCabe, R.M., Hickey, B.M., Kudela, R.M., Lefebvre, K.A., Adams, N.G., Bill, B.D., Gulland, F.M.D., Thomson, R.E., Cochlan, W.P., Trainer, V.L. 2016. An unprecedented coastwide toxic algal bloom linked to anomalous ocean conditions. Geophysical Research Letters 43, 10366-10376, doi:10.1002/2016GL070023.

McGilliard, C.R., Punt, A.E., Methot, Jr., R.D., Hilborn, R., 2015. Accounting for marine reserves using spatial stock assessments. Canadian Journal of Fisheries and Aquatic Sciences 72, 262-280.

McGillicuddy Jr, D.J., Townsend, D.W., He, R., Keafer, B.A., Kleindinst, J.L., Manning, J.P., Mountain, D.G., Thomas, M.A., Anderson, D.M., 2011. Suppression of the 2010 Alexandrium fundyense bloom by changes in physical, biological, and chemical properties of the Gulf of Maine. Limnology and Oceanography 56, 2411-2426.

McGoodwin, J. R., 2007. Effects of climatic variability on three fishing economies in high latitude regions: Implications for fisheries policies. Marine Policy 31, 40-55.

McIlgorm, A., Hanna, S., Knapp, G., Le Floc'H, P., Millerd, F., Pan, M., 2010. How will climate change alter fishery governance? Insights from seven international case studies. Marine Policy 34, 170-177.

McPhaden, M. J.,1993. TOGA-TAO and the 1991-93 E1 Niño-Southern Oscillation event. Oceanography 6, 36-44.

Meehl, G.A., Goddard, L., Boer, G., Burgman, R., Branstator, G., Cassou, C., Corti, S., Danabasoglu, G., Doblas-Reyes, F., Hawkins, E., Karspeck, A., Kimoto, M., Kumar, A., Matei, D., Mignot, J., Msadek, R., Navarra, A., Pohlmann, H., Rienecker, M., Rosati, A., 
Schineider, E., Smith, D., Sutton, R., Teng, H., van Oldenborgh, G.J., Vecchi, G., Yeager, S., 2014. Decadal climate prediction: An update from the trenches. Bulletin of the American Meteorological Society 95, 243-267.

Meehl, G.A., Teng, H., 2012. Case studies for initialized decadal hindcasts and predictions for the Pacific region. Geophysical. Research Letters 39, L22705, doi: 10.1029/2012GL053423.

Meinke, H., Stone, R., 2005. Seasonal and inter-annual climate forecasting: The new tool for increasing preparedness to climate variability and change in agricultural planning and operations. Climatic Change 70, 221-253.

Methot Jr., R.D., Tromble, G.R., Lambert, D.M., Greene, K.E., 2014. Implementing a sciencebased system for preventing overfishing and guiding sustainable fisheries in the U.S. ICES Journal of Marine Science 71, 183-194.

Methot, Jr., R. D., 2009. Stock Assessment: Operational Models in Support of Fisheries Management. In: Future of Fisheries Science - Proceedings of the $50^{\text {th }}$ Annual Symposium of the American Institute of Fishery Research biologists, Seattle, WA. Springer. Fish and Fisheries Series 31, pp. 137-165.

Meza, F. J., Hansen, J.W., Osgood, D., 2008. Economic value of seasonal climate forecasts for agriculture: Review of ex-ante assessments and recommendations for future research. Journal of Applied Meteorology and Climatology 47, 1269-1286.

Miller, K.A., Munro, J.R., 2004. Climate and cooperation: A new perspective on the management of shared fish stocks. Marine Resource Economics 19, 367-393.

Miller, T. J., Hare, J.A., Alade, L.A., 2016. A state-space approach to incorporating environmental effects on recruitment in an age-structured assessment model with an application to Southern New England yellowtail flounder. Canadian Journal of Fisheries and Aquatic Sciences 73, 1261-1270.

Mills, K., Pershing, A.J., Brown, C.J., Chen, Y., Chiang, F-S., Holland, D.S., Lehuta, S., Nye, J.A., Sun, J.C., Thomas, A.C., Wahle, R.A., 2013. Fisheries management in a changing climate: Lessons from the 2012 ocean heat wave in the Northwest Atlantic. Oceanography 26, 191-195. 
Msadek, R., Delworth, T.L., Rosati, A., Anderson, W.G., Vecchi, G.A., Chang, Y-S., Dixon, K.W., Gudgel, R.G., Stern, W.F., Wittenberg, A.T., Yang, X-Q., Zeng, F., Zhang, R., Zhang, S., 2014a. Predicting a Decadal Shift in North Atlantic Climate Variability Using the GFDL Forecast System. Journal of Climate 27, 6472-6496, doi: 10.1175/JCLI-D-1300476.1.

Msadek, R., Vecchi, G.A., Winton, M., Gudgel, R.G., 2014b. Importance of initial conditions in seasonal predictions of Arctic sea ice extent. Geophysical Research Letters 41, 52085215.

Milly, P.C.D., Betancourt, J., Falkenmark, M., Hirsch, R.M., Kundzewicz, Z.W., Lettenmaier, D.P., Stouffer, R.J., 2008. Climate change - Stationarity is dead: Whither water management? Science 319, 573-574.

Mo, K.C., Lettenmaier, D.P., 2014. Hydrologic prediction over the conteminous United states using the National Multi-Model Ensemble. Journal of Hydrometeorology 15, 1457-1472. Mochizuki, T., Ishii, M., Kimoto, M., Chikamoto, Y., Watanabe, M., Nozawa, T., Sakamoto, T.T., Shiogama, H., Awaji, T., Sugiura, N., Toyoda, T., Yasunaka, S., Tatebe, H., Mori, M., 2010. Pacific decadal oscillation hindcasts relevant to near-term climate prediction. Proceeding of the National Academy of Science of the United States of America 107, 1833-1837.

Mohn, R.K., Chouinard, G.A., 2007. Harvest control rules for stocks displaying dynamic production regimes. ICES Journal of Marine Science 64, 693-697.

Morgan, M. J., Shelton, P.A., Rideout, R.M., 2014. An evaluation of fishing mortality reference points under varying levels of population productivity in three Atlantic cod (Gadus morhua) stocks. ICES Journal of Marine Science 71, 1407-1416.

Moss, R.H., Edmonds, J.A., Hibbard, K.A., Manning, M.R., Rose, S.K., van Vuuren, D.P., Carter, T.R., Emori, S., Kainuma, M., Kram, T., Meehl, G.A., Mitchell, J.F.B., Nakicenovic, N., Riahl, K., Smith, S.J., Stouffer, R.J., Thomson, A.M., Weyant, J.P., Wilbanks, T.J., 2010. The next generation of scenarios for climate change research and assessment. Nature 463, 747-756.

Mueter, F.J., Bond, N.A., Ianelli, J.N., Hollowed, A.B., 2011. Expected declines in recruitment of walleye pollock (Theragra chalcogramma) in the eastern Bering Sea under future climate change. ICES Journal of Marine Science 68, 1284-1296. 
Munch, S.B., Kottas A., 2009. A Bayesian modeling approach for determining productivity regimes and their characteristics. Ecological Applications 19, 527-537.

Muñoz, Á. G., López, P., Velásquez, R., Monterrey, L., León, G., Ruiz, F., Recalde, C., Cadena, J., Mejía, R., Paredes, M., Bazo, J., Reyes, C., Carrasco, G., Castellón, Y., Villarroel, C., Quintana, J., Urdaneta, A., 2010. An Environmental Watch System for the Andean Countries: El Observatorio Andino. Bulletin of the American Meteorological Society 91, $1645-1652$.

Murakami, H., Vecchi, G.A., Underwood, S., Delworth, T., Wittenberg, A.T., Anderson, W., Chen, J.-H., Gudgel, R., Harris, L., Lin, S.-J., Zeng, F., 2015. Simulation and prediction of Category 4 and 5 hurricanes in the high-resolution GFDL HiFLOR coupled climate model. Journal of Climate 28, 9058-9079.

Murakami, H., Vecchi, G.A., Villarini, G., Delworth, T.L., Gudgel, R., Underwood, S., Yang, X., Zhang, W., Lin, S.-J., In review. Seasonal Forecasts of Category 4 and 5 Hurricanes and Landfalling Tropical Cyclones using a High-Resolution GFDL Coupled Climate Model. Geophysical Research Letters.

Murphy, G.L., 1966. Population biology of the Pacific sardine (Sardinops Caerulea). Proceedings of the California Academy of Sciences 34, 1-79.

Myers, R.A., 1998. When do environment-recruitment correlations work? Reviews in Fish Biology and Fisheries 8, 285-305.

Newman, M., Alexander, M.A., Scott, J.D., 2011. An empirical model of tropical ocean dynamics. Climate Dynamics 37, 1823-1841.

Nicholls, N., 1999. Cognitive illusions, heuristics, and climate prediction. Bulletin of the American Meteorological Society 80, 2217-2238.

Nielsen, A., Berg, C.W., 2014. Estimation of time-varying selectivity in stock assessments using state-space models. Fisheries Research 158, 96-101.

Nye, J.A., Link, J.S., Hare, J.A., Overholtz, W.J., 2009. Changing spatial distribution of fish stocks in relation to climate and population size on the Northeast United States continental shelf. Marine Ecology Progress Series 393, 111-129.

Ottersen, G., Stige, L.C., Durant, J.M., 2013. Temporal shifts in recruitment dynamics of North Atlantic fish stocks: effects of spawning stock and temperature. Marine Ecology Progress Series 480, 205-225. 
2273

2274

2275

2276

2277

2278

2279

2280

2281

2282

2283

2284

2285

2286

2287

2288

2289

2290

2291

2292

2293

2294

2295

2296

2297

2298

2299

2300

2301

2302

2303

Pacific Fishery Management Council and National Marine Fisheries Service, 2014. Draft Environmental Impact Statement (DEIS) for proposed Harvest Specifications and Management Measures for the Pacific Coast Groundfish Fishery and Amendment 24 to The Pacific Coast Groundfish Fishery Management Plan. 1074 pp. PFMC and NMFS, Portand, OR and Seattle, WA.

Palmer, M.C., Deroba, J.J., Legault, C.M., Brooks, E.N., 2016. Comment on "Slow adaptation in the face of rapid warming leads to collapse of the Gulf of Maine cod fishery." Science $352,423$.

Pauly D., Alder J., Booth S., Cheung W.W.L., Close C., Sumaila U.R., Swartz W., et al., 2008. Fisheries in large marine ecosystems: Descriptions and diagnoses. In The UNEP Large Marine Ecosystems Report: A Perspective on Changing Conditions in LMEs of the World's Regional Seas, pp. 23-40. Ed. by Sherman K., Hempel G.. UNEP, Nairobi, Kenya.

Payne, M.R., Hatfield, E.M.C., Dickey-Collas, M., Falkenhaug, T., Gallego, A., Gröger, J., Licandro, P., Llope, M., Munk, P., Röckmann, C., Schmidt, J.O., Nash, R.D.M., 2009. Recruitment in a changing environment: the 2000s North Sea herring recruitment failure. ICES Journal of Marine Science 66, 272-277.

Payne, M.R., Egan, A., Fässlerm S.M.M., Hátún, H., Holst, J.C., Jacobsen, J.A., Slotte, A., Loeng, H., 2012. The rise and fall of the NE Atlantic blue whiting (Micromesistus poutassou). Marine Biology Research 8, 475-487.

Payne, M.R., Barange, M., Cheung, W.W.L., MacKenzie, B.R., Batchelder, H.P., Cormon, X., Eddy, T.D., Fernandes, J.A., Hollowed, A.B., Jones, M.C., Link, J.S., Neubauer, P., Ortiz, I., Queiros, A.M., Paula, J.R., 2016. Uncertainties in projecting climate-change impacts in marine ecosystems. ICES Journal of Marine Science 73, 1272-1282.

Peck, M.A., Reglero, P., Takahashi, M., Catalán, I.A., 2013. Life cycle ecophysiology of small pelagic fish and climate-driven changes in populations. Progress in Oceanography 116, 220-245.

Perälä, T., Kuparinen, A., 2015. Detecting regime shifts in fish stock dynamics. Canadian Journal of Fisheries and Aquatic Sciences 72, 1619-1628.

Perry, A. L., Low, P.J., Ellis, J.R., Reynolds, J.D., 2005. Climate change and distribution shifts in marine fishes. Science 308, 1912-1915. 
2304

2305

2306

2307

2308

2309

2310

2311

2312

2313

2314

2315

2316

2317

2318

2319

2320

2321

2322

2323

2324

2325

2326

2327

2328

2329

2330

2331

2332

2333

Perry, R.I., Cury, P., Brander, K., Jennings, S., Möllman, C., Planque, B., 2010. Sensitivity of marine systems to climate and fishing: Concepts, issues and management responses. Journal of Marine Systems 79, 427-435.

Pershing, A.J., Alexander, M.A., Hernandez, C.M., Kerr, L.A., Le Bris, A., Mills, K.E., Nye, J.A., Record, N.R., Scannell, H.A., Scott, J.D., Sherwood, G.D., Thomas, A.C., 2015. Slow adaptation in the face of rapid warming leads to collapse of the Gulf of Maine cod fishery. Science 350, 809-812.

Peterman, R.M., Pyper, B.J., Grout, J.A., 2000. Comparison of parameter estimation methods for detecting climate-induced changes in productivity of Pacific salmon (Oncorhynchus spp.). Canadian Journal of Fisheries and Aquatic Sciences 57, 181-191.

Peterman, R.M., Pyper, B.J., MacGregor, B.W., 2003. Use of the Kalman filter to reconstruct historical trends in productivity of Bristol Bay sockeye salmon (Oncorhynchus nerka). Canadian Journal of Fisheries and Aquatic Sciences 60, 809-824.

Peterman, R.M., Dorner, B., 2012. A widespread decrease in productivity of sockeye salmon (Oncorhynchus nerka) populations in Western North America. Canadian Journal of Fisheries and Aquatic Sciences 69, 1255-1260.

Phillips, S.J., Anderson, R.P., Schapire, R.E., 2006. Maximum entropy modeling of species geographic distributions. Ecological Modelling 190, 231-259.

Piechota, T.C., Dracup, J.A., 1999. Long-Range Streamflow Forecasting Using El NiñoSouthern Oscillation Indicators. Journal of Hydrologic Engineering 4, 144-151.

Pikitch, E.K., Santora, C., Babock, E.A., Bakun, A., Bonfil, R., Conover, D.O., Dayton, P., Doukakis, P., Fluharty, D., Heneman, B., Houde, E.D., Link, J., Livingston, P.A., Mangel, M., McAlister, M.K., Pope, J., Sainsbury, K.J., 2004. Ecosystem-based fishery management. Science 305, 346-347.

Pinsky, M.L., Mantua, N.J., 2014. Emerging Adaptation Approaches for climate ready fisheries management. Oceanography 27, 146-159.

Pinsky, M.L., Worm, B., Fogarty, M.J., Sarmiento, J.L., Levin, S.A., 2013. Marine taxa track local climate velocities. Science 341, 1239-1242.

Platt, T., Fuentes-Yaco, C., Frank, K.T., 2003. Spring algal bloom and larval fish survival. Nature 423, 398-399. 
2334

2335

2336

2337

2338

2339

2340

2341

2342

2343

2344

2345

2346

2347

2348

2349

2350

2351

2352

2353

2354

2355

2356

2357

2358

2359

2360

Plagányi, E.E., Punt, A.E., Hillary, R., Morello, E.B., Thébaud, O., Hutton, T., Pillans, R.D., Thorson, J.T., Fulton, E.A., Smith, A.D.M., Smith, F., Bayliss, P., Haywood, M., Lyne, V., Rothlisberg, P.C., 2014. Multispecies fisheries management and conservation: tactical applications using models of intermediate complexity. Fish and Fisheries 15, 1-22.

Pohlmann, H., Jungclaus, J.H., Kohl, A., Stammer, D., Marotzke, J., 2009. Initializing decadal climate predictions with the GECCO oceanic synthesis: Effects on the North Atlantic. Journal of Climate 22, 3926-3938.

Poloczanska, E.S., Brown, C.J., Sydeman, W.J., Kiessling, W., Schoeman, D.S., Moore, P.J., Brander, K., Bruno, J.F., Buckley, L.B., Burrows, M.T., Duarte, C.M., Halpern, B.S., Holding, J., Kappel, C.V., O’Connor, M.I., Pandolfi, J.M., Parmesan, C., Schwing, F., Thompson, S.A., Richardson, A.J., 2013. Global imprint of climate change on marine life. Nature Climate Change 3, 919-925.

Pörtner, H.O., Knust, R., 2007. Climate change affects marine fishes through the oxygen limitation of thermal tolerance. Science 315, 95-97.

Pörtner, H.O., Farrell, A.P., 2008. Physiology and Climate Change. Science 322, 690-692.

Punt, A.E., 2011. The impact of climate change on the performance of rebuilding strategies for overfished groundfish species of the U.S. west coast. Fisheries Research 109, 320-329.

Punt, A.E., A'mar, Z.T., Bond, N.A., Butterworth, D.S., de Moor, C.L., De Oliveira, J.A.A., Haltuch, M.A., Hollowed, A.B., Szuwalski, C., 2014a. Fisheries management under climate and environmental uncertainty: control rules and performance simulation. ICES Journal of Marine Science 71, 2208-2220.

Punt, A.E., Szuwalski, C.S., Stockhausen, W., 2014b. An evaluation of stock-recruitment proxies and environmental change points for implementing the US Sustainable Fisheries Act. Fisheries Research 157, 28-40.

Quinn, T.J., Deriso, R.B., 1999. Quantitative Fish Dynamics. Oxford University Press, Oxford. Randall, D.A., Wood, R.A., Bony, S., Colman, R., Fichefet, T., Fyfe, J., Kattsov, V., Pitman, A., Shukla, J., Srinivasan, J., Stouffer, R.J., Sumi, A., Taylor, K. E., 2007. Climate models and their evaluation. In: Solomon, S., Qin, D., Manning, M., Chen, Z., Marquis, M., Averyt, K.B., Tignor, M., Miller, H.L. (Eds), Climate Change 2007: The Physical Science Basis, Contribution of Working Group I to the Fourth Assessment Report of the 
Intergovernmental Panel on Climate Change, Cambridge University Press, Cambridge, UK, and New York, pp. 589-662.

Richardson, D.S. 2000. Skill and relative economic value of the ECMWF ensemble prediction system. Quarterly Journal of the Royal Meteorological Society 126, 649-667.

Robson, J.I., Sutton, R., Lohmann, K, Smith, D., 2012. Causes of the rapid warming of the North Atlantic Ocean in the mid-1990s. Journal of Climate 25, 4116-4134.

Rodgers, K.B., Lin, J., Frölicher, T.L., 2015. Emergence of multiple ocean ecosystem drivers in a large ensemble suite with an Earth system model. Biogeosciences 12, 3301-3320.

Rose, K.A., Allen, J.I., Artioli, Y., Barange, M., Blackford, J., Carlotti, F., Cropp, R., Daewel, U., Edwards, K., Flynn, K., Hill, S., Hille Ris Lambers, R., Huse, G., Mackinson, S., Megrey, B.A., Moll, A., Rivkin, R., Salihoglu, B., Schrum, C., Shannon, L., Shin, Y., Smith, S.L., Smith, C., Solidoro, C., St John, M., Zhou, M., 2010. End-to-end models for the analysis of marine ecosystems: challenges, issues, and next steps. Marine and Coastal Fisheries: Dynamics, Management and Ecosystem Science 2, 115-130.

Rutterford, L.A., Simpson, S.D., Jennings, S., Johnson, M.P., Blanchard, J.L., Schön, P-J., Sims, D.W., Tinker, J., Genner, M.J., 2015. Future fish distributions constrained by depth in warming seas. Nature Climate Change 5, 569-573.

Saba, G.K., Fraser, W.R., Saba, V.S., Iannuzzi, R.A., Coleman, K.E., Doney, S.C., Ducklow, H.W., Martinson, D.G., Miles, T.N., Patterson-Fraser, D.L., Stammerjohn, S.E., Steinberg, D.K., Schofield, O.M., 2013. Winter and spring controls on the summer food web of the coastal West Antartica Peninsula. Nature Communications 5, 4318, doi: 10.1038/ncomms5318.

Saba, V.S., Griffies, S.M., Anderson, W.G., Winton, M., Alexander, M.A., Delworth, T.L., Hare, J.A., Harrison, M.J., Rosati, A., Vecchi, G.A., Zhang, R., 2016. Enhanced warming of the Northwest Atlantic Ocean under climate change. Journal of Geophysical ResearchOceans 121, 118-132.

Saha, S., Nadiga, S., Thiaw, C., Wang, J., Wang, W., Zhang, Q., van den Dool, H.M., Pan, H-L., Moorthi, S., Behringer, D., Stockes, D., Pena, M., Lord, S., White, G., Ebisuzaki, W., Peng, P., Xie, P., 2006. The NCEP climate forecast system. Journal of Climate 19, 34833517. 
Sainsbury, K.J., Punt, A.E., Smith, A.D.M., 2000. Design of operational management strategies for achieving fishery ecosystem objectives. ICES Journal of Marine Science 57, 731-741.

Salinger, J., Hobday, A.J., Matear, R., O'Kane, T.J., Risbey, J., Eveson, J.P., Fulton, E.A., Feng, M., Plaganyi, E.E., Poloczanska, E., Marshall, A., Thompson P.A., 2016. Decadal-scale forecasting of climate drivers for marine applications. Advances in Marine Biology 74, 168.

Sansom, P.G., Ferro, C.A.T., Stephenson, D.B., Goddard, L., Mason, S.J., 2016. Best practices for post-processing ensemble climate forecasts, part I: selecting appropriate recalibration methods. Journal of Climate 29, 7247-7264.

Schindler, D.E., Hilborn, R., 2015. Prediction, precaution, and policy under global change. Science 347, 953-954.

Schirripa, M.J., Colbert J.J., 2006. Interannual changes in sablefish (Anoplopoma fimbria) recruitment in relation to oceanographic conditions within the California Current System. Fisheries Oceanography 15, 25-36.

Schirripa, M.J., Goodyear, C.P., Methot, R.M., 2009. Testing different methods of incorporating climate data into the assessment of US West Coast sablefish. ICES Journal of Marine Science 66, 1605-1613.

Shackell, N.L., Ricard, D., Stortini, C., 2014. Thermal habitat index of many Northwest Atlantic temperate species stays neutral under warming projected for 2030 but changes radically by 2060 . Plos One 9, e90662.

Sharp, G.D., 1987. Climate and fisheries: cause and effect or managing the long and short of it all. South African Journal of Marine Science 5, 811-838.

Shukla, S., Sheffield, J., Wood, E.F., Lettenmaier, D.P., 2013. On the sources of global land surface hydrologic predictability. Hydrology and Earth System Science 17, 2781-2796.

Séférian, R., Bopp, L., Gehlen, M., Swingedouw, D., Mignot, J., Guilyardi, E., Servonnat, J., 2014. Multiyear predictability of tropical marine productivity. Proceedings of the National Academy of Sciences of the United States of America 111, 11646-11651.

Senina, I., Sibert, J., Lehodey, P., 2008. Parameter estimation for basin-scale ecosystem-linked population models of large pelagic predators: Application to skipjack tuna. Progress in Oceanography 78, 319-335.

Servonnat, J., Mignot, J., Guilyardi, E., Swingedouw, D., Séférian, R., Labetoulle, S., 2014. 
Reconstructing the subsurface ocean decadal variability using surface nudging in a perfect model framework. Climate Dynamics 44, 1-24.

Sibert, J., Senina, I., Lehodey, P., Hampton, J., 2012. Shifting from marine reserves to maritime zoning for conservation of Pacific bigeye tuna (Thunnus obesus). Proceedings of the National Academy of Sciences of the United States of America 109, 18221-18225.

Siedlecki, S.A., Kaplan, I.C., Hermann, A.J., Nguyen, T.T., Bond, N.A., Newton, J.A., Williams, G.D., Peterson, W.T., Alin, S.R., Feely, R.A., 2016. Experiments with seasonal forecasts of ocean conditions for the Northern region of the California Current upwelling system. Scientific Reports 6, 27203, doi: 10.1038/srep27203.

Sigmond, M., Fyfe, J.C., Flato, G.M., Kharin, V.V., Merryfield, W.J., 2013. Seasonal forecast skill of Arctic sea ice area in a dynamical forecast system. Geophysical Research Letters 40, 529-534, doi: 10.1002/grl.50129.

Skern-Mauritzen, M., Ottersen, G., Handegard, N.O., Huse, G., Dingsor, G.E., Stenseth, N.C., Kjesbu, O.S., 2015. Ecosystem processes are rarely included in tactical fisheries management. Fish and Fisheries 17, 165-175.

Smith, A.D.M., Fulton, E.A., Hobday, A.J., Smith, D.C., Shoulder, P. 2007. Scientific tools to support practical implementation of ecosystem based fisheries management. ICES Journal of Marine Science 64, 633-639.

Smith, A.D.M., Brown, C.J., Bulman, C.M., Fulton, E.A., Johnson, P., Kaplan, I.C., LozanoMontes, H., Mackinson, S., Marzloff, M., Shannon, L.J., Shin, Y-J, Tam, J., 2011. Impacts of fishing low trophic level species on marine ecosystems. Science 333, 11471150.

Smith, D.M., Eade, R., Pohlmann, H., 2013. A comparison of full-field and anomaly initialization for seasonal to decadal climate prediction. Climate Dynamics 41, 33253338.

Spillman C.M., 2011. Operational real-time seasonal forecasts for coral reef management. Journal of Operational Oceanography 4, 13-22.

Spillman, C.M., Alves, O., 2009. Dynamical seasonal prediction of summer sea surface temperatures in the Great Barrier Reef. Coral Reefs 28, 197-206. 
Spillman, C.M., Heron, S.F., Jury, M.R., Anthony, K.R.N., 2011. Climate change and carbon threats to coral reefs national meteorological and ocean services as sentinels. Bulletin of the American Metereological Society 92, 1581-1586.

Spillman, C.M., Hobday, A.J., 2014. Dynamical seasonal ocean forecasts to aid salmon farm management in a climate hotspot. Climate Risk Management 1, 25-38.

Spillman, C.M., Hartog, J.R., Hobday, A.J., Hudson, D., 2015. Predicting environmental drivers for prawn aquaculture production to aid improved farm management. Aquaculture 447: $56-65$.

Stammer, D., Balmaseda, M., Heimbach, P., Köhl, A., Weaver, A., 2016. Ocean data assimilation in support of climate applications: Status and perspectives. Annual Reviews in Marine Science 8, 491-518.

Stanski, H.R., Wilson, L.J., Burrows, W.R., 1989. Survey of common verification methods in meteorology. WMO World Weather Watch Technical Report No. 8, WMO/TD No. 358.

Stock, C.A., Alexander, M.A., Bond, N.A., Brander, K.M., Cheung, W.L., Curchitser, E.N., Delworth, T.L., Dunne, J.P., Griffies, S.M., Haltuch, M.A., Hare, J.A., Hollowed, A.B., Lehodey, P., Levin, S.A., Link, J.S., Rose, K.A., Rykaczewski, R.R., Sarmiento, J.L., Stouffer, R.J., Schwing, F.B., Vecchi, G.A., 2011. On the use of IPCC-class models to assess the impact of climate on Living Marine Resources. Progress in Oceanography 88, $1-27$.

Stock, C. A., Pegion, K., Vecchi, G.A., Alexander, M.A., Tommasi, D., Bond, N.A., Fratantoni, P.S., Gudgel, R.G., Kristiansen, T., O’Brien, T.D., Xue, Y., Yang, X., 2015. Seasonal sea surface temperature anomaly prediction for coastal ecosystems. Progress in Oceanography 137, 219-236.

Stockdale, T.N., Anderson, D.L.T., Balmaseda, M.A., Doblas-Reyes, F., Ferranti, L., Mogensen, K., Palmer, T.N., Molteni, F., Vitart, F., 2011. ECMWF seasonal forecast system 3 and its prediction of sea surface temperature. Climate Dynamics 37, 455-471.

Stroeve, J.C., Kattsov, V., Barrett, A., Serreze, M., Pavlova, T., Holland, M., Meier, W.N., 2012. Trends in Arctic sea ice extent from CMIP5, CMIP3 and observations. Geophysical Research Letters 39, L16502, doi:10.1029/2012GL052676. 
Stroeve, J., Hamilton, L.C., Bitz, C.M., Blanchard-Wrigglesworth, E., 2014. Predicting September sea ice: Ensemble skill of the SEARCH Sea Ice Outlook 2008-2013. Geophysical Research Letters 41, 2411-2418.

Stumpf, R.P., Culver, M.A., 2003. Forecasting harmful algal blooms in the Gulf of Mexico. NOAA Technical Memorandum NOS NCCOS 1, 51-54.

Svensson, C., 2016. Seasonal river flow forecasts for the United Kingdom using persistence and historical analogues. Hydrological Sciences Journal 61, 19-35.

Svensson, C., Brookshaw, A., Scaife, A.A., Bell, V.A., Mackay, J.D., Jackson, C.R., Hannaford, J., Davies, H.N., Arribas, A., Stanley, S., 2015. Long-range forecasts of UK winter hydrology. Environmental Research Letters 10, 064006.

Szuwalski, C.S., Punt, A.E. 2013. Fisheries management for regime-based ecosystems: a management strategy evaluation for the snow crab fishery in the eastern Bering Sea. ICES Journal of Marine Science 70, 955-967.

Takle, E.S., Anderson, C.J., Andresen, J., Angel, J., Elmore, R.W., Graming, B.M., Guinan, P., Hilberg, S., Kluck, D., Massey, R., Niyogi, D., Schneider, J.M., Shulski, M.D., Todey, D., Widhalm, M., 2014. Climate Forecasts for Corn Producer Decision Making. Earth Interactions $18,1-8$.

Thomas, C.R., Heron, S.F., 2011. South-East Asia Coral Bleaching Rapid Response: Final Report. Commonwealth Scientific and Industrial Research Organization. 20 pp.

Thorson, J.T., Pinsky, M.L., Ward, E.J. 2016. Model-based inference for estimating shifts in species distribution, area occupied and centre of gravity. Methods in Ecology and Evolution 7, 990-1002.

Tranchant, B., Reffray, G., Greiner, E., Nugroho, D., Koch-Lattouy, A., Gaspar, P., 2016. Evaluation of an operational ocean model configuration at $1 / 12^{\circ}$ spatial resolution for the Indonesian seas (NEMO2.3/INDO12) - Part 1: Ocean physics. Geoscientific Model Development 9, 1037-1064.

Travers, M., Shin, Y.J., Jennings, S., Cury, P., 2007. Towards end-to-end models for investigating the effects of climate and fishing in marine ecosystems. Progress in Oceanography $75,751-770$. scp 
Tribbia, J., Troccoli, A. 2007. Getting the coupled model ready at the starting blocks. In A. Troccoli, M. Harrison, D. L. T. Anderson, S. J. Mason (Eds.), Seasonal Climate: Forecasting and Managing Risk (93-128). Dordrecht: Springer Academic Publishers. Tommasi, D., Stock, C., Pegion, K., Vecchi, G.A., Methot, R.D., Alexander, M., Checkley, D., Accepted. Improved management of small pelagic fisheries through seasonal climate prediction. Ecological Applications, doi: 10.1002/eap.1458.

Tommasi, D., Nye, J., Stock, C., Hare, J.A., Alexander, M., Drew, K., 2015. Effect of environmental conditions on juvenile recruitment of alewife (Alosa pseudoharengus) and blueback herring (Alosa aestivalis) in freshwater: a coastwide perspective. Canadian Journal of Fisheries and Aquatic Sciences 72, 1037-1047.

van den Dool, H. 2007. Empirical Methods in Short-term Climate Prediction. Oxford, UK: Oxford University Press.

van Hooidonk, R., Maynard, J.A., Liu, Y.Y., Lee, S.K., 2015. Downscaled projections of Caribbean coral bleaching that can inform conservation planning. Global Change Biology 21, 3389-3401.

van Keeken, O. A., van Hoppe, M., Grift, R.E., Rijnsdorp, A.D., 2007. Changes in the spatial distribution of North Sea plaice (Pleuronectes platessa) and implications for fisheries management. Journal of Sea Research 57, 187-197.

van Putten, E.I., Farmery, A., Green, B.S., Hobday, A.J., Lim-Camacho, L., Norman-López, A., Parker, R. 2015. The environmental impact of two Australian rock lobster fishery supply chains under a changing climate. Journal of Industrial Ecology, doi: 10.1111/jiec.12382. van Vuuren, D.P., Edmonds, J., Kainuma, M., Riahi, K., Thomson, A., Hibbard, K., Hurtt, G.C., Kram, T., Krey, V., Lamarque, J-F., Matsui, T., Meinshausen, M., Nakicenovic, N., Smith, S.J., Rose, S.K., 2011. Representative concentration pathways: An overview. Climatic Change 109, 5-31.

Vanhatalo, J., Hobday, A.J., Little, L.R., Spillman, C.M., 2016. Downscaling and extrapolating dynamic seasonal marine forecasts for coastal ocean users. Ocean Modelling 100, 20-30. Vaughan, C., Dessai, S., 2014. Climate services for society: origins, institutional arrangements, and design elements for an evaluation framework. WIREs Climate Change 5, 587-603, doi: 10.1002/wcc.290 
Vecchi, G.A., Zhao, M., Wang, H., Villarini, G., Rosati, A., Kumar, A., Held, I.M., Gudgel, R., 2011. Statistical-Dynamical Predictions of Seasonal North Atlantic Hurricane Activity. Monthly Weather Review 139, 1070-1082.

Vecchi, G.A., Delworth, T., Gudgel, R., Kapnick, S., Rosati, A., Wittenberg, A.T., Zeng, F., Anderson, W., Balaji, V., Dixon, K., Jia, L., Kim, H.-S., Krishnamurthy, L., Msadek, R., Stern, W.F., Underwood, S.D., Villarini, G., Yang, X., Zhang, S., 2014. On the Seasonal Forecasting to Regional Tropical Cyclone Activity. Journal of Climate 27, 7994-8016. Vecchi, G.A., Villarini, G., 2014. Next season's hurricanes. Science 343, 618-619.

Vert-pre, K.A., Amoroso, R.O., Jensen, O.P., Hilborn, R., 2013. Frequency and intensity of productivity regime shifts in marine fish stocks. Proceedings of the National Academy of Sciences of the United States 110, 1779-1784.

Vidard, A., Anderson, D.L., Balmaseda, M., 2007. Impact of ocean observation systems on ocean analysis and seasonal forecasts. Monthly Weather Review 135, 409-429.

Vitart, F., 2006. Seasonal forecasting of tropical storm frequency using a multi-model ensemble. Quarterly Journal of the Royal Meteorological Society 132, 647-666.

Vitart, F., Stockdale, T.N., 2001. Seasonal forecasting of tropical storms using coupled GCM integrations. Monthly Weather Review 129, 2521-2527.

von Storch, H., Zwiers, F.W. 2001. Statistical Analysis in Climate Research. Cambridge, UK: Cambridge University Press.

Wang, E., Zhang, Y., Luo, J., Chiew, F.H.S., Wang, Q.J., 2011. Monthly and seasonal streamflow forecasts using rainfall-runoff modeling and historical weather data. Water Resources Research 47, W05516, doi: 10.1029/2010WR009922.

Wang, H., Schemm, J.K.E., Kumar, A., Wang, W., Long, L., Chelliah, M., Bell, G.D., Peng, P., 2009. A statistical forecast model for Atlantic seasonal hurricane activity based on the NCEP dynamical seasonal forecast. Journal of Climate 22, 4481-4500.

Wang, W., Chen, M., Kumar, A., 2013. Seasonal prediction of Arctic sea ice extent from a coupled dynamical forecast system, Monthly Weather Review 141, 1375-1394.

Warner, T.T., 2011. Numerical Weather and Climate Prediction. Cambridge, UK: Cambridge University Press. 
Wayte, S., 2013. Management implications of including a climate-induced recruitment shift in the stock assessment for jackass morwong (Nemadactylus macropterus) in south-eastern Australia. Fisheries Research 142, 47-55.

Wilderbuer, T., Stockhausen, W., Bond, N., 2013. Updated analysis of flatfish recruitment response to climate variability and ocean conditions in the Eastern Bering Sea. Deep Sea Research II 94, 157-164.

Wilks, D.S. 2011. Statistical Methods in Atmospheric Science. Burlington, MA, USA: Elsevier Academic Press.

Williams, J.W., Jackson, S.T., 2007. Novel climates, no-analog communities, and ecological surprises. Frontiers in Ecology and the Environment 5, 475-482.

Wittenberg, A., Rosati, A., Delworth, T.L., Vecchi, G.A., Zeng, F., 2014. ENSO modulation: Is it decadally predictable? Journal of Climate 27, 2667-2681.

Worm, B., Hilborn, R., Baum, J.K., Branch, T.A., Collie, J.S., Costello, C., Fogarty, M.J., Fulton, E.A., Hutchings, J.A., Jennings, S., Jensen, O.P., Lotze, H.K., Mace, P.M., McClanahan, T.R., Minto, C., Palumbi, S.R., Parma, A.M., Ricard, D., Rosenberg, A.A., Watson, R., Zeller, D., 2009. Rebuilding global fisheries. Science 325, 578-585.

Xue, Y. Wen, C., Kumar, A., Balmaseda, M., Fujii, Y., Alves, O., Martin, M., Yang, X., Vernieres, G., Desportes, C., Lee, T., Ascione, I., Gudgel, R., Ishikawa, I., 2016. In review. A Real-time Ocean Reanalyses Intercomparison Project in the context of tropical Pacific observing system and ENSO monitoring. Climate Dynamics.

Xue, Y., Leetmaa, A., Ji, M., 2000. ENSO prediction with Markov models: The impact of sea level. Journal of Climate 13, 849-871.

Yang, X., Rosati, A., Zhang, S., Delworth, T.L., Gudgel, R.G., Zhang, R., Vecchi, G., Anderson, W., Chang, Y.S., DelSole, T., Dixon, K., Msadek, R., Stern, W.F., Wittenberg, AT., Zeng, F.R., 2013. A predictable AMO-like pattern in the GFDL fully coupled ensemble initialization and decadal forecasting system. Journal of Climate 26, 650-661.

Yang, X., Vecchi, G.A., Gudgel, R.G., Delworth, T.L., Zhang, S., Rosati, A., Jia, L., Stern, W.F., Wittenberg, AT., Kapnick, S., Msadek, R., Underwood, S.D., Zeng, F., Anderson, W., 2015. Seasonal predictability of extratropical storm tracks in GFDL's high-resolution climate prediction model. Journal of Climate 28, 3592-3611. 
Ye, H., Beamish, R.J., Glaser, S.M., Grant, S.C.H., Hsieh, C-H., Richards, L.J., Schnute, J.T., Sugihara, G., 2015. Equation-free mechanistic ecosystem forecasting using empirical dynamic modeling. Proceedings of the National Academy of Sciences of the United States of America 112, E1569-E1576.

Yeager, S., Karspeck, A., Danabasoglu, G., Tribbia, J., Teng, H., 2012. A decadal prediction case study: late twentieth-century North Atlantic Ocean heat content. Journal of Climate 25, 5173-5189, doi: 10.1175/JCLI-D-11-00595.1.

Yuan, X., Wood, E.F., Ma, Z., 2015. A review on climate-model-based seasonal hydrological forecasting: physical understanding and system development. WIREs Water 2, 523-536.

Zador, S., Holsman, K.K., Aydin, K.A., Gaichas, S., In press. Ecosystem considerations in Alaska: the value of qualitative assessments. ICES Journal of Marine Science, doi: 10.1093/icesjms/fsw144.

Zebiak, S.E., Orlove, B., Muñoz, A.G., Vaughan, C., Hansen, J., Troy, T., Thomson, M.C., Lustig, A., Garvin, S., 2015. Investigating El Nino-Southern Oscillation and society relationships. WIREs Climate Change 6, 17-34, doi: 10.1002/wcc.294

Zhang, S., Harrison, M.J., Rosati, A., Witternberg, A.T., 2007. System design and evaluation of coupled ensemble data assimilation for global oceanic climate studies. Monthly Weather Review 135, 3541-3564.

Zhang, S., Han, G., Xue, Y., Ruiz, J.J., 2015. Data Assimilation in Numerical Weather and Climate Models. Advances in Meteorology 2015, 626893, doi: 10.1155/2015/626893.

Zhang, W., Vecchi, G.A., Murakami, H., Delworth, T., Wittenberg, A.T., Rosati, A., Underwood, S., Anderson, W., Harris, L., Gudgel, R., Lin, S.J., Villarini, G., Chen, J.H., 2016. Improved simulation of tropical cyclone response to ENSO in the Western North Pacific in the high-resolution GFDL HiFLOR coupled climate model. Journal of Climate 29, 1391-1415.

Zhao, M., Held, I.M., and Vecchi, G.A., 2010: Retrospective forecasts of the hurricane season using a global atmospheric model assuming persistence of SST anomalies. Monthly Weather Review 138, 3858-3868.

Zinyengere, N., Mhizha, T., Mashonjowa, E., Chipindu, B., Geerts, S., Raes, D., 2011. Using seasonal climate forecasts to improve maize production decision support in Zimbabwe. Agricultural and Forest Meteorology 151, 1792-1799. 


\section{Figure Captions}

2629

2630

2631

2632

2633

2634

2635

2636

2637

2638

2639

2640

2641

2642

2643

2644

2645

2646

2647

2648

2649

2650

2651

2652

2653

2654

2655

2656

2657

2658

2659

2660

2661

2662

2663

2664

2665

2666

2667

2668

2669

2670

2671
Figure 1. Overview of simulation design for seasonal and decadal predictions and climate projections. GHG refers to greenhouse gases. Note that the year for shifting from pre-industrial to historical forcing in climate projections, here set to 1860 , can differ between climate models. "Forcings" in the climate change context refer to specified solar insolation and concentrations of radiatively active atmospheric constituents.

Figure 2. Temperature anomalies at 55-m depth from six different ocean reanalysis products for April 2015 relative to each-product 1981-2010 climatology. The bottom left panel shows the ensemble mean, and the bottom right the ratio of signal (ensemble mean) to noise (ensemble spread).

Figure 3. Left panel: One-month lead probabilistic forecast of SST for summer (June, July, and August, JJA) initialized in May 2016 from the North American Multi-Model Ensemble (NMME). This forecast was produced using all the ensemble members provided by each model participating in the NMME. It therefore reflects both initial condition and model uncertainty. Warm colors (yellow-orange) indicate areas with a significant probability of experiencing uppertercile temperatures, with the probability of such terciles ranging from 40-100\% depending on the degree of shading. Analogous interpretations exist for the anomalously cool (blue colors) or near climatological (gray colors) conditions. Right panel: Ranked probability skill score for the forecast presented in the left panel. The color bar represents the relative improvement of the probability forecast (left panel) over climatology, with 0 indicating no skill over climatology. Note the higher predictive skill in the North Atlantic, North Pacific and at the equator.

Figure 4. May-June surface and bottom temperature/salinity biases (model minus observations) for the US Northeast Continental Shelf. Observations are based on May-June climatologies of NOAA ship-based in situ measurements from 1977 to 2009. Model output is from each climate model's 1990 control simulation (40-year mean). The average global ocean (atmosphere) resolutions for CM2.1, CM2.5FLOR, CM2.5, and CM2.6 are 100-km (200-km), 100-km (50$\mathrm{km}), 25-\mathrm{km}(50-\mathrm{km})$, and $10-\mathrm{km}(50-\mathrm{km})$, respectively. Note that the operational GFDL seasonal climate prediction system uses CM2.5FLOR. Refer to Saba et al. 2016 for further details on the models and experiments.

Figure 5. Temporal and spatial scales of fisheries decisions (circles) and atmospheric weather phenomena (clouds). Atmospheric weather processes adapted from Troccoli et al. (2007), Fig. 2.1. Note that "resilience and sustainability" and "rebuilding plans and protected areas" decisions are made across a range of spatial scales. Here they are associated with large spatial scales to reflect the significant impact of large scale climate processes, such as global climate change, on their outcome.

Figure 6. Anomaly correlation coefficients (ACCs) as a function of forecast initialization month (x-axis) and lead-time (y-axis) in the National Atmospheric and Oceanic Administration (NOAA) Geophysical Fluid Dynamics Laboratory (GFDL) CM2.5 FLOR and NOAA National Centers for Environmental Prediction CFSv2 global climate prediction systems for the Gulf of 
Alaska (GoA) large marine ecosystem (Stock et al. 2015). Note how late winter-early spring SST anomaly prediction skill exceeds persistence at long lead-times (4-12 months). Grey dots indicate ACCs significantly above 0 at a 5\% level; white upward triangles indicate ACCs significantly above persistence at a $10 \%$ level with ACC $>0.5$; white downward triangles indicate ACCs significantly above persistence at a $10 \%$ level with ACC $<0.5$.

Figure 7 Left column: idealized environmental forcing historical time series, and short term forecast ( \pm 1 standard deviation) based on seasonal climate forecast (blue), forecast based on assumption that future conditions will be within the historical variability (red), and truth (black); central columns: probability density function of environmental forcing and of environmentallydependent productivity parameters; right column: productivity historical time series and its oneyear forecast based on a dynamic environmental driver (blue) or on average environmental conditions (red). Arrows represent the different steps of an environmentally-explicit stock assessment framework.

Figure 8. Regional probabilistic forecast skill for maximum air temperature (upper tercile), minimum air temperature (lower tercile), and rainfall (upper tercile) based on tercile probabilities for each lead-time. The skill score corresponds to the ratio of the number of correct forecasts to the total number of forecasts for the period of 1981-2010 (Adapted from Spillman et al., 2015).

Figure 9. Left: Maps showing the average SST for the GAB as forecast by POAMA on 17 Dec 2015 for the next fortnight and the next two calendar months. The mean SST over the whole area shown is given in the top left corner of each map. The black line represents the 200-m contour. Right: Corresponding areas of preferred SBT habitat, where values $>1$ indicate more preferred habitat and values $<1$ indicate less preferred habitat.

Figure 10. Example of the GMRI lobster forecast as delivered to the fishing industry via Twitter on March 24, 2016. The first panel shows the spring temperature from the NERACOOS coastal ocean buoys in spring 2016 (red line) used to generate the forecast. Temperatures in 2016 have been higher than the 2000-2014 average. The second panel shows that SST has been anomalously warm throughout the Maine coastal region for March 2016. The bottom panel is the actual forecast, predicting a $68 \%$ chance that the season will start three weeks earlier than normal, a $31 \%$ chance that it will start two weeks early, and only a $1 \%$ chance that it will begin one week early. The normal high-landings period for Maine lobster is considered to start between July 3 and 10 .

Figure 11. Comparison of (a) Coral Reef Watch 4-Month Bleaching Outlook with (b) 4-month composite of maximum Bleaching Alert Area from real-time satellite data for the same period, August-November 2015. The levels refer to potential bleaching intensity, with possible bleaching starting at a warning thermal stress level, bleaching likely at an Alert Level 1 and bleaching mortality likely at an Alert Level 2. Note successful prediction of severe bleaching in Kiribati and Hawaii.

Figure 12. Probability of sardine presence, for July (left) and August (right) of 2015. These two to three month forecasts are the average of a three-member ensemble, initialized as April $15^{\text {th }}$, May 1, and May $15^{\text {th }}$. Due to relatively warm sea surface temperature, the forecasts predict habitat suitable for sardine throughout the region. The exception is low salinity water for which 
2718

2719

2720

2721

2722

2723

2724

2725

2726

2727

2728

2729

2730

2731

2732

2733

2734

2735

2736

2737

2738

2739

2740

2741

2742

2743

2744

2745

2746

2747

the model would expect sardine to be found at more intermediate rather than warm temperatures. This leads to low probability of presence in the less saline Columbia River plume. Note that recent declines in sardine stock size (which is not included in the model) may be resulting in unoccupied, but suitable, habitat in the northern region.

Figure 13. Example output from the global (top) and regional (bottom) SEAPODYM model configurations developed though the INDESO project.

Figure 14. Habitat maps indicating zones of SBT distribution (see text for explanation of zones), obtained using POAMA seasonal forecasts of ocean temperature. The upper left plot shows the historical daily climatology of the zones (yellow ribbon), the current year's observed zone locations to date (red ribbon) and the latest monthly forecasts of zone location (red stars). The arrows along the other panels indicate whether the zones are moving north or south relative to the POAMA nowcast.

Figure 15. Steps required for successful integration of climate predictions into LMR decision frameworks. (Adapted from Hobday et al., 2016).

\section{Appendix}

Table A1. List of six operational ocean reanalysis products from 1979-present used in the Realtime Ocean Reanalysis Intercomparison Project. See

http://www.cpc.ncep.noaa.gov/products/GODAS/multiora_body.html for a link to download some of these reanalysis products. The data assimilation column lists the observation types used for their estimation (T/S for temperature and salinity; SLA: altimeter-derived sea level anomalies; SST: sea surface temperature, SIC: sea-ice concentration), as well as assimilation techniques used for reanalysis: Ensemble Optimal Interpolation (EnOI), Ensemble Kalman Filter (EnKF), Variational methods (3DVar). The atmospheric surface forcing is usually provided by atmospheric reanalyses, using either direct daily fluxes, or different bulk formulations. There are also systems that use fluxes from coupled data assimilation systems (Coupled DA).

\begin{tabular}{|c|c|c|c|c|c|}
\hline Product & Forcing & $\begin{array}{c}\text { Ocean } \\
\text { Model }\end{array}$ & $\begin{array}{c}\text { Data } \\
\text { Assim. } \\
\text { Method }\end{array}$ & $\begin{array}{c}\text { Ocean } \\
\text { Observations }\end{array}$ & $\begin{array}{c}\text { Analysis } \\
\text { Period }\end{array}$ \\
\hline $\begin{array}{c}\text { NCEP } \\
\text { GODAS } \\
\text { NGODAS })\end{array}$ & NCEP-R2 & $\begin{array}{c}1^{\circ} \times 1 / 3^{\circ} \\
\text { MOM3 }\end{array}$ & 3DVAR & T/SST & 1979-present \\
\hline $\begin{array}{c}\text { GFDL } \\
\text { (ECDA) }\end{array}$ & Coupled DA & $\begin{array}{c}1^{\circ} \times 1 / 3^{\circ} \\
\text { MOM4 }\end{array}$ & EnKF & T/S/SST & 1979-present \\
\hline $\begin{array}{c}\text { BOM } \\
\text { (PEODAS) }\end{array}$ & $\begin{array}{c}\text { ERA40 to 2002; } \\
\text { NCEP-R2 } \\
\text { thereafter }\end{array}$ & $\begin{array}{c}1^{\circ} \times 2^{\circ} \\
\text { MOM2 }\end{array}$ & EnKF & T/S/SST & 1970-present \\
\hline $\begin{array}{c}\text { ECMWF } \\
\text { (ORAS4) }\end{array}$ & $\begin{array}{c}\text { ERA40 to 1988; } \\
\text { ERAi thereafter }\end{array}$ & $\begin{array}{c}1^{\circ} \times 1 / 3^{\circ} \\
\text { NEMO3 }\end{array}$ & 3DVAR & $\begin{array}{c}\text { SLA/T/S/SST/ } \\
\text { SIC }\end{array}$ & 1979-present \\
\hline $\begin{array}{c}\text { JMMA } \\
\text { MOVE-G2) }\end{array}$ & $\begin{array}{c}\text { JRA55 corr }+ \\
\text { CORE Bulk }\end{array}$ & $\begin{array}{c}1^{\circ} \times 0.5^{\circ} \\
\text { MRI.CO }\end{array}$ & 3DVAR & $\begin{array}{c}\text { SLA/T/S/SST/ } \\
\text { SIC }\end{array}$ & 1979-present \\
\hline
\end{tabular}




\begin{tabular}{|c|c|c|c|c|c|}
\hline & & M3 & & & \\
\hline NASA \\
$\begin{array}{c}\text { MERRA } \\
\text { Ocean) }\end{array}$ & MERRA + & $\begin{array}{c}0.5^{\circ} \times 1 / 4^{\circ} \\
\text { MOM4 }\end{array}$ & EnOI & $\begin{array}{c}\text { SLA/T/S/SST/ } \\
\text { SIC }\end{array}$ & 1979 -present \\
\hline
\end{tabular}


2751 Table A2. Living marine resources for which there is a linkage between their dynamics and

2752 environmental variability. These includes those determined by Myers 1998 as robust to re-

2753 evaluation, marked by an *, and those described by Skern-Mauritzen et al. 2015 as making use of

2754 environmental information in their management, marked by a $\uparrow$. For all other examples, the

2755 reference is provided.

2756

\begin{tabular}{|c|c|c|c|}
\hline Species & Region & $\begin{array}{c}\text { Environmental } \\
\text { Driver }\end{array}$ & Reference \\
\hline $\operatorname{Cod} * \dagger$ & Barents Sea & Temperature & \\
\hline $\operatorname{Cod}^{*}$ & Eastern Baltic & Salinity & \\
\hline $\mathrm{Cod}^{*}$ & Labrador & Salinity & \\
\hline $\operatorname{Cod}^{*}$ & NW Atlantic & $\begin{array}{l}\text { Calanus spp. } \\
\text { abundance }\end{array}$ & \\
\hline Eurasian Perch* & $\begin{array}{l}\text { Windemere and } \\
\text { Baltic region }\end{array}$ & Temperature & \\
\hline Pike Perch* & $\begin{array}{l}\text { Netherlands and } \\
\text { Baltic region }\end{array}$ & Temperature & \\
\hline Herring* & $\begin{array}{l}\text { Southern British } \\
\text { Columbia }\end{array}$ & Temperature & \\
\hline Herring* & $\begin{array}{l}\text { Northern } \\
\text { Newfoundland }\end{array}$ & Temperature & \\
\hline Sardine $* \dagger$ & California & Temperature & \\
\hline Sardine $\dagger$ & Mediterranean & Chlorophyll a & \\
\hline Anchovy & Mediterranean & Chlorophyll a & \\
\hline Sea Bass* & South Britain & Temperature & \\
\hline Smallmouth bass* & Lake Opeongo & Temperature & \\
\hline Smallmouth bass* & North Lake Huron & Temperature & \\
\hline White Hake $†$ & $\begin{array}{l}\text { Southeastern Atlantic } \\
\text { (West Africa) }\end{array}$ & NAO & \\
\hline Mutton Snapper $\dagger$ & $\begin{array}{l}\text { South Atlantic/Gulf } \\
\text { of Mexico }\end{array}$ & $\begin{array}{l}\text { Temperature and } \\
\text { salinity }\end{array}$ & \\
\hline Yellowtail flounder* & $\begin{array}{l}\text { Southern New } \\
\text { England }\end{array}$ & Temperature & \\
\hline Plaice* & Kattegat & Wind & \\
\hline Skipjack tuna $\dagger$ & Eastern Pacific & $\begin{array}{l}\text { Temperature, ocean } \\
\text { currents, primary } \\
\text { production }\end{array}$ & \\
\hline Swordfish $\dagger$ & Southeastern Pacific & $\begin{array}{l}\text { Ocean climate, } \\
\text { hydrography, primary } \\
\text { production }\end{array}$ & \\
\hline
\end{tabular}




\begin{tabular}{|l|l|l|l|}
\hline Striped Marlin† & Northeastern Pacific & $\begin{array}{l}\text { Ocean climate, } \\
\text { hydrography, primary } \\
\text { production }\end{array}$ & \\
\hline Pacific hake & California Current & Ocean currents & Agostini et al. 2006 \\
\hline Sablefish & California Current & $\begin{array}{l}\text { Ekman transport, sea } \\
\text { level }\end{array}$ & $\begin{array}{l}\text { Schirripa and Colbert } \\
\text { 2006 }\end{array}$ \\
\hline Pink salmon $\dagger$ & North Pacific & $\begin{array}{l}\text { Temperature and prey } \\
\text { availability }\end{array}$ & $\begin{array}{l}\text { PDO and prey } \\
\text { availability }\end{array}$ \\
\hline $\begin{array}{l}\text { Coho and Chinook } \\
\text { Salmon }\end{array}$ & Columbia River & $\begin{array}{l}\text { Peterson and } \\
\text { Schwing 2003, Bi et } \\
\text { al. 2011, Peterson } \\
\text { and Burke 2013, } \\
\text { Burke et al. 2013) }\end{array}$ \\
\hline Chinook Salmon & Snake River & $\begin{array}{l}\text { Air temperature, river } \\
\text { flow, upwelling, PDO }\end{array}$ & Zabel et al. 2013 \\
\hline Lobster* & Gulf of Maine & Temperature & \\
\hline Northern shrimp* & Gulf of Maine & Temperature & \\
\hline Banana prawn* & Gulf of Carpentaria & Salinity & \\
\hline
\end{tabular}




\section{Global Climate Observing System}

e.g. satellites, Argo, meteorological stations
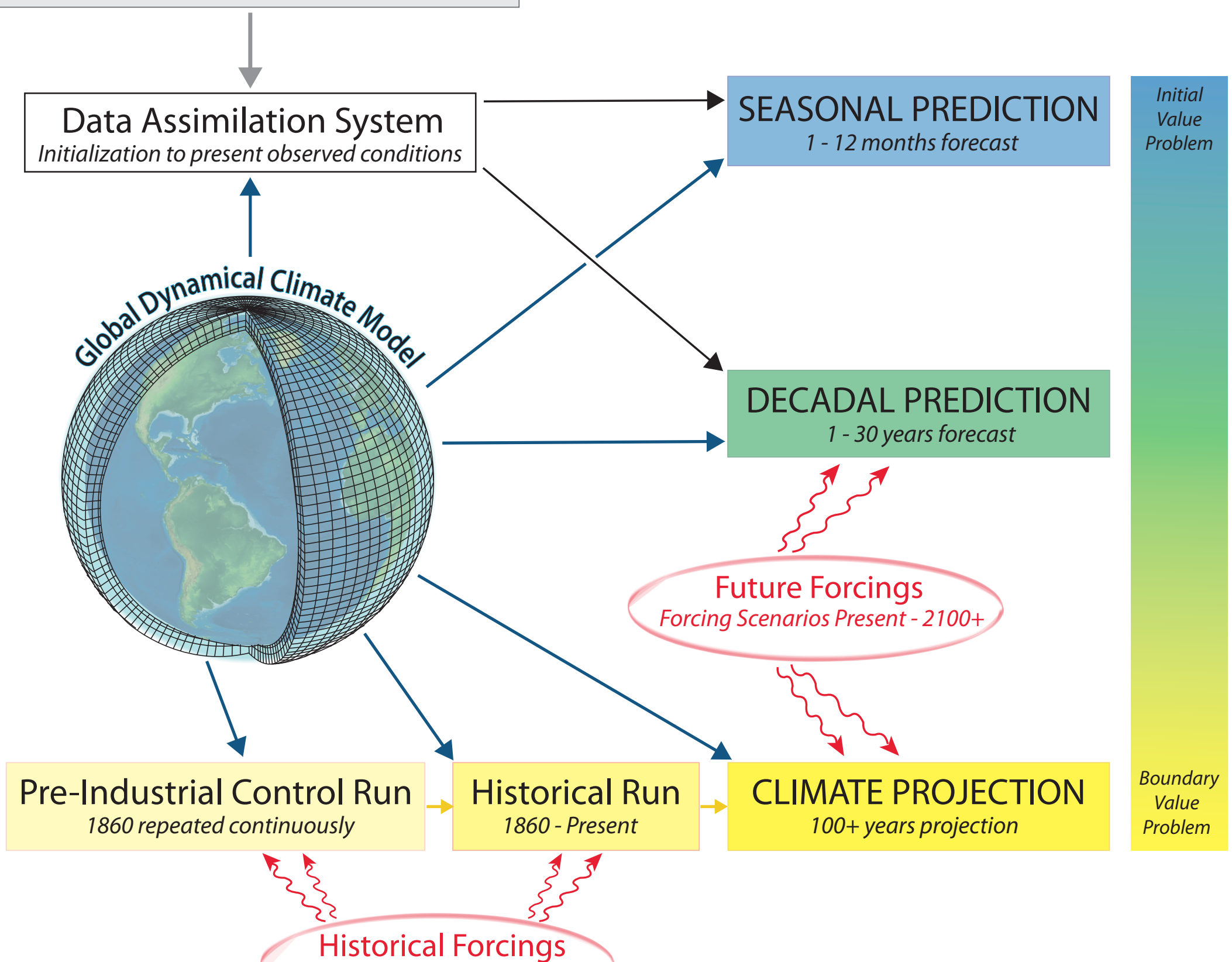

e.g. GHG, Aerosols, Ozone, Solar 
NMME Probabilistic SST Forecast for JJA, lead 1

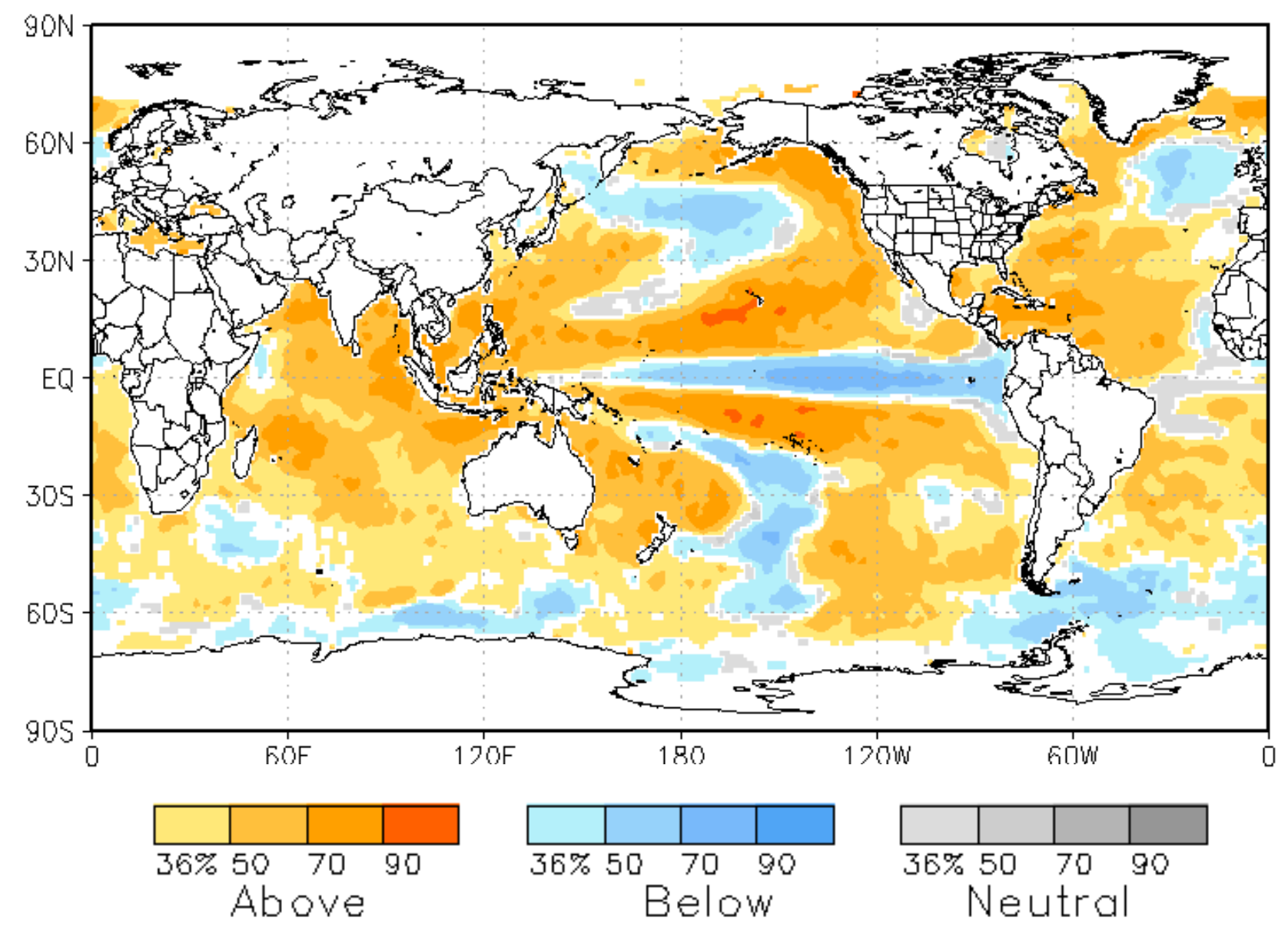

RPSS for the Probabilistic SST Forecast for JJA, lead 1

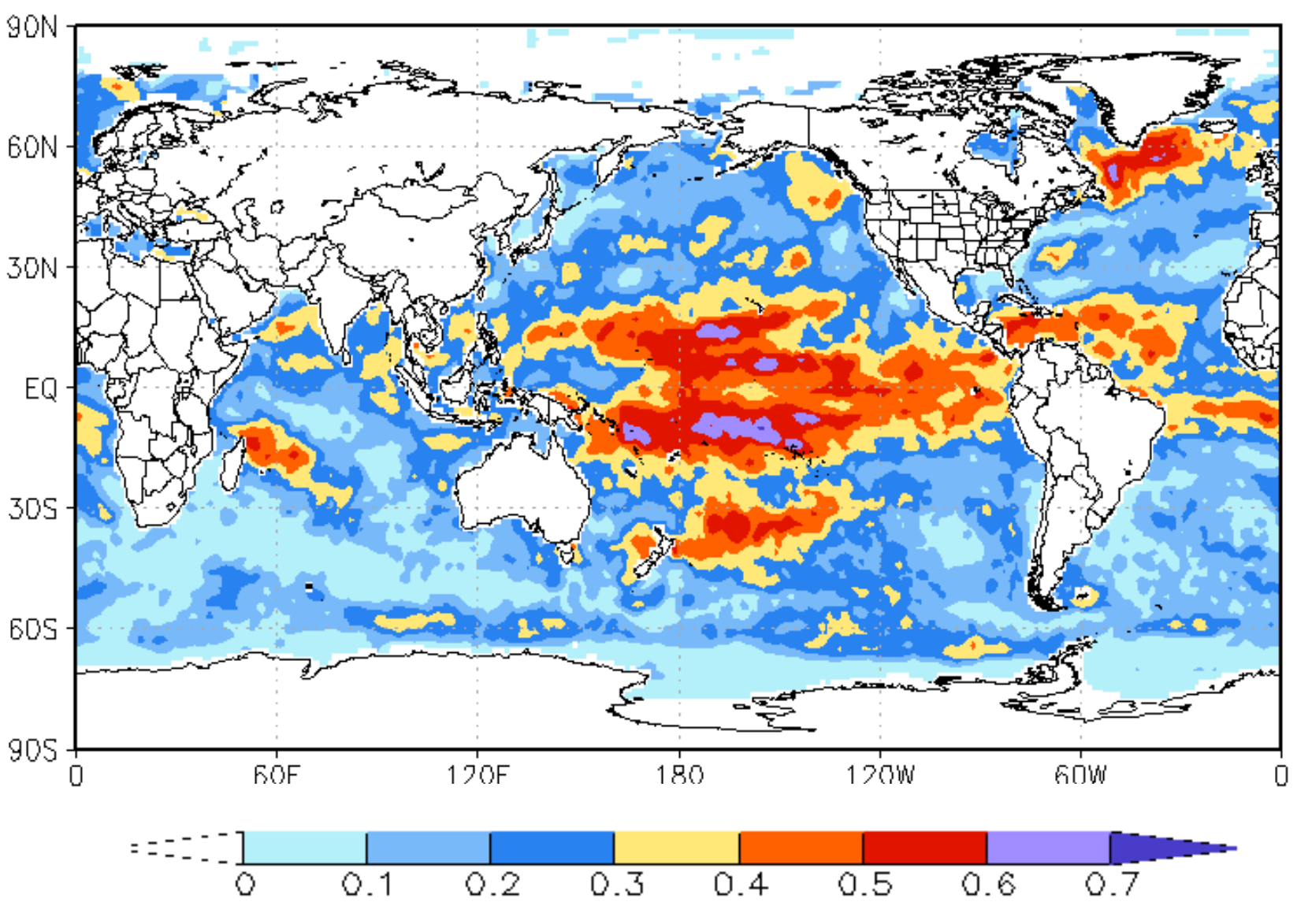




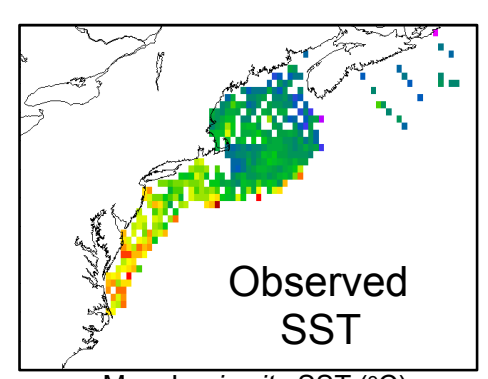

May-Jun in situ SST $\left({ }^{\circ} \mathrm{C}\right)$

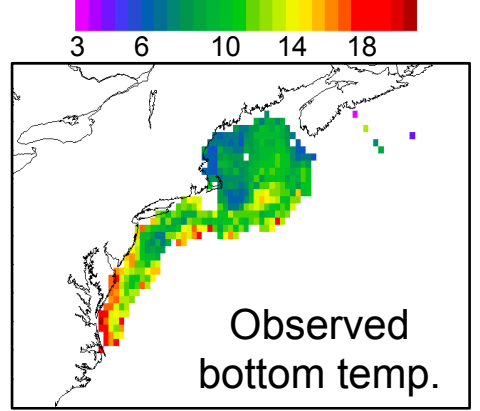

May-Jun in situ bottom temp. $\left({ }^{\circ} \mathrm{C}\right)$
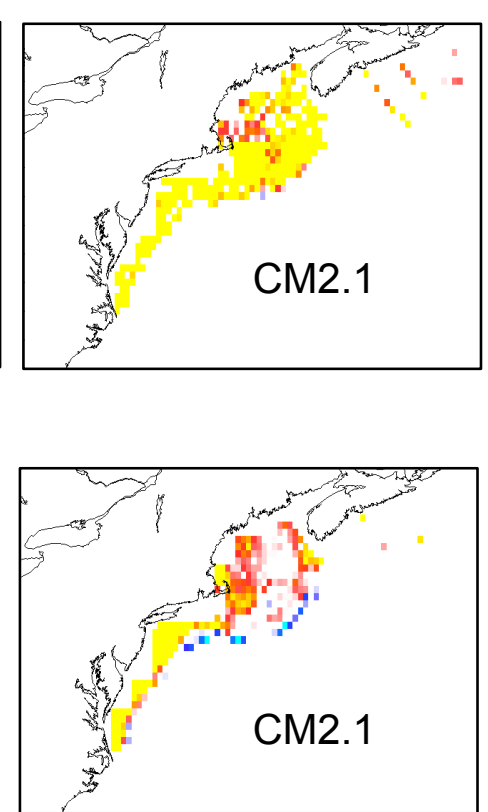

CM2.1

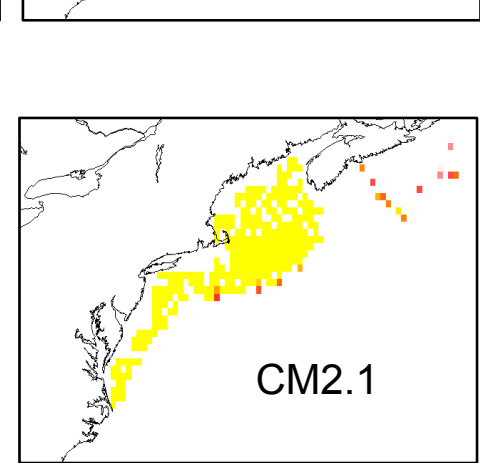

May-Jun in situ SSS (psu) $\begin{array}{lllll}29.4 & 30.6 & 31.8 & 33.0 & 34.2\end{array}$
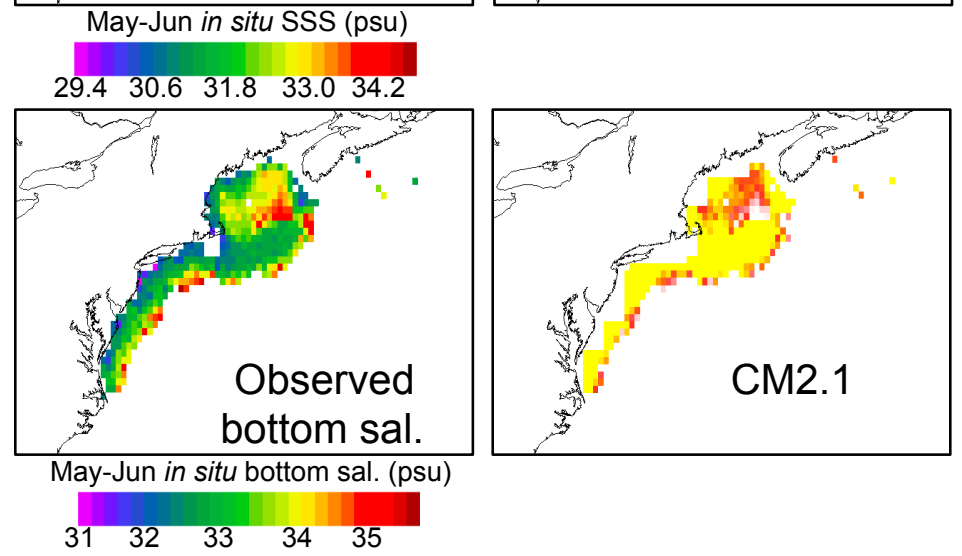

$\begin{array}{lllll}31 & 32 & 33 & 34 & 35\end{array}$
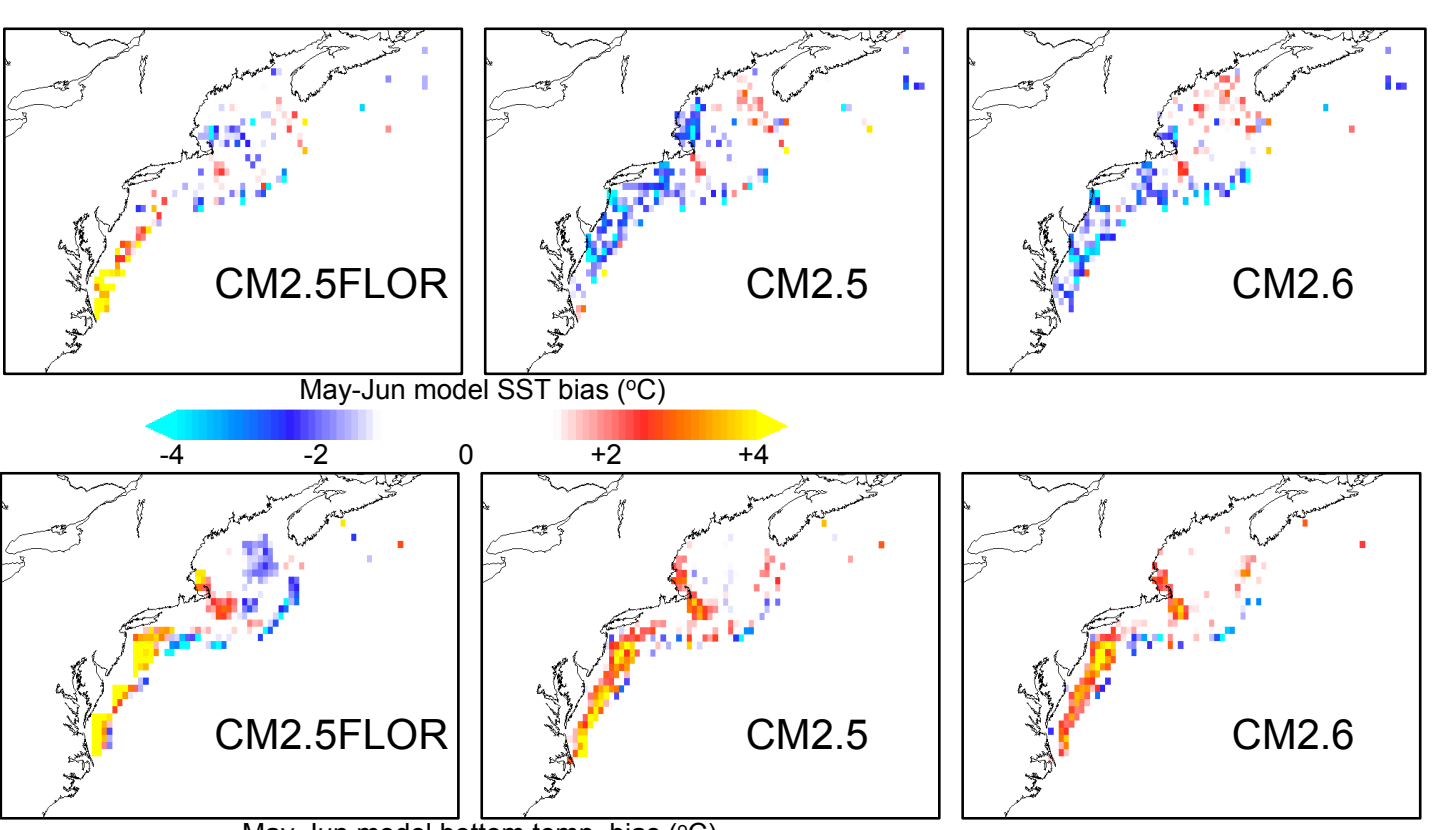

del SST bias $\left({ }^{\circ} \mathrm{C}\right)$
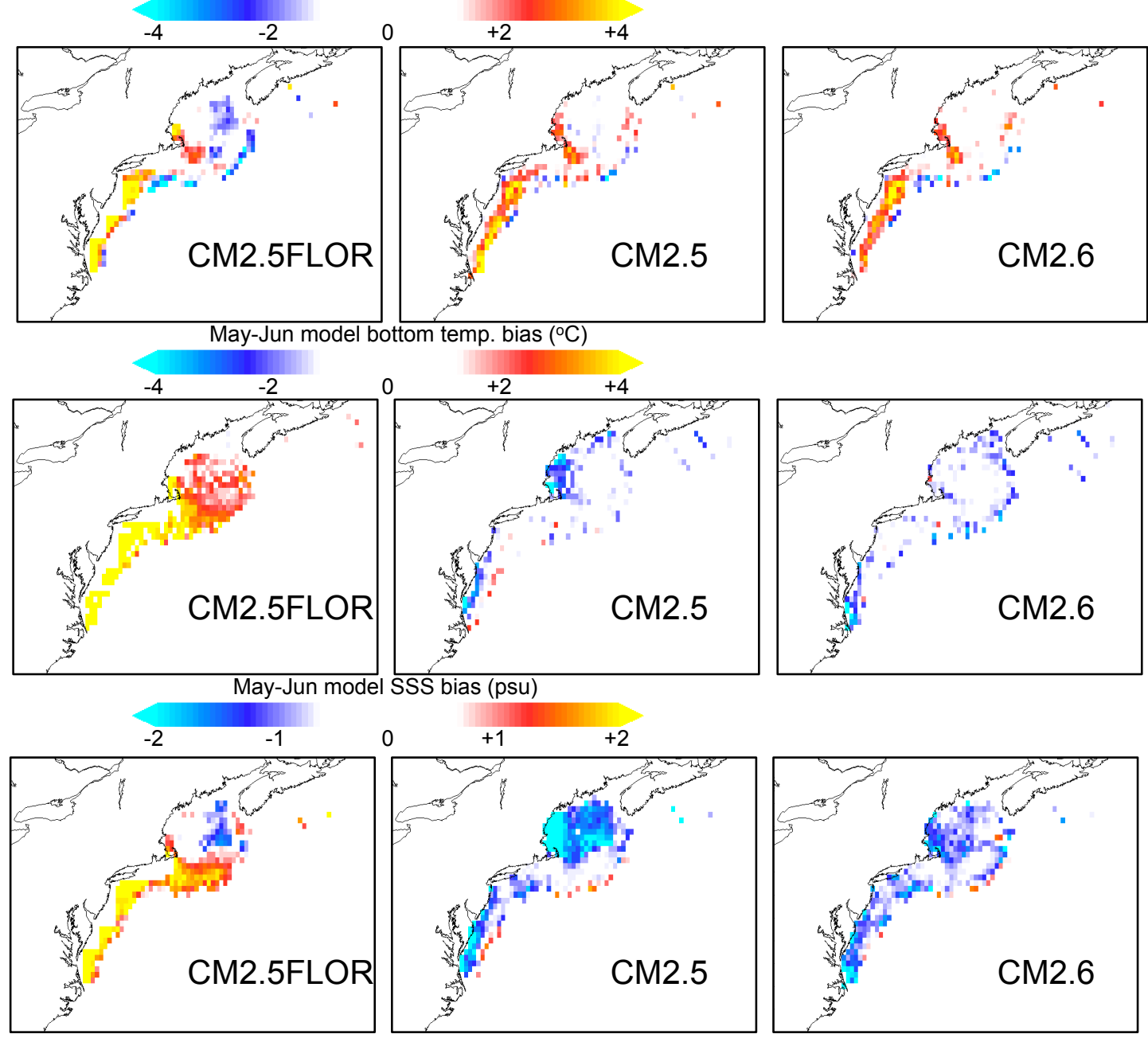

May-Jun model bottom sal. bias (psu)

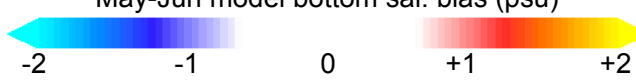




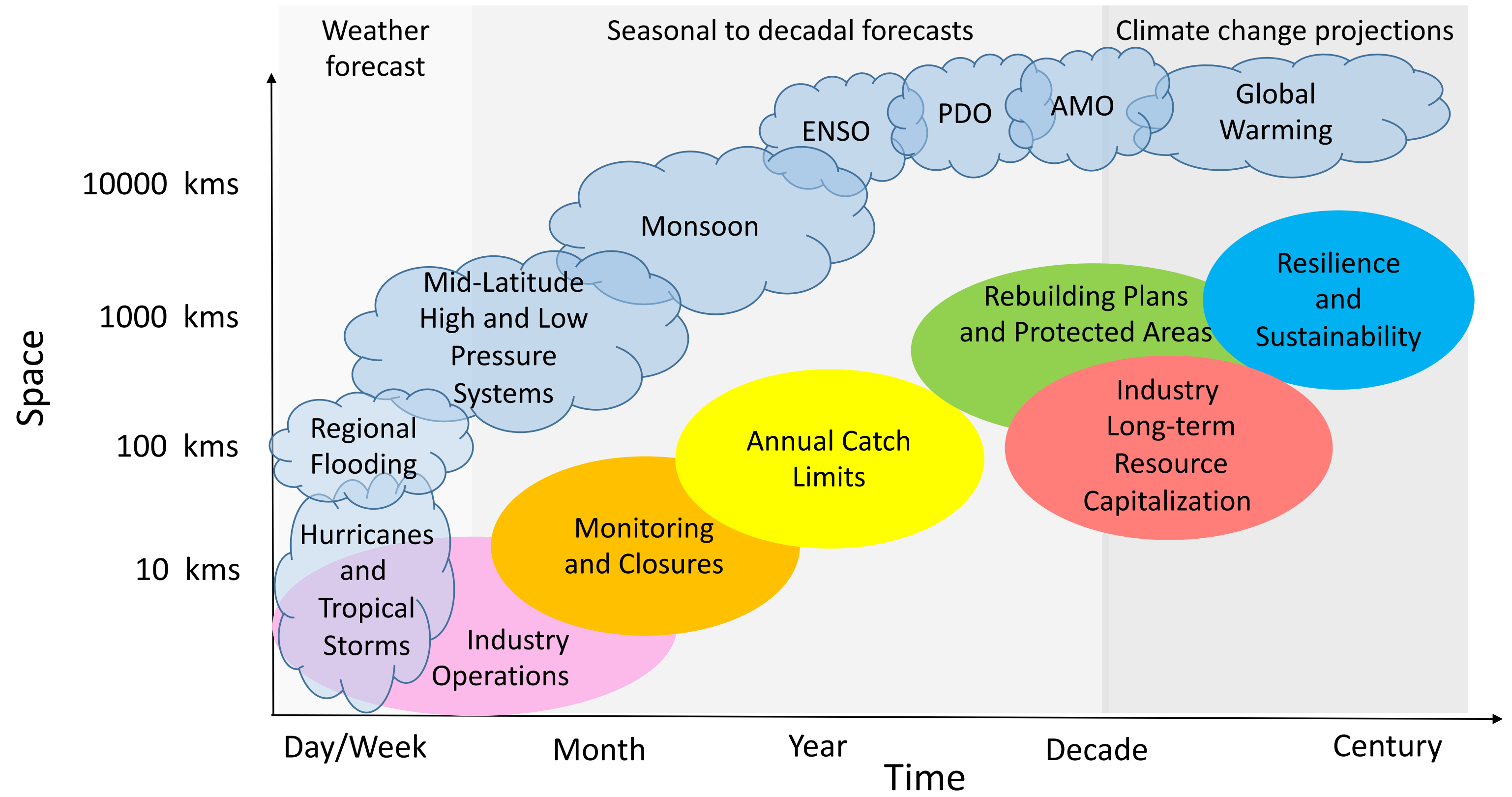


CM2.5 FLOR, GoA

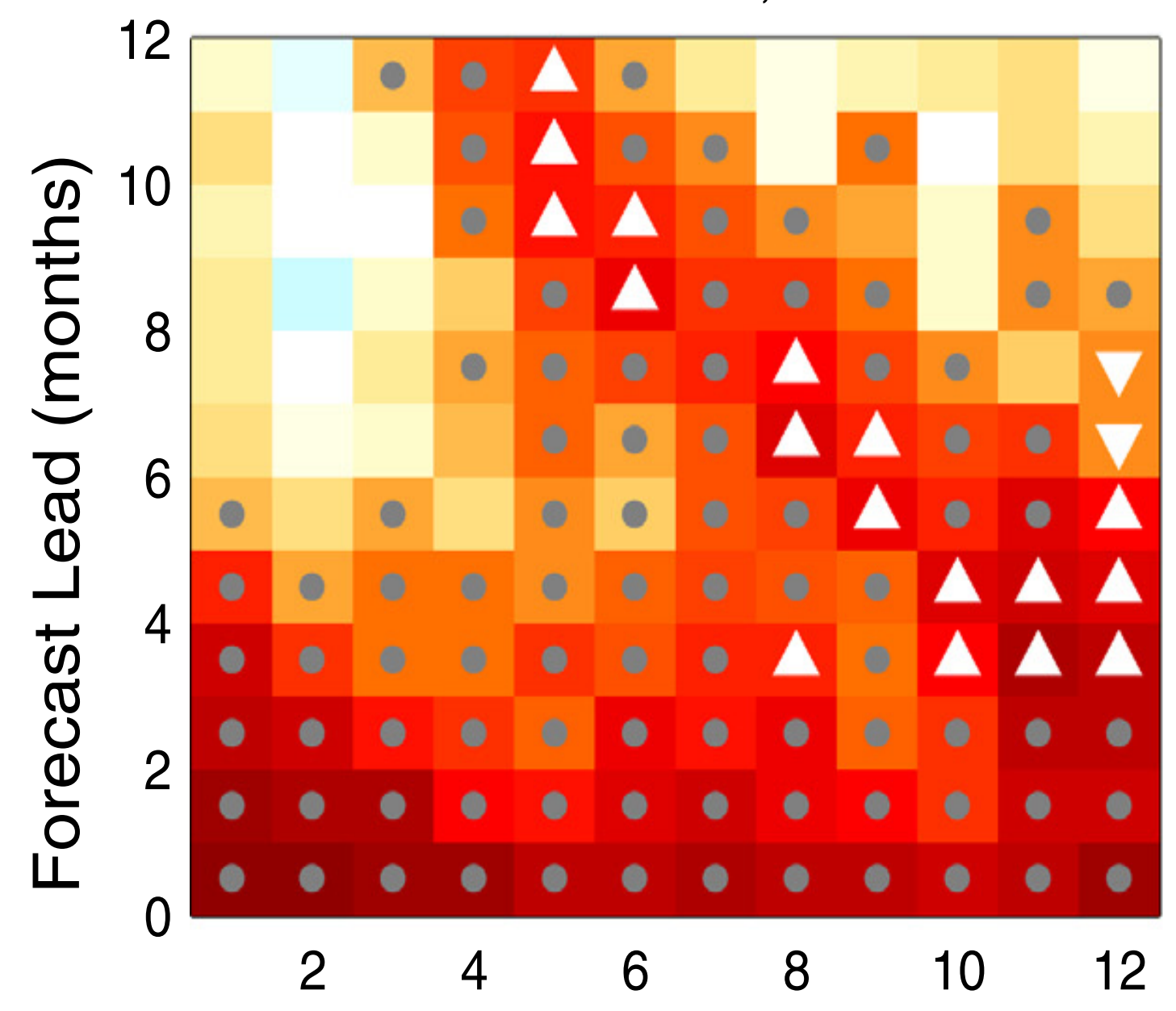

CFSv2, GoA

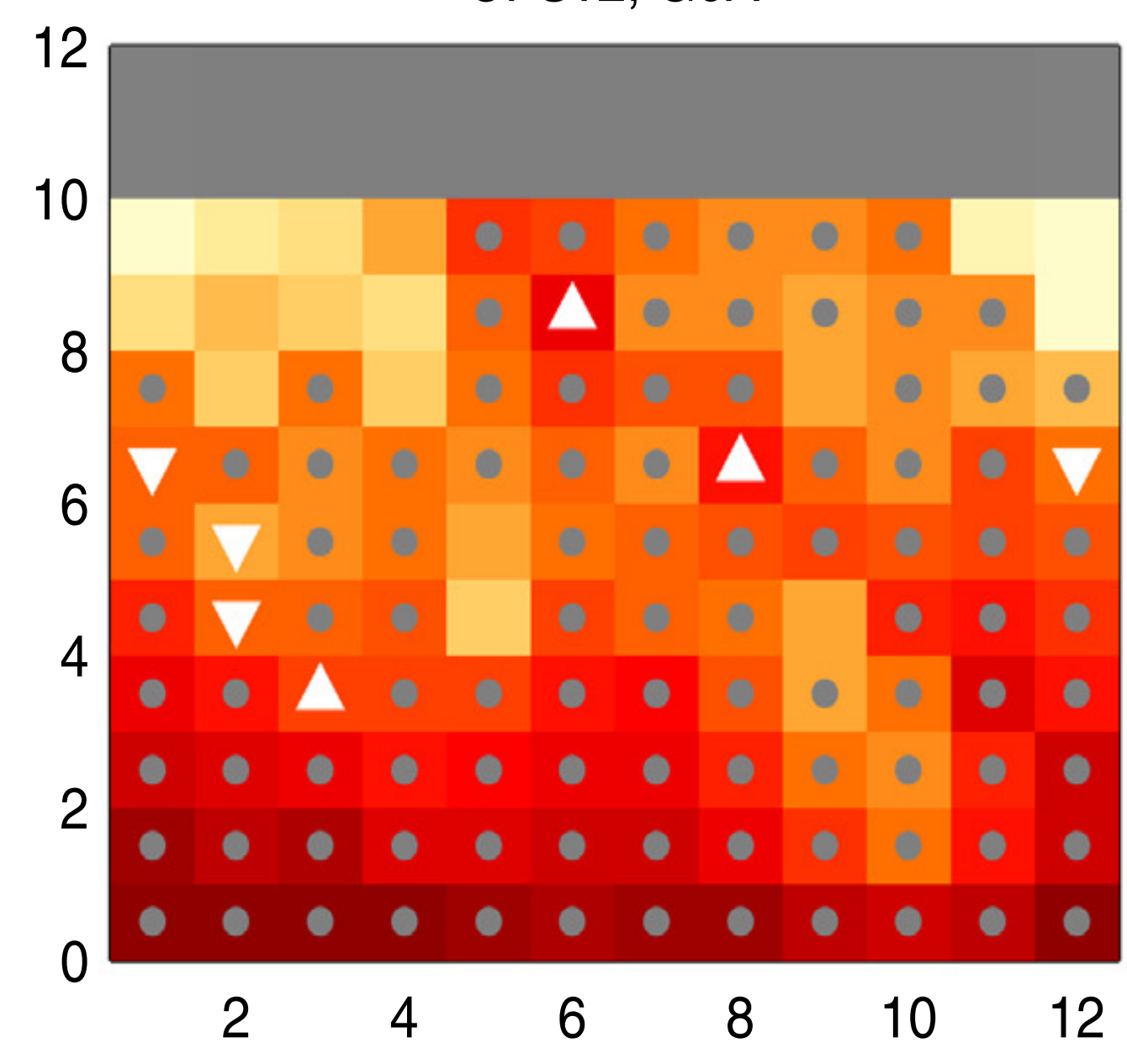

Initializaton Month

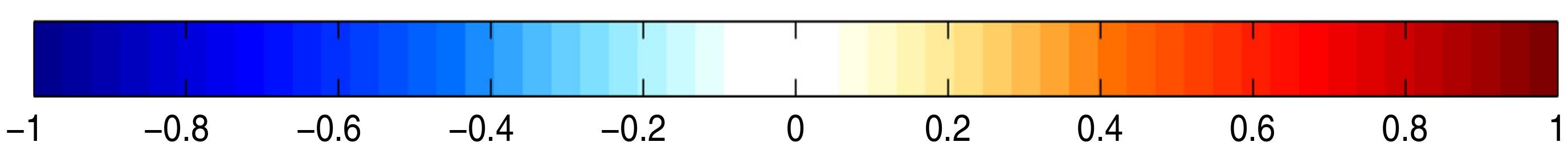


a. Future environment similar to the past
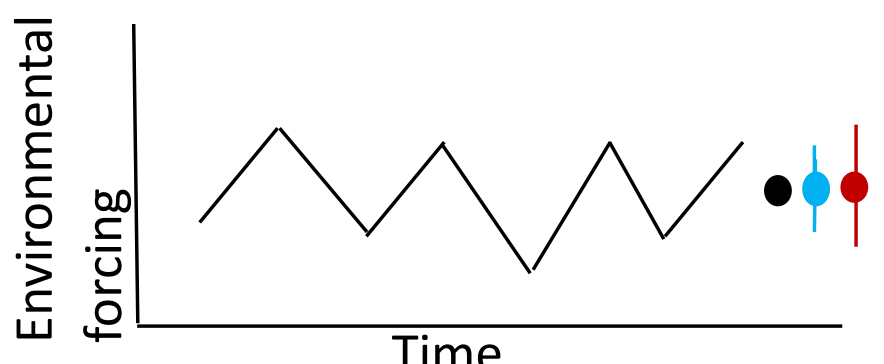

b. Sudden shift in environmental driver
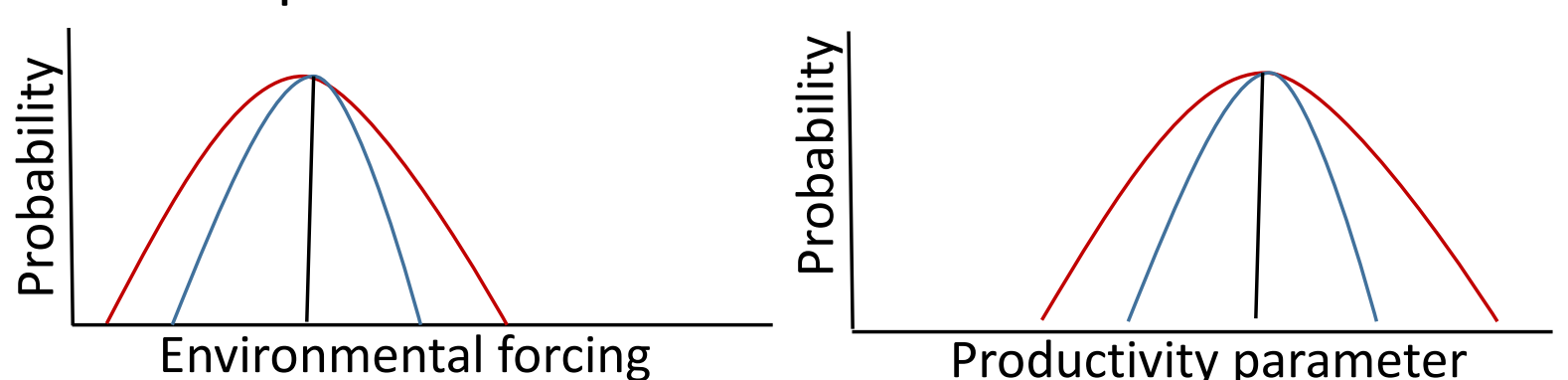

Productivity parameter

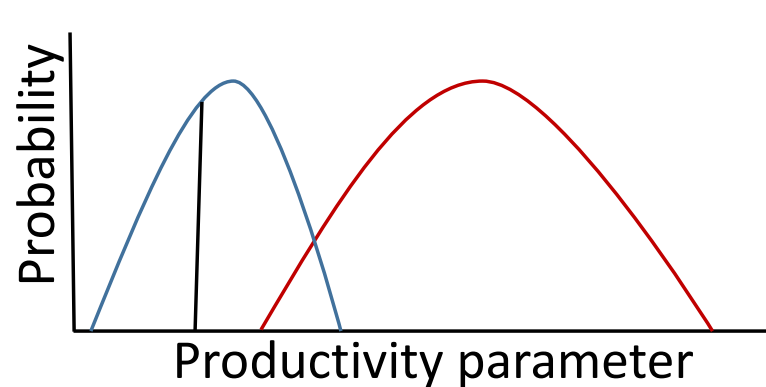

Environmental forcing

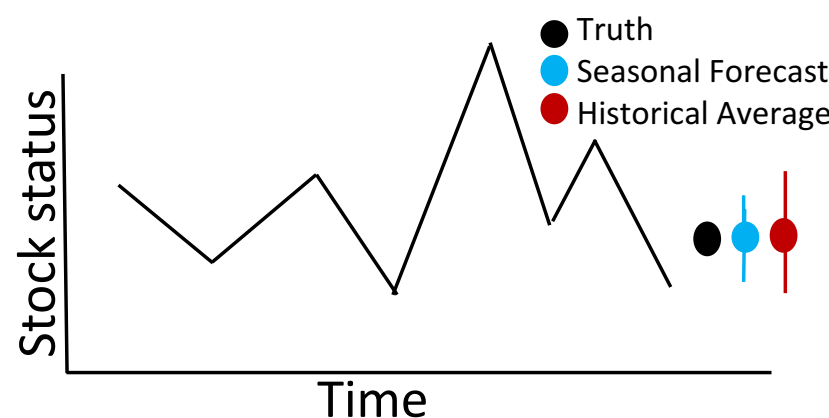

Time

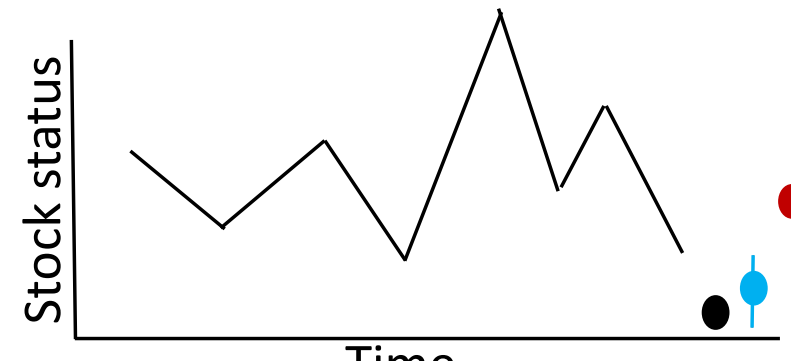

Time
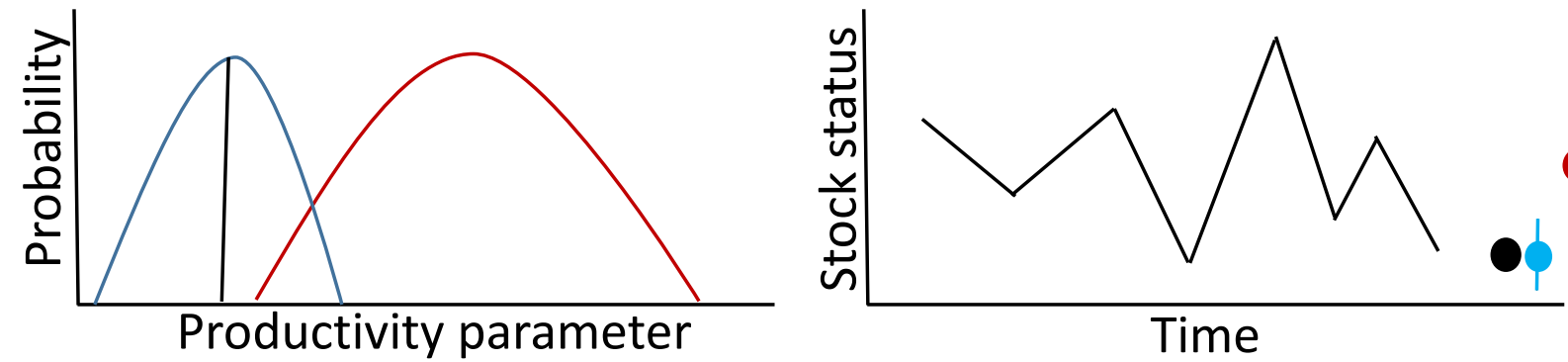

Productivity parameter

Time

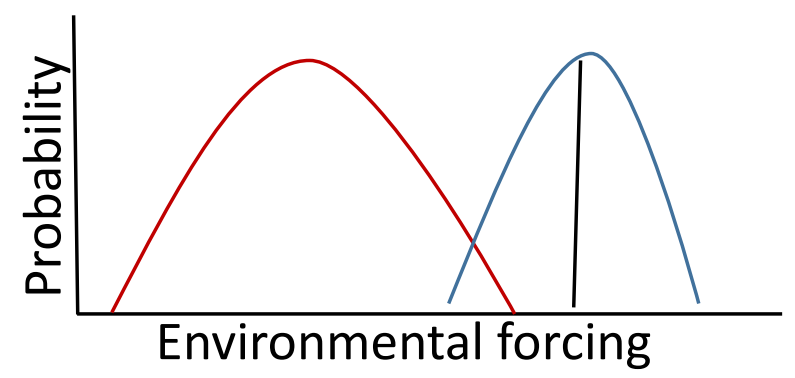

d. Same as c but environment-productivity relationship breaks down
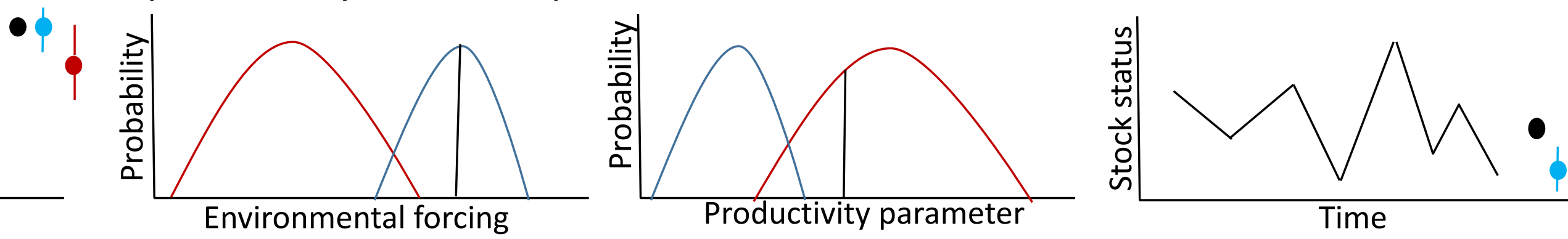
Tmax

above the upper tercile

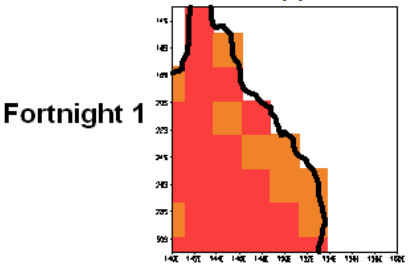

Fortnight 1

Fortnight 2

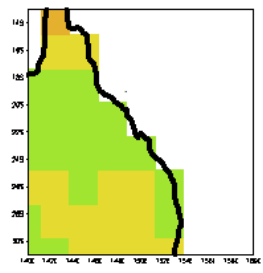

Month (for 10-31 day leads) $\mathrm{m}$

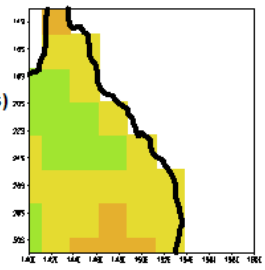

Season (for 10-31 day leads)

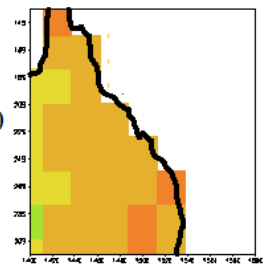

Tmin
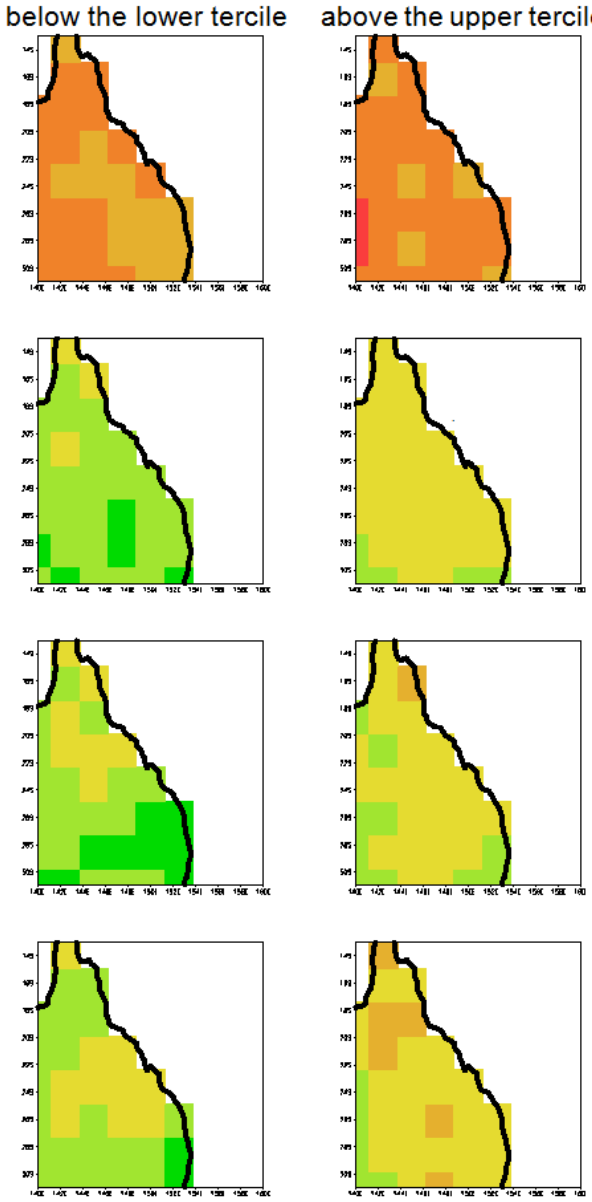

Rainfall

above the upper tercile
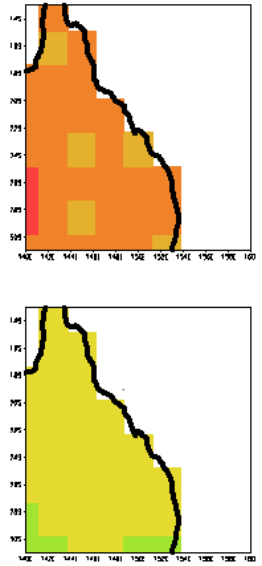

0.78

0.74

0.7

0.66

0.62

0.58 
Forecast: fortnight starting 17 Dec 2015

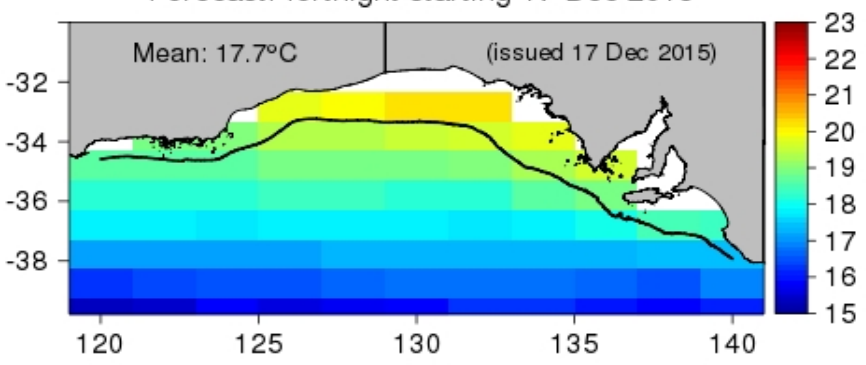

Forecast: January 2016

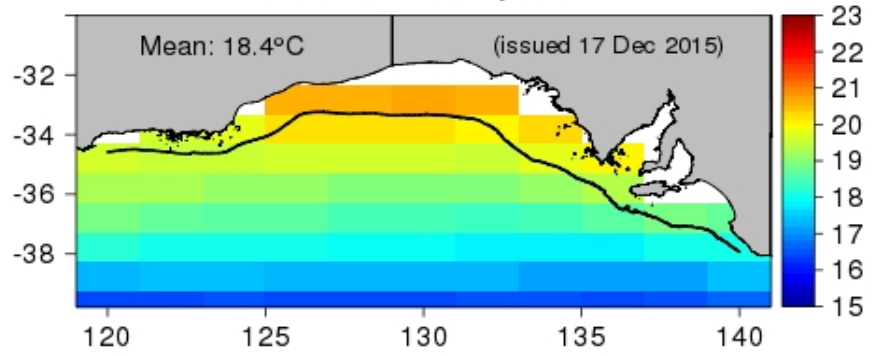

Forecast: February 2016

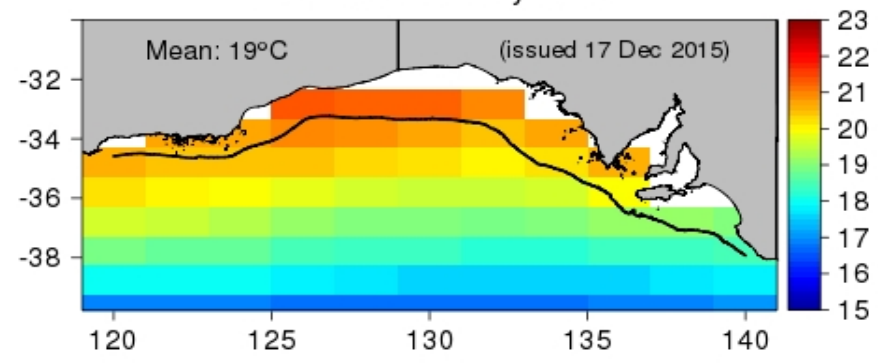

Preferred habitat

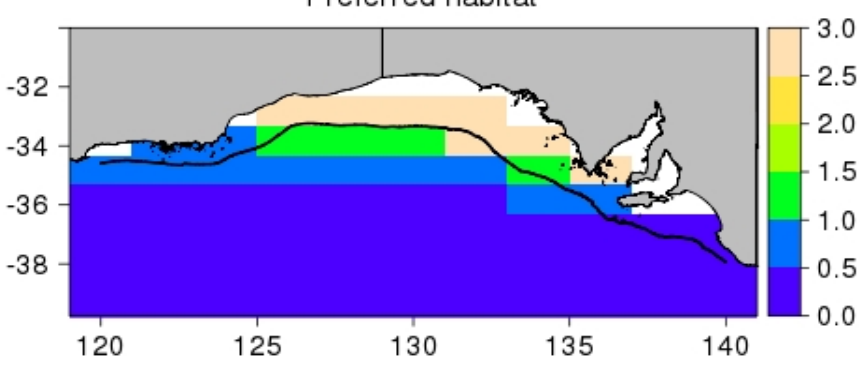

Preferred habitat

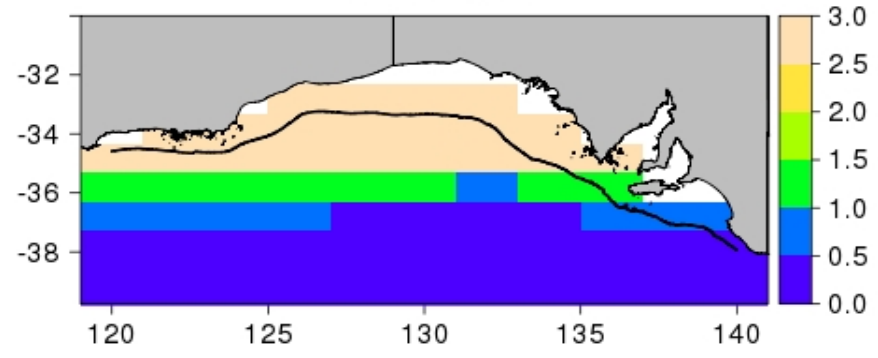

Preferred habitat

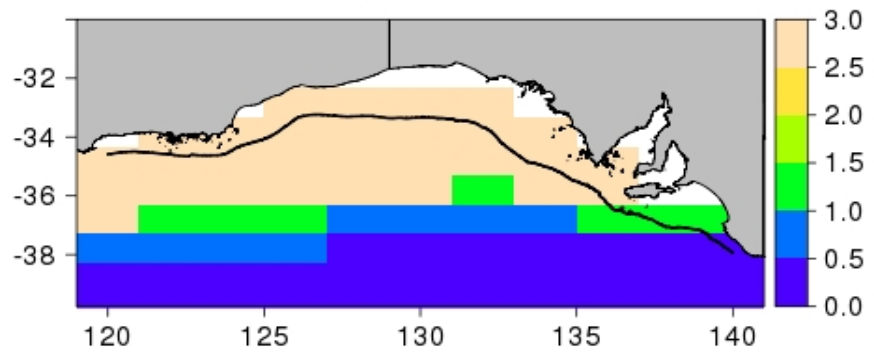


Andrew Pershing @Sci_Officer · Mar 24

Updated \#lobster forecast from @GMRI. Increasing chance of the season starting 3+ weeks early.

Avg. Temperature at $164 \mathrm{ft}(50 \mathrm{~m})$ Sea Surface Temperatures, 3/9-3/16/2016 NERACOOS Buoys

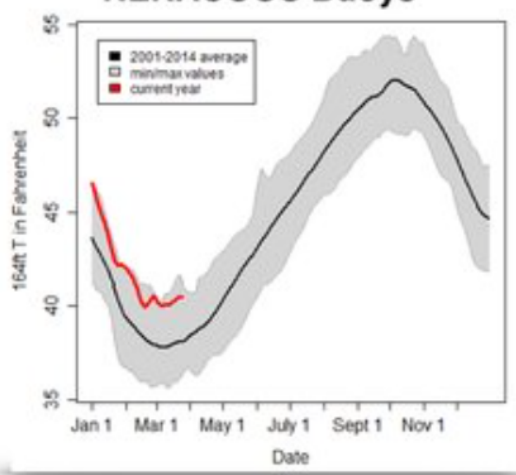
NASA MURSST

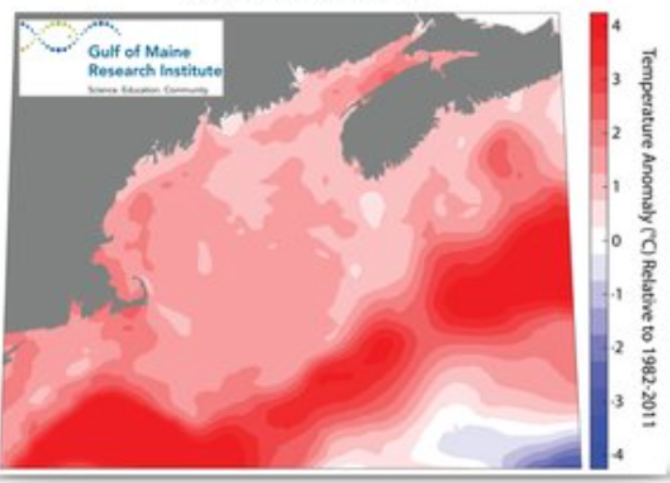

March 24 Forecast for the Start of the Summer Lobster Season

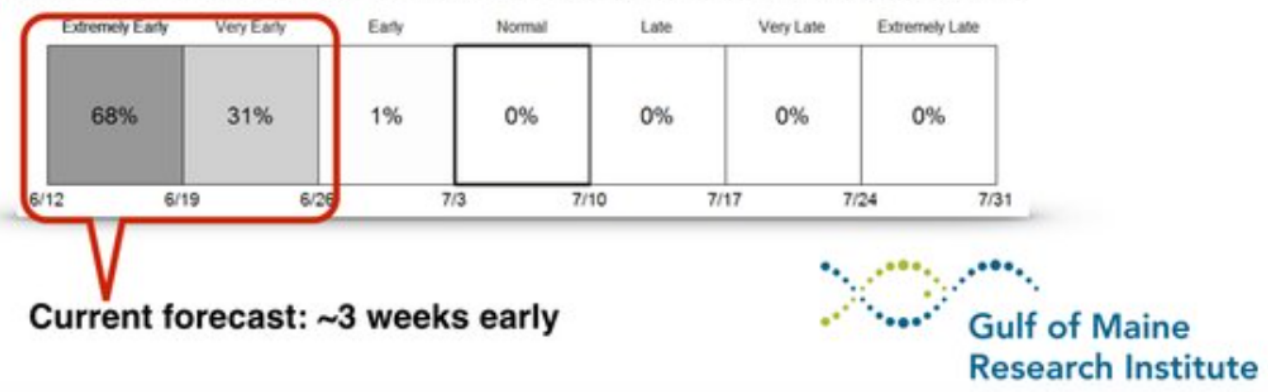



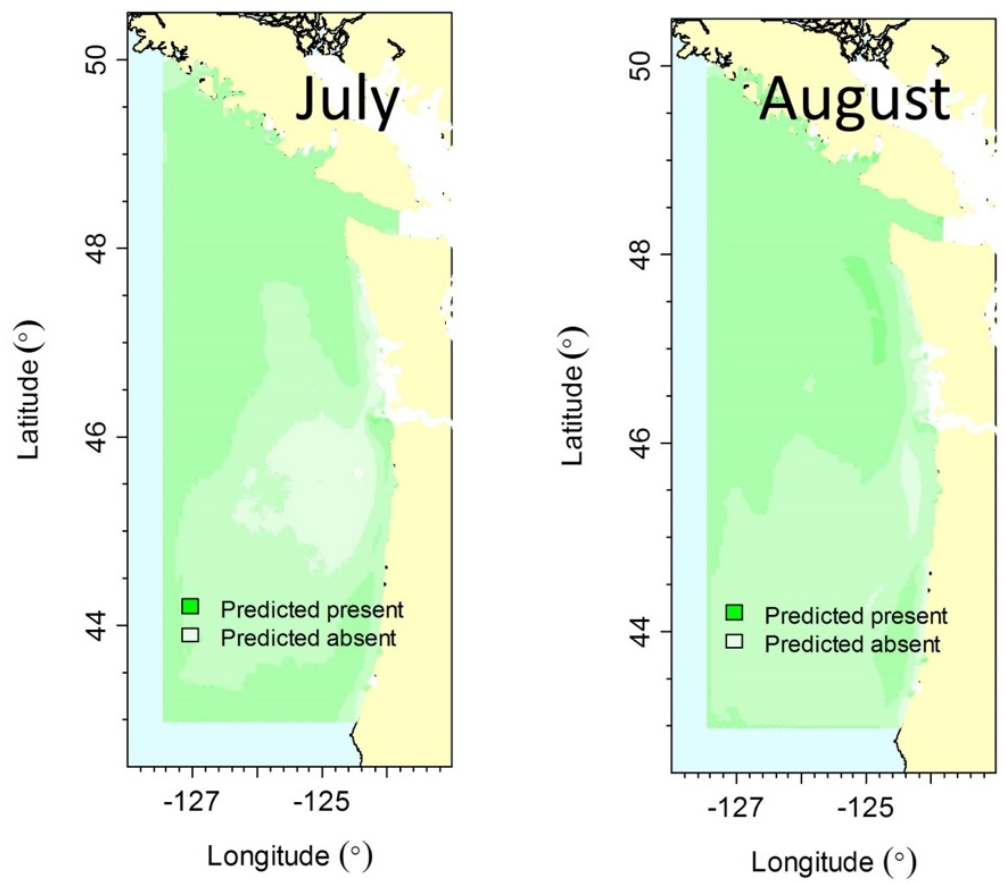


\section{Operational Global Model $\left(1^{\circ} \mathrm{x}\right.$ week) predicting:}

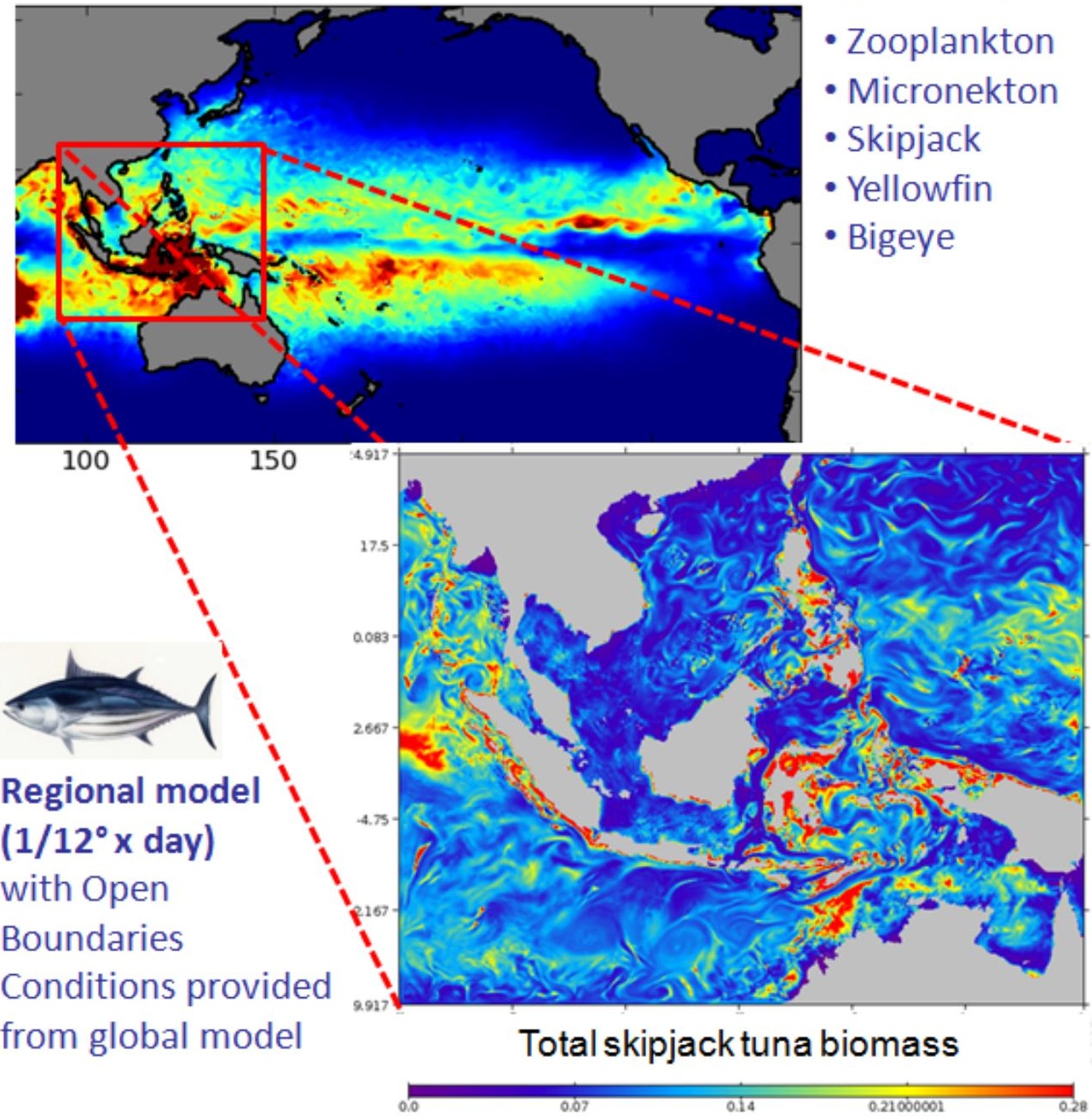



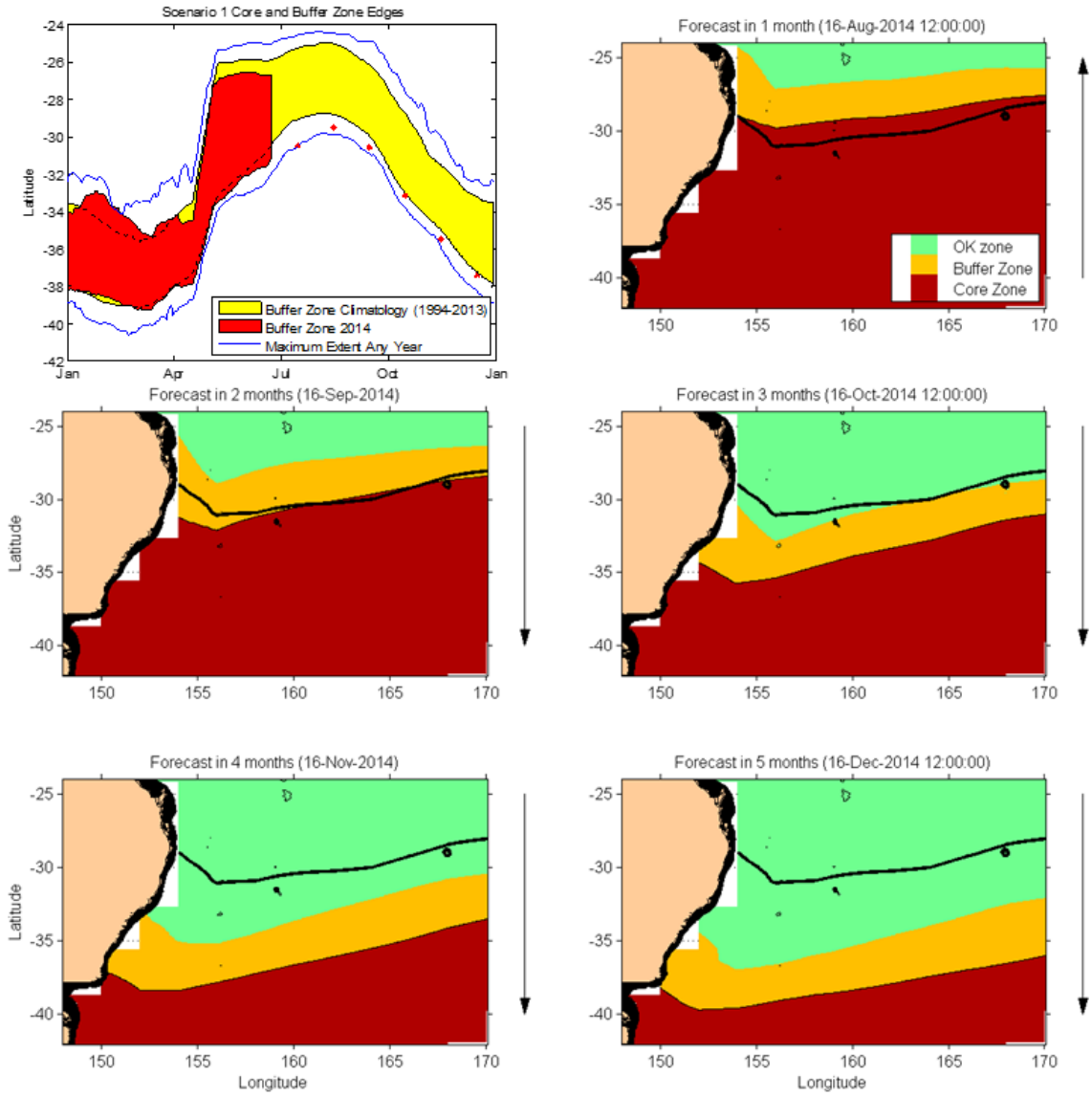


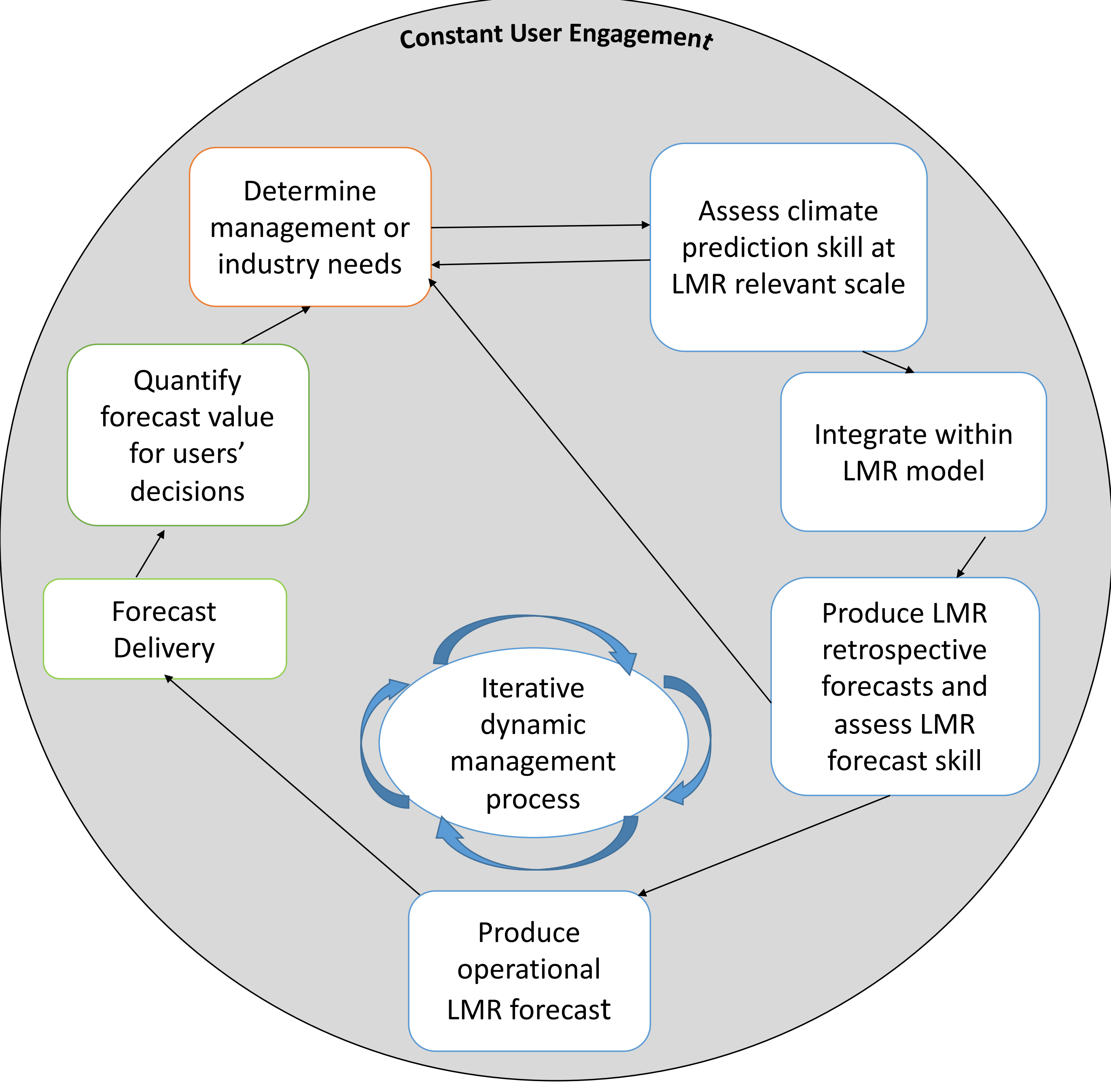

